\title{
Costly Ignorance
}

Citation for published version (APA):

Eberhardt, W. (2018). Costly Ignorance: Enhancing Consumer Financial Decision Making. [Doctoral Thesis, Maastricht University]. Off Page Amsterdam. https://doi.org/10.26481/dis.20180420we

Document status and date:

Published: 01/01/2018

DOI:

10.26481/dis.20180420we

Document Version:

Publisher's PDF, also known as Version of record

\section{Please check the document version of this publication:}

- A submitted manuscript is the version of the article upon submission and before peer-review. There can be important differences between the submitted version and the official published version of record.

People interested in the research are advised to contact the author for the final version of the publication, or visit the DOI to the publisher's website.

- The final author version and the galley proof are versions of the publication after peer review.

- The final published version features the final layout of the paper including the volume, issue and page numbers.

Link to publication

\footnotetext{
General rights rights.

- You may freely distribute the URL identifying the publication in the public portal. please follow below link for the End User Agreement:

www.umlib.nl/taverne-license

Take down policy

If you believe that this document breaches copyright please contact us at:

repository@maastrichtuniversity.nl

providing details and we will investigate your claim.
}

Copyright and moral rights for the publications made accessible in the public portal are retained by the authors and/or other copyright owners and it is a condition of accessing publications that users recognise and abide by the legal requirements associated with these

- Users may download and print one copy of any publication from the public portal for the purpose of private study or research.

- You may not further distribute the material or use it for any profit-making activity or commercial gain

If the publication is distributed under the terms of Article $25 \mathrm{fa}$ of the Dutch Copyright Act, indicated by the "Taverne" license above, 
Costly Ignorance

-

Enhancing Consumer Financial Decision Making

Wiebke Eberhardt 
(c) 2018 Wiebke Eberhardt

ISBN: 978-94-6182-881-1

Cover design by Jelle van der Velde

Layout and printing by Off Page, Amsterdam, The Netherlands

All rights reserved. No part of this publication may be reproduced, stored in a retrieval system, or transmitted, in any form, or by any means, electronic, mechanical, photocopying, recording or otherwise, without the prior permission of the author. 


\title{
Costly Ignorance
}

\section{Enhancing Consumer Financial Decision Making}

\author{
DISSERTATION
}

to obtain the degree of Doctor at Maastricht University, on the authority of Prof. Dr. Rianne M. Letschert, Rector Magnificus,

in accordance with the decision of the Board of Deans, to be defended in public on Friday, April 20th, 2018, at 12:00

by Wiebke Eberhardt 
PROMOTORS:

Prof. Dr. Martin Wetzels

Prof. Dr. Rob Bauer

CO-PROMOTORS:

Prof. Dr. Elisabeth Brüggen

Dr. Thomas Post

ASSESSMENT COMMITTEE:

Prof. Dr. Jos Lemmink, Chairman

Prof. Dr. Rachel Pownall

Prof. Dr. Benedict Dellaert (Erasmus University Rotterdam)

Dr. Gülden Ülkümen (University of Southern California)

This research was financially supported by the Network on Studies on Pensions, Aging and Retirement (Netspar). I thank Investment and Pensions Europe (IPE) for additional support. 
Für meine Familie 


\section{ACKNOWLEDGEMENTS}

"Er is maar weinig te koop waarvan je rijker wordt"

(Toon Hermans)

In the following, I would like to thank a lot of wonderful people who have supported me (almost) free of charge during the past four years, from whom I have learned an invaluable lot and with whom I have created priceless memories.

Starting with how it all started, I thank Lisa and Thomas for taking me on board of their Netspar project. Lisa, especially during the last months of my PhD you became a lion mother type of supervisor who protected and guided me. Thomas, you have a great blunt humor and direct way of dealing with people that is just too Dutch for your German accent. I am very grateful for what I have learned from the both of you during our meetings, both on professional as well as on personal level. Rob, you have been an invaluable coach with great connections in the world of pensions. You taught me a great deal in your institutional investors course, and I really enjoyed the ICPM 2016 discussion forum in Helsinki together with Els and Inka. We still owe you a piano and cello duet - well, maybe at Inka's defense... Martin, thank you for introducing me to R, Smart PLS, finite mixture modeling, and more advanced ways of thinking of theoretical models. You were always approachable and gave me a lot of feedback. I would also like to express my deepest gratitude to my reading committee, Jos Lemmink, Rachel Pownall, Benedict Dellaert and Gülden Ülkümen, who put a lot of time and effort in evaluating my dissertation.

The past four years, I enjoyed a double load of seminars, department trips, PhD activities and discussions with colleagues at the MSCM and Finance department. Carina, Cécile, Eefje, Els, Francien, Nicole and Pascalle: you ladies do an amazing job. To all of my dear colleagues at MSCM: it was inspiring and wonderful (to use Gaby's words) to be a member of your department, L\&L team, and of course winner of the 2016 MSCM cup (go Team Green!). And to all of my dear colleagues at Finance: thank you for welcoming me so warmly even though I was "marketing, only marketing, not marketing-finance, only marketing?!" (still hurts Paulo) when I started. A special thank you to Peter for his support and very helpful guidance during my Netspar grant application. I look forward to many more discussions, seminars, lunches, Ardennes weekends and Jaap's motivational beats in the upcoming years. To Rudolf and his team at BISS: I am happy to work in such a special place with so many brilliant people, and glad to be able to participate in a lot of interesting projects.

Wändi, you have been a true mentor. I guess there are few who are able to be very successful in life while being honest and kind to everyone at the same time. My time in Leeds, our dinners at Hotel Chocolat, the 24 hour visit in Chicago, and meetings in London and Maastricht certainly belong to the highlights of my PhD. JoNell, we had a great time together during that summer day in Harrington, and it is a pleasure and honor to work with you. Thank you Andrea, Alycia, Astrid, Barbara, Carmen, Eirini, Simon, Sonja, Vedran, 
Yasmina and everyone who I have met at or through Leeds University Business School Centre for Decision Research for the nice and fruitful (non) research related discussions. You are a lovely team! Jane, we should be in the next AirBnB marketing campaign with all the fun, good and bad cake, and hot cuppas we had in front of the fire with Mr. Scruff.

I want to thank everyone at Netspar for the continued cooperation, access to a great network, a platform for discussion opportunities and to present my research. Within my Netspar project, I was involved in a very rewarding cooperation with Aegon. I want to thank all former and current colleagues there, especially Frits, Jacqueline, and Sandra, for the trust they have put in me. Chantal, je houdt me altijd weer de praktijk spiegel voor, je bent ontzettend scherp en kritisch en zowel als onderzoeksmaatje, NYC reisbuddy en natuurlijk advies gevende jongens mama een echte topper! I was also so lucky to spend a couple of weeks at NEST Pensions in London. Matthew, Michelle, Ric, Will and the whole team: it is incredible to see how motivated and passionate you all are while being faced with a tremendous challenge. Thank you for all the inspiration - and well, letting me sit right next to the window.

My fellow (former) PhDs, Ade, Anika, Annick, Ehsan, Francisco, Gaby, Gildas, Hang, Hannah, Ile, Joyce, Kimberley, Leticia, Liz, Matteo, Matthijs, Michael, Mike, Ming, Mukul, Nadine, Nagihan, Piet, Pomme, Runliang, Stefania, Steffi, Tim, Tobias, merci! Aleks, for being the best tutor I have ever had. Little Andrea is blessed to have you and Simona as her proud and brave parents. Alex, obviously for putting out that weird research assistant job add with which all the fun started, for never-ending lunches at the best Suppenküche in town, for dogsitting Dommelkes. Looking forward to many more homemade Beluga level dinners with you and Muriel! Ale, Juan and Paulo for being so kind and helpful after Jelle's accident. Finance ladies, Anouk, Irene, Lidwien, Marina, Nora, thank you for Amsterdam sleepovers, baby lunches and presents, the lovely get-togethers with wine, weirdly shaped crêpes, picknick food and pizza. Iman and Clarissa, for being fellow crazy first years and going to ASSA sessions throughout the whole day, every day, in Philadelphia, and making ice-cold NYC even cooler. Johannes, for being the walking encyclopedia you are and introducing me to the world of research. $M$, for being a stunning weirdo and Susan for always getting what I mean. Marleen and Vera, it would have been so much harder without all your irony during our coffees, lunches and EMAC conference fun in Groningen and Valencia. Luuk and Pieter, for fun pension communication meetings on the city wall. Patrick, my fellow MarketingFinance PhD, for bringing plants to life in mysterious ways, being our Aachen Christmas market tour guide, and inspiring Jelle and me to make the right rental car choice during our honeymoon in California. Robert, for peculiar discussions on the meaning of life, Finland and weird Russian books amongst other things - ever since I have been research assistant of you three SSF musketeers. Ruud, for all the times we calculated those Brand Management scores super-duper fast! Sally Banana, for the pink Hello Kitty office fun which made my first PhD weeks so much brighter. 
Outside of the ivory tower (my office was on the fourth floor after all), I am grateful for my friends. They make me richer without costing anything - well, except for gasoline and train tickets. Eva, was haben wir schon alles erlebt in 28 Jahren Freundschaft. Mit einer Tasse Ostfriesentee konnten wir schon immer über alles reden (mittlerweile nicht mehr auf Luftsesseln sondern mit Dommel auf dem Schoss). Nur für dich komme ich nach Köln. Mari, was ein Glück dass wir damals bei Herrn Ebber zusammen im Englisch LK waren. Danke für dein „ansteckendes“ Lachen, unser Jahr in Maastricht zusammen mit Tränen im Stadtpark, Laufen am Albertkanal und nights out in London, FFM und Ahaus. Man kann hiervon leben, muss man aber nicht. Drüber lachen aber wohl - und das am liebsten mit euch. Annemarie, Daniel, Sterre en Linde, we kijken al uit naar de volgende pannenkoeken avond met jullie! Meine Ahauser Birte, Lisa, Mareike, und Sarah, auch wegen euch ist es immer schön, nach Hause zu kommen (und bald noch schöner Bibi!). Laura und Robert, über SBE Intro Gruppe, Rüdiger, Dunkeldeutschland, zu Kulturschock am Starnberger See - Weisswein und Weisswurst gibt es nur mit euch. Lisette and Steve, we can always count on you and hope that we can walk the white Wauzer gang together for a very long time. Nina, die peinlichen Momente beim zwangerschapsyoga waren doch nicht umsonst... Maya, Hajo und wir werden noch ganz viel Lärm bei euch im Garten machen. Dank aan mijn collega's van het Rode Kruis m3, jullie doen fantastisch en belangrijk werk! Zo veel liefde voor de allerleukste lichting (10!) en het allerliefste en meest ambitieuze damesdispuut ter wereld. Vriendschap voor het leven, ontstaan in Enschede. Nefertiti, marhaba nefer!

My paranymphs Inka and Judy, you are wunderbar. Schwesterherz, it is rare for sisters to still live in the same city, even more rare for them to do the same work and have an office next to each other. Ob als Kollegin, Schwester, bruidsmeisje, Tante - auf dich ist einfach Verlass Liebes. Just as Sheldon, you will always have your spot (in the back of our Volvo). So even though you are the real overachiever (\#harvardsis): please do not go too far away after your PhD (or at least come back soon)! Judy, you are the best mind reader, fellow gossiper, wedding planner, research proposal reader, grammar nerd, fellow remarkable nose, the most intelligent make-up artist ever, and one of my dearest friends. Rogier, you know who you are. Printing costs are per page. And sorry for not taking your advice regarding dogs and children names - we hope that you will still want to be our neighbors in that Brabant village where we will all someday move to...

I dedicate this dissertation to my family. Even if I talk a lot, I do not tell them often enough what they mean to me. My family at large: first of all to my grandparents. Oma Usch und Opa Bonno, bei euch auf Norderney komme ich immer wieder zur Ruhe. Nichts hilft besser gegen Stress als ein Strandspaziergang, nach welchem einem der Duft von gebratener Butter entgegen kommt, wenn man euer Huus Ostend betritt und Oma grade Mittagessen macht. Oma Ulla und Opa Dirk, dass Bildung wichtig ist, wurde uns schon jung mit Kinder Brockhaus zu Weihnachten eingeflößt - genauso wie die Liebe zu den Niederlanden. Ich kann nur hoffen, dass Jelle und mir das Glück gegönnt ist, gemeinsam genauso gesund 
alt zu werden wie ihr vier. Hajo und Inka, ein Geschwisterband wie wir es haben, gibt es nicht oft. Bruderherz und Papa, nicht ohne Grund trägt unser Sohn (auch) eure Namen. Den sturen Eberhardt Dickkopf hat er schon, aber hoffentlich wird lüttji Hajo auch mal so humorvoll, scharf ironisch, und warmherzig wie ihr. Anne und Papa, Familie Banken, wir sind immer gerne mit und bei Euch! Meine liebe Mama, vor allem jetzt wo ich selber Mutter bin, realisiere ich mir, was du in den letzten Jahren geleistet hast. Wir drei waren dir am Allerwichtigsten und gleichzeitig hast du uns Toleranz, Disziplin, Demut und vor allem eine unbegrenzte Leidenschaft für Bücher beigebracht. Ich bin stolz eure Enkelin, Schwester und Tochter zu sein. Dank ook aan mijn lieve schoonfamilie. Stamppot en DWDD voor de open haard, zondag ontbijtjes met heerlijke koffie, jaarlijkse zomervakanties, logeren bij mijn schoonzusjes tijdens conferenties en wandelingen met de hondjes - de koude kant heeft het maar goed bij jullie! (Opa) Hajo en Evelien, fijn dat jullie er altijd voor ons zijn en meteen naar het (veel te verre) zuiden komen als we jullie nodig hebben.

And then, my own small family. Dommel, for bringing so much dog happiness to our lives, always brightening my day when I come home. Thinking is much easier when I am walking with you. Jelle, gezond samen zijn is het allerbelangrijkste voor mij. Je bent er altijd voor me. Je brengt me weer tot rust na een drukke dag. Je vertelde me wanneer ik maar moest stoppen met werken en op de bank komen zitten, en wanneer mijn conferentie verhaal beter moest omdat het "echt veel te vaag" was. Je vrouwtje brabbelt maar wat door met haar Duits accent, en toch hou je het al bijna negen jaar met me vol. Je bent de allerliefste man en papa en ik hou simpelweg heel veel van jou. Mein lieber lüttji Hajo, du bist zeitlich perfekt, genau eine Woche nachdem diese Arbeit zu den Professoren ging, auf die Welt gekommen. Seitdem du da bist, hast du unser Leben gründlich entschleunigt, und das tut grade richtig gut. Wenn du so alt bist, dass du das hier lesen kannst, wird es in unserem Leben sicherlich ein wenig turbulenter zugehen und haben wir schon viel mehr zusammen von dieser Welt entdeckt. Schließlich hat mir das Reisen (nach Boulder, Chicago, Helsinki, Namur, Turin, Philadelphia, Valencia, und gemeinsam mit dir im Bauch nach Leeds, London und New York!) während der letzten vier Jahre mit am meisten Spaß gemacht. Deine Mama zu sein und dich gesund aufwachsen zu sehen ist unbeschreiblich schön und kostbar. 



\section{CONTENTS}

Acknowledgements

List of Figures vii

List of Tables viii

$\begin{array}{lll}\text { Chapter } 1 & \text { Introduction }\end{array}$

Chapter 2 The Retirement Belief Model: Understanding Retirement

Information Search 13

Chapter 3 Framing the Future: Using Investment and Assurance Frames

to Encourage Retirement Information Search

Chapter 4 Aging and Financial Decision Making: The Benefit of Experience and Emotion

Chapter 5 Conclusion

References

$\begin{array}{lll}\text { Addendum } & \text { Appendices } & 100\end{array}$

Valorization Addendum $\quad 117$

Summary $\quad 121$

$\begin{array}{ll}\text { Curriculum Vitae } & 122\end{array}$ 


\section{LIST OF FIGURES}

Figure 1.1: Dissertation outline 7

Figure 2.1: Retirement Belief Model 18

Figure 2.2: Demographics on intention (NL) 27

Figure 2.3: Demographics on intention (UK) 32

Figure 3.1: Gain and loss frames used in study 1

Figure 3.2: Loss frame used in study 1

Figure 3.3: Investment, assurance and control frames used in study 2

Figure 3.4: Main study 2 investment and assurance frames 52

Figure 3.5: Study 2 clicking ratios within frames 53

Figure 4.1: Schematic representation of credit card repayment task 65

Figure 4.2: Characteristics per age decade 68

Figure 4.3: PROCESS models 


\section{LIST OF TABLES}

Table 1.1: Comparison pension systems United Kingdom and The Netherlands 4

Table 1.2: Overview dissertation chapters 10

Table 2.1: Descriptive statistics on RBM constructs 24

Table 2.2: Descriptives sample The Netherlands ( $N=583)$

Table 2.3: PLS results: sample The Netherlands ( $N=583)$

Table 2.4: PLS results United Kingdom $(N=1,156)$

Table 3.1: Study 2 descriptive statistics 53

Table 3.2: The effect of assurance and investment framing on information acquisition 54

Table 4.1: Descriptive statistics, number of items, and Cronbach's alpha 63

Table 4.2: Correlations 69

Table 4.3: Regressions predicting financial decision making measures $\quad 70$

Table 4.4: Regressions predicting financial DOI 74 

chapter 1

Introduction 

"Do not regret growing older. It is a privilege denied to many." (author unknown)

Given that one has saved enough to enjoy a comfortable old age and is aging healthy, growing older is certainly a privilege and something to look forward to. Neither wealth nor health at old age can be taken for granted, but consumers can increase their chances of an enjoyable retreat from working life - for example by saving for retirement. However, most people do not like to think about or prepare for this phase of their life: a recent study by a large American financial services provider, for example, finds that consumers spent less time on planning an individual retirement account investment than they do choosing a restaurant, buying a flat screen TV or tablet (TIAA-CREF 2014). Many participants in pension plans know little about saving for retirement, do not read information provided by pension funds, do not consult a financial advisor and consider pension information as too difficult (Gustman et al. 2012; Lusardi and Mitchell 2011). That way, they may not learn on time whether they are financially prepared for retirement: a worldwide survey among more than 16,000 respondents showed that two thirds of retirees who did not prepare adequately for retirement did not realize this until they had retired (HSBC 2015).

Financial planning and planning for retirement in particular becomes even more important in the light of current developments: according to a recent UN report, "the proportion of persons aged 60 and over is expected to double between 2007 and 2050, and their actual number will more than triple, reaching 2 billion by 2050" (UN 2016). This unprecedented demographic change as well as the consequences of the financial crisis and low interest rate environment put pension systems around the world under pressure. As a result, governments and employers increasingly shift risks and responsibility for retirement planning towards individuals, such as pension plan participants (Bodie, Marcus, and Merton 1988; Knoef et al. 2016; Lindbeck and Persson 2003; Van Rooij, Kool, and Prast 2007). These developments imply that it is getting more and more crucial that pension plan participants become active and find out whether they are on target to meet their retirement income goals. If consumers know that there is free financial information available but decide to ignore it, their behavior can be categorized as "information avoidance" (Golman, Hagmann, and Loewenstein 2017) - or "costly ignorance" as it is phrased in the title of my dissertation.

\subsection{CURRENT CHALLENGES FOR CONSUMERS MAKING FINANCIAL DECISIONS}

In recent years, financial decision making has become increasingly difficult and complex for consumers (Hershey, Austin, and Guitierrez 2015). Due to shifts from defined benefit (DB) to defined contribution (DC) pension plans for example, saving for retirement involves more personal responsibility and more risk (Gough and Niza 2011). Other products, such as reverse mortgages, are important for the elderly, but too complex to understand for many (Davidoff, 
Gerhard, and Post 2017). In order to protect consumers from financial service providers who make use of consumers' behavioral biases, the European Commission introduced new consumer financial protection legislation and the Consumer Financial Protection Bureau was established in the United States (Agarwal et al. 2015). Improving consumers' financial decision making quality is high on policy agenda's around the world.

In this dissertation, I study consumers' financial decision making in two countries: the Netherlands and the United Kingdom (UK).

A comparison of both countries' pension schemes is given in Table 1.1. Both countries have a three pillar pension system. The first pillar includes a basic state pension, which people in the UK are eligible for if they paid National Insurance for at least ten years. In the Netherlands, the first pillar flat-rate pension income that all residents living in the Netherlands for 40 years receive is related to the net minimum wage, which results in a relatively low old-age poverty rate (Bovenberg and Gradus 2015). The second pillar consists of occupational pensions, that is arrangements by employers to provide their employees with pension benefits. The UK Pensions Act of 2008 introduced automatic enrollment, which meant that employers are obliged to enroll their employees in a pension scheme. While the Netherlands have a mandatory second pillar in which employees are covered with industry-wide schemes and are not allowed to make investment choices themselves or leave the plan, UK employees can opt out of their occupational pension. Not only the accumulation phase in the Netherlands is mandatory, Dutch retirees also do not have a choice during their annuitized payout phase. In the UK, this changed with the freedom

Table 1.1: Comparison pension systems United Kingdom and The Netherlands

\begin{tabular}{|c|c|c|}
\hline & United Kingdom & The Netherlands \\
\hline Total pension assets 2016 (USD billion) & 2.868 & 1.296 \\
\hline Pension assets / GDP ratio (percent) & 108.2 & 168.3 \\
\hline $\begin{array}{l}\text { Rating Mercer Melbourne Global } \\
\text { Pension Index } 2017\end{array}$ & $\mathrm{C}+$ & $\mathrm{B}+$ \\
\hline Structure first pension pillar & $\begin{array}{l}\text { Single tier state pension } \\
\text { supported by income-tested } \\
\text { pension credit }\end{array}$ & Flat-rate public pension \\
\hline Structure second pension pillar & $\begin{array}{l}\text { Occupational pensions with } \\
\text { opt-out possibility, minimum } \\
\text { contribution } 2 \%\end{array}$ & $\begin{array}{l}\text { Quasi-mandatory earnings- } \\
\text { related occupational pension } \\
\text { linked to industrial agreements }\end{array}$ \\
\hline Structure third pension pillar & Various private arrangements & Various private arrangements \\
\hline Payout retirement phase & $\begin{array}{l}\text { Participants can choose } \\
\text { between six options how to } \\
\text { take out their pension money }\end{array}$ & $\begin{array}{l}\text { Participants have no choice, } \\
\text { annuitized payout phase }\end{array}$ \\
\hline Share DB plans of total plans (percent) & 72 & 95 \\
\hline
\end{tabular}


and choice agenda of 2015: retirees do no longer have to purchase an annuity, but have six options among which taking their whole pension pot at once or in chunks, or receiving an adjustable income (UK government 2017). Most (95\%) of Dutch second pillar pension plans are semi DB plans, in which the pension providers and employers carry the investment risk for the DB payouts they promise. In the UK, this percentage is lower, with $72 \%$ of plans being DB plans (Bovenberg and Gradus 2015). The rest of plans are DC plans, which means that the monthly contribution and not the final benefit is defined. Here, pension plan participants carry the investment risk since there is no guaranteed payout at retirement age. The third pillar then includes personal pensions, all financial products that people can use to save or invest for retirement with tax benefits. In addition, individuals can of course have other sources of retirement income such as savings, investments, a mortgage-free house or income from work after they retired.

With the introduction of automatic enrollment, the UK pension system improved on coverage, but still has a challenge in reaching adequacy of their pensions and is therefore still C-rated (Mercer 2017). The Netherlands has one of the highest pension assets to GDP ratio (168.3\%), while the United Kingdom scores much lower (108.2\%) - which is higher than Canada (102.8\%) but lower than Australia (126\%) or the United States (121.1\%; Willis Tower Watson, 2017). However, while the Netherlands have one of the best pension systems in the world, reforms are taking place that will change the pension landscape rapidly. While most Dutch pension plan participants expect replacement rates of more than $70 \%$, currently around $31 \%$ of households face a gross replacement rate of lower than $70 \%$ when taking into account all wealth accruals, with large differences between groups: $46 \%$ of self-employed households for example face a pension gap (Knoef et al. 2015).

In addition to pension related challenges, the UK Financial Conduct Authority sees consumer debt as one of its main priorities. Outstanding credit card debts have risen steadily and have reached record levels of $£ 68$ billion this year (as compared to $£ 55$ in 2012; Financial Times 2017). Credit cards are less of a problem for Dutch households, since it is common to pay back your credit card debt monthly. However, the Dutch household debt ratio is still among the highest in Europe, which is mainly due to rising student debts and high mortgages (CBS 2015).

\subsection{THE NEED FOR MORE KNOWLEDGE ON THE SEARCH FOR FINANCIAL INFORMATION}

Research in behavioral finance and marketing has mainly focused on downstream financial behaviors such as enrollment and contribution rates in pension plans (Beshears et al. 2011; Thaler and Benartzi 2004), delaying retirement (e.g. Manoli and Weber 2016; Van Schie, Dellaert and Donkers 2015), credit card repayment (Amar et al. 2011), or saving behavior (Ülkümen and Cheema 2011). However, without information on, for example, their current 
retirement or consumption situation, consumers cannot make educated decisions about their finances. If people insufficiently search for information about their expected pension benefits, some of them may encounter significant pension gaps resulting in detrimental welfare effects at retirement (Post et al. 2014). The search for financial information leads to better financial decision making and is therefore the first step to securing financial wellbeing. Financial knowledge has been linked to positive financial outcomes in the past, such as more planning for retirement, better saving and investment decisions, and better debt management (Lusardi and Mitchell 2014). Well-informed consumers also respond better to financial incentives for pension planning (Chan and Stevens 2008).

Thus, the search for financial information is very important for downstream financial behaviors, but has received little attention in the extant literature. Therefore, I focus on the search for financial information as key dependent variable in my dissertation. Information search can be divided into two categories: goal-directed search (where consumers look for specific information, for example on what kind of product to buy), and ongoing search (where consumers look for more general information on for example the eligible pension age; Van Schie, Donkers, and Dellaert 2012). Since retirement is far away for many and the financial environment changes continuously, I focus on ongoing information search. Specifically, this ongoing search can include three consecutive questions that consumers may need to answer: First, what they are currently saving. Taking the Dutch three pillar pension system as an example, consumers need to have at least a rough estimate of the combined amount that they will receive out of these three pillars when they retire. With this information in mind, the second question to think about would be how one wants to live and then third, whether what one is currently saving will be enough to afford the desired lifestyle during retirement.

In this dissertation, I look at three different research objectives related to enhancing consumer financial decision making. First, my co-authors and I investigate what drives differences in pension plan participants' retirement information search. Internal factors such as sociodemographic characteristics (e.g. age, income), beliefs (e.g. perceived benefits of information search), cognitive (e.g. numeracy) and non-cognitive (e.g. emotions) characteristics can influence whether participants search for information.

In addition, there are external factors such as media coverage on pensions and framed communication that participants receive via email or mail which may trigger participants to start searching for additional information. Second, my co-authors and I therefore look at how framing such communication can help to activate pension plan participants and stimulate them to acquire information. After participants have obtained information, they can decide whether the outcome is better or worse than expected. This is a subjective process, since consumers with the same income levels have been shown to perceive their financial situation differently, based on, for example, the internal factors mentioned (such as age or financial knowledge; Joo and Grable 2004; Shim et al. 2009). If the outcome is worse 
than expected, participants can adapt their financial decision making and decide to save more, delay retirement, spend less, or adapt their credit card use.

Internal factors influence this financial decision making process as well, since even with sufficient information, participants may not be able or willing to take certain financial decisions. Third, my co-authors and I accordingly investigate the role that age-related cognitive changes (i.e. in numeracy and experience-based knowledge) and non-cognitive changes (i.e. in emotions and motivation) play with regard to financial decision making.

A simplified model of financial decision making and how I cover it in my chapters is given in Figure 1.1. I will now summarize the findings related to the three research objectives of my dissertation.

\section{What drives differences in participants' retirement information search?}

When consumers do not prepare for retirement, this can be attributed to various reasons. Older and wealthier consumers for example are more likely to save for retirement. However, sociodemographic characteristics alone insufficiently explain whether and how consumers prepare for old age (Binswanger and Carman 2012). Information search takes effort and retirement is far away for many, so low levels of self-control and high levels of intertemporal discounting have been offered as explanations for why consumers do not take action (e.g. Laibson 1997; Thaler and Benartzi 2004). In addition, even if consumers sufficiently search for information, an implicit assumption is that they understand savings and the information they receive, which is not the case for many (e.g. McKenzie and Liersch 2011).

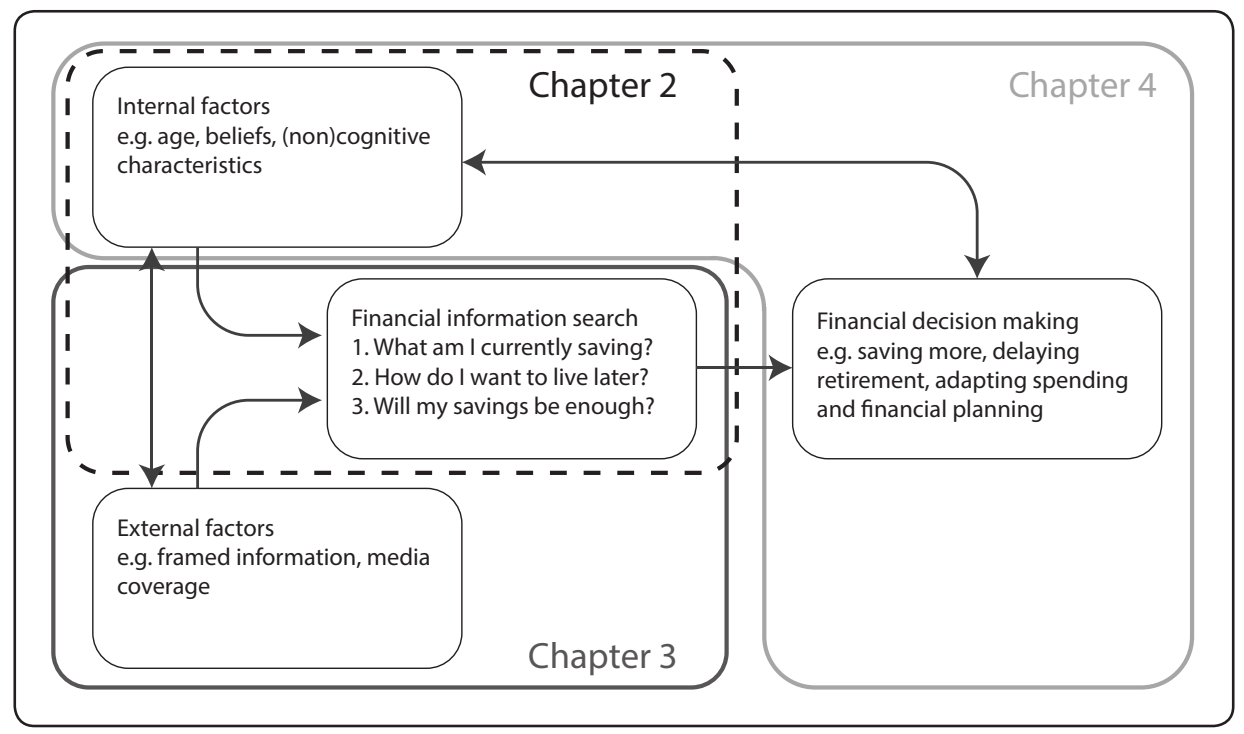

Figure 1.1: Dissertation outline 
In chapter 2 , we propose that there are drivers and barriers of information search beyond demographic characteristics, since consumers differ along many dimensions, such as beliefs, emotions, risk preferences, financial literacy and trust in their pension provider. We employ a conceptual model, which is built on a comprehensive set of factors that influence information search: the Retirement Belief Model. We test the Retirement Belief Model with pension plan participants in the Netherlands $(N=583)$ and in the United Kingdom $(N=1,156)$. Our results show that a holistic model like the Retirement Belief Model performs far better than demographic factors alone in understanding retirement information search. The "usual suspects", that is the older, higher educated, wealthier and male participants are more likely to be informed. However, we also find that high levels of perceived benefits (for example a sense of security that one gains), trust and retirement anxiety are important drivers of information search intention.

Based on the Retirement Belief Model and the data gathered, we segment participants into three distinct segments. We find that beliefs and psychographic dimensions play a very important role, and are essential in forming those segments. We show that using only sociodemographic information is insufficient for segmenting pension plan participants. For different segments, it differs which beliefs determine the intention to become active.

\section{How can framing help to activate pension plan participants to acquire information?}

Several interventions have been proposed for how policy makers and pension providers can help consumers to prepare for retirement, ranging from using smart defaults (e.g. Choi et al. 2003), nudging (Thaler and Sunstein 2008), financial education (e.g. Lusardi and Mitchell 2014), communicating social norms (e.g. Beshears et al. 2015; Winterich and Nenkov 2015), and framing information appeals (e.g. Brown et al. 2008; Saez 2009). Framing, that is, adapting the wording but not the content of communication, can be a powerful nudge to shape the intentions and behaviors of consumers in a desired direction (Saez 2009; ülkümen and Cheema 2011). While for example financial education can be really costly and may not always be efficient (Fernandes et al. 2014), framing interventions provide low cost, yet high potential opportunities. They are therefore especially interesting for policymakers since minor changes in message wording can significantly alter a consumer's perception and response, while avoiding the cost of expensive awareness campaigns and programs (Saez 2009). In chapter 3 , we analyze the difference that communication framing can make in activating pension plan participants.

Gain and loss frames, for example, build on the concept of prospect theory and loss aversion (Tversky and Kahneman 1981) and have been tested in different domains. An action or choice can be framed in terms of what one gains when performing the action (for example, expected positive future outcomes) or what one loses when not behaving in a certain way (for example, emphasizing expected negative future outcomes). We observe two main findings: First, loss frames can be a powerful nudge, but they also result in more 
negative emotions and evaluations compared to the gain frame. Second, we therefore develop two frames for pension communication, which tap into similar gain and loss mechanisms while avoiding the use of loss wording. The investment frame - the gain alternative - emphasizes that pension plan participants can gain by investing in their future and searching for information. In contrast, the assurance frame - the loss alternative stresses that participants can prevent negative consequences through the sense of security that they obtain when learning about their expected pension benefits. We test these two frames in the field with 7,315 participants of a Dutch DC pension plan and find that assurance framing is twice as effective in engaging participants to click on a movie link (explaining pension scheme changes) compared to the investment frame. With these frames, we find no differences in frame evaluation or negative emotions.

\section{What role do age-related cognitive and non-cognitive changes play with regard to financial decision making?}

In chapter 4, we look at how financial decision making quality changes with age. While consumers of all ages face difficult financial decisions that affect their financial wellbeing (such as preparing for retirement), the literature on cognitive aging suggests that especially older adults struggle with cognitively demanding decisions (e.g. Del Missier et al. 2015; Mather and Carstensen 2005). In contradiction to findings from the cognitive aging literature, however, the studies that have examined the relationship between age and financial decision making have found that older consumers generally seem to perform better than younger adults (e.g. Li et al. 2013, 2015). Two cognitive and two non-cognitive individual-differences characteristics may potentially explain age differences in financial decision making (Bruine de Bruin 2016). On the one hand, older consumers face age-related decline in cognitive abilities (such as numeracy) that could potentially harm their ability to make financial decisions (Bruine de Bruin et al. 2015; Weller et al. 2013; Finucane et al. 2005). On the other hand, older consumers also have acquired more experience-based knowledge that may benefit their financial decisions (Bruine de Bruin, Parker and Fischhoff 2007, 2012; Li et al. 2013, 2015). Additionally, older consumers experience changes in emotions and motivation, which have also been identified as potentially relevant to making good decisions (e.g. Bruine de Bruin 2016; Strough, Parker, and Bruine de Bruin 2015).

In a nationally representative sample from the United Kingdom ( $N=926)$, we analyze the role of these cognitive (numeracy and experience-based knowledge) and non-cognitive characteristics (emotions and motivation) across four measures of financial decision making, including performance measures of sunk cost and credit card repayment decisions, as well as self-report measures of money management and financial decision outcomes. First, we find that older consumers perform better on all four measures of financial decision making. Second, the significant positive relationship between age and financial decision making holds, even after controlling for demographics and the four characteristics (numeracy, experience-based knowledge, emotions and motivation). Third, we examine how numeracy, 
experience-based knowledge, emotions and motivation contribute to age differences in financial decisions. Older consumers especially benefit from their higher levels of experience-based knowledge and lower levels of negative emotions.

\section{Dissertation outline}

In each of the following chapters I discuss my research regarding one of the three research objectives stated above. In Table 1.2, I provide an overview of the chapters as a reading guide. I take a multidisciplinary approach in this dissertation and look at financial decision making from different angles: in chapter 2 , my co-authors and I take a marketing perspective and examine which factors drive differences in participants' retirement information search.

Table 1.2: Overview dissertation chapters

\begin{tabular}{|c|c|c|c|}
\hline & Chapter 2 & Chapter 3 & Chapter 4 \\
\hline $\begin{array}{l}\text { Main field of } \\
\text { contribution }\end{array}$ & Marketing & Economics & $\begin{array}{l}\text { Judgment and decision } \\
\text { making }\end{array}$ \\
\hline Research question & $\begin{array}{l}\text { What drives differences in } \\
\text { participants' retirement } \\
\text { information search? }\end{array}$ & $\begin{array}{l}\text { How can framing help } \\
\text { to activate pension plan } \\
\text { participants to acquire } \\
\text { information? }\end{array}$ & $\begin{array}{l}\text { What role do age-related } \\
\text { cognitive and non- } \\
\text { cognitive changes play } \\
\text { with regard to financial } \\
\text { decision making? }\end{array}$ \\
\hline $\begin{array}{l}\text { Independent } \\
\text { variable(s) }\end{array}$ & $\begin{array}{l}\text { Beliefs, retirement anxiety, } \\
\text { risk taking, financial } \\
\text { literacy, trust and socio- } \\
\text { demographic factors }\end{array}$ & $\begin{array}{l}\text { Gain and loss framing; } \\
\text { assurance and investment } \\
\text { framing }\end{array}$ & $\begin{array}{l}\text { Numeracy, experience- } \\
\text { based knowledge, } \\
\text { negative emotions and } \\
\text { motivation }\end{array}$ \\
\hline Dependent variable(s) & $\begin{array}{l}\text { Information search } \\
\text { intention }\end{array}$ & $\begin{array}{l}\text { Information search } \\
\text { behavior }\end{array}$ & Financial decision making \\
\hline Research sample & $\begin{array}{l}\text { Pension plan participants } \\
\text { in the Netherlands } \\
(\mathrm{N}=583) \text { and in the UK } \\
(\mathrm{N}=1,156)\end{array}$ & $\begin{array}{l}\text { Student samples, pension } \\
\text { plan participants in the } \\
\text { Netherlands }(N=7,315)\end{array}$ & $\begin{array}{l}\text { Nationwide UK sample } \\
(\mathrm{N}=926)\end{array}$ \\
\hline Data & $\begin{array}{l}\text { Survey, administrative } \\
\text { data }\end{array}$ & $\begin{array}{l}\text { Laboratory experiments, } \\
\text { field experiment }\end{array}$ & Survey \\
\hline Methodology & $\begin{array}{l}\text { Partial least squares } \\
\text { regressions }\end{array}$ & $\begin{array}{l}\text { Mean and percentage } \\
\text { tests }\end{array}$ & $\begin{array}{l}\text { Ordinary least squares } \\
\text { regressions, mediation } \\
\text { models }\end{array}$ \\
\hline Main results & $\begin{array}{l}\text { Beliefs, especially } \\
\text { perceived benefits, and } \\
\text { emotions add value in } \\
\text { explaining information } \\
\text { search }\end{array}$ & $\begin{array}{l}\text { Assurance frame is twice } \\
\text { as effective as investment } \\
\text { frame in triggering } \\
\text { information search } \\
\text { behavior }\end{array}$ & $\begin{array}{l}\text { Older adults make better } \\
\text { financial decisions and } \\
\text { benefit from experience- } \\
\text { based knowledge and less } \\
\text { negative emotions }\end{array}$ \\
\hline
\end{tabular}


Understanding pension plan participants better is the first step in improving pension communication and helping marketers to develop better campaigns. In chapter 3 , my co-authors and I mainly contribute to the field of economics by exploring how framing information can help activating participants to acquire information. In my final chapter, my co-authors and I follow research practices that are more common in psychology and judgment and decision making to investigate what role age-related cognitive and noncognitive changes play with regard to financial decision making. I discuss my findings in chapter 5 , and explain the implications of my findings for policy makers, pension funds, insurance companies and other financial institutions. 



\section{chapter $\mathbf{2}$}

\section{The Retirement Belief Model: Understanding Retirement Information Search}

This chapter is co-authored with: Elisabeth Brüggen (Maastricht University), Thomas Post (Maastricht University) and Chantal Hoet (Aegon) 



\subsection{INTRODUCTION}

Transformative service research focusses on "creating uplifting changes" aimed at improving the lives of consumer entities (Anderson et al. 2013). Accordingly, a core area of transformative service research is pensions, a financial service designed to establish consumers' long-run financial well-being. The relevance of studying pension planning has sharply increased as insufficient pension benefits form one of the biggest challenges of aging societies in the 21st century.

According to a recent UN report, "the proportion of persons aged 60 and over is expected to double between 2007 and 2050, and their actual number will more than triple, reaching 2 billion by 2050" (UN 2016). Pension systems around the world are under more pressure for reforms than ever before. Reasons for this are increased government debt, a low-growth and low-interest economics environment, significant unemployment, and the increasing prevalence of DC schemes and the related increased responsibility on individuals to understand their pension arrangement (Mercer 2017). Governments and employers increasingly shift risks and responsibility for individual retirement planning towards pension plan members (Bodie, Marcus, and Merton 1988; Van Rooij, Kool, and Prast 2007), which means that it is getting more and more important that people become active and get to know whether they are on target to meet their retirement income goals.

However, many people know very little about saving for retirement, do not read information provided by pension funds, do not consult a financial advisor and consider pension information too difficult (Chan and Stevens 2008; Dushi and Honig 2015; Gustman, Steinmeier, and Tabatabai 2012; Lusardi and Mitchell 2011; 2014). A recent study by a large American financial services provider for example finds that people spent less time on planning an individual retirement account investment than people do choosing a restaurant, buying a flat screen TV or tablet (TIAA-CREF 2014). This type of behavior can be categorized as "active information avoidance" since participants know that there is free information available, but do not search for it (Golman, Hagmann, and Loewenstein 2017). Participants who insufficiently search for information about their expected pension benefits may not learn on time whether they are financially prepared for retirement (Van Schie, Donkers, and Dellaert 2012). Some of them may therefore encounter significant pension gaps resulting in detrimental welfare effects at retirement (Post et al. 2014). Munnell et al. (2015) estimate that $53 \%$ of all working households in the United States will not be able to keep their living standard in retirement.

Brüggen et al. (2017) stress the importance for conducting research on how to increase pension plans participants' interest in acquiring information on their expected pension benefit to improve long-run financial well-being. Existing research from economics, marketing, and finance has provided insights on how to improve, for example, retirement savings intentions (e.g., Hershfield et al. 2011), investment behavior (e.g., Sunden and Surette 1998), retirement age planning (e.g., Gustman et al. 2012), or financial literacy (Lusardi 
and Mitchell 2014). However, two key issues remain largely unaddressed. First, research on the very first step in pension planning, acquiring the necessary information on one's individual pension situation, is scarce. This is surprising given that information acquisition is at the beginning of the funnel, and decisions such as increasing savings for retirement, changing the asset allocation, or deciding upon retirement age can only be taken after acquiring the necessary information. Thus, information search is a first and very crucial step that people must take before they can take other decisions that will affect their financial well-being. Second, most studies only include one (e.g. Hansen 2012) or a few (Hershey, Jacobs-Lawson, and Neukam 2002) drivers of people's behavior. It is thereby impossible to draw conclusions on the relative importance of those drivers and the relationship between them. What is lacking is a unifying framework that includes the most relevant drivers and factors with the strongest effect on motivating participants to acquire information on their retirement savings and expected benefits. To address this gap in the literature, we employ the Retirement Belief Model (RBM). The RBM incorporates insights from the Health Belief Model, a widely applied model explaining information search in the health prevention domain (Glanz, Rimer, and Viswanath 2015; Janz and Becker 1984).

By developing the RBM, we make the following contributions. First, we generate important insights on understanding people's information search behavior in order to stimulate them to acquire the necessary information for their retirement planning. Thus, while previous research looked at downstream behaviors (e.g., saving and investing), we focus on the start of the planning process. Second, we construct a unifying framework incorporating multiple factors related to information search intention from different literatures at the same time to better understand their relative importance. The core RBM is theoretically grounded in the theory of reasoned action and its extended version theory of planned behavior (Ajzen 1991), and includes the five beliefs self-efficacy, benefits, barriers, severity and susceptibility. Using an interdisciplinary lens, we add factors to the core RBM that have been identified in the economics, finance, psychology and (service) marketing literature on retirement planning. Factors that have been identified and studied extensively in the (service) marketing literature are trust (e.g. Hansen 2012), propensity to plan (e.g. Lynch et al. 2010) and emotions (e.g. Xin Ding et al. 2010). Research on retirement planning in economics and finance typically studies factors such as risk taking (e.g. Dohmen et al. 2011), or financial literacy (e.g. Lusardi and Mitchell, 2014). We also control for socio-economic characteristics such as age, gender, and income. Our interdisciplinary approach brings all of these factors together into one holistic model, thereby making it possible to investigate the relationship between those variables.

We test the RBM using field survey data from 583 participants in the Netherlands, and assess the generalizability of the model in a survey with 1,156 British participants who are in a very different economic, cultural, and institutional context. We find that the RBM core beliefs as well as, for example, trust and retirement anxiety are indeed important drivers of 
information search. While the survey elicits only information search intentions we also find in additional analyses that our results generalize to actual behaviors. For the Dutch sample, this means that participants who indicate higher information search intentions in the survey are indeed more likely to read pension newsletters. For the British sample, we see that the participants who indicate higher intentions are more likely to register on the pension fund's website.

Third, beyond its theoretical contributions, our work has actionable implications for pension plan providers, which have already found their way into practice. Managers have used our insights to adjust their communication so that the factors that stimulate information acquisition are emphasized. Furthermore, the RBM has been used in practice to segment people with the goal to derive deeper insights on the heterogeneity between them (Danaher 1998): knowing which factors matter for which segment helps developing communication for sub-groups of pension-plan participants (see Appendix G).

We organize the rest of the article as follows. First, we explain the conceptual background of the RBM, derive hypotheses for the core model, and define and explain the additional variables. We then describe our field surveys in the Netherlands and the United Kingdom, discuss our analyses techniques, and present the results. Finally, we draw conclusions, explain our theoretical contributions as well as managerial implications, and note some limitations and opportunities for further research.

\subsection{THE RETIREMENT BELIEF MODEL}

To generate more knowledge on what distinguishes participants who do and do not search for information about retirement, we developed the Retirement Belief Model (see Figure 2.1). The model is conceptually rooted in the theory of reasoned action and its extended version theory of planned behavior (Ajzen 1991; Conner and Armitage 1998). We thereby follow recommendations by Mende and van Doorn (2015), who suggest to study theory of planned behavior in the context of financial well-being. Within the theory of reasoned action, intentions are understood as predictors of behavior. However, even when individuals have good intentions to pursue a behavior, they may lack the skills to do so and refrain from taking action. The theory of planned behavior therefore includes the concept of self-efficacy, which means that these intentions only translate into behavior if individuals feel capable of what they would need to do (Conner and Armitage 1998).

Since long-term health and money decisions are both influenced by time-discounting preferences (Gubler and Pierce 2014), the RBM is inspired by research on preventive health behaviors. The Health Belief Model was developed to explain what motivates individuals to participate in cancer screenings or health check-ups (Rosenstock 2005, 1974). According to the Health Belief Model, which is one of the most well-established models within health promotion, individuals are more likely to engage in a certain behavior, if they (1) feel 
that they are able to change something about their situation (self-efficacy), (2) think that benefits of taking action weigh heavier than the costs (benefits vs. barriers), (3) believe that

the consequences of (not) engaging in a behavior are severe (severity), and finally (4) that they are at risk of experiencing an undesirable outcome (susceptibility) (Glanz, Rimer, and Viswanath 2015; Janz and Becker 1984). These five beliefs are the core of our RBM.

Next to the beliefs, we include additional factors that may also influence whether participants search for information about their retirement situation. To derive these additional factors, we used the following procedure: we first reviewed the extant literature in economics, finance, psychology and (services) marketing. We categorized all factors and rank ordered them according to our perception of their importance for this research question. We took this preliminary list and enlisted feedback from representatives from the pension sector (communication managers, customer contact agents, and key account managers from pension funds and insurance companies), public policy makers from ministries, and academic experts from the fields of economics, finance, and marketing. We used the insights from this two-step procedure to conceptualize our final RBM, which we next describe in more detail.

\section{Core constructs: beliefs}

The central part of the RBM are beliefs about retirement information search: perceived self-efficacy, benefits, barriers, severity and self-efficacy. A belief is defined as "subjective

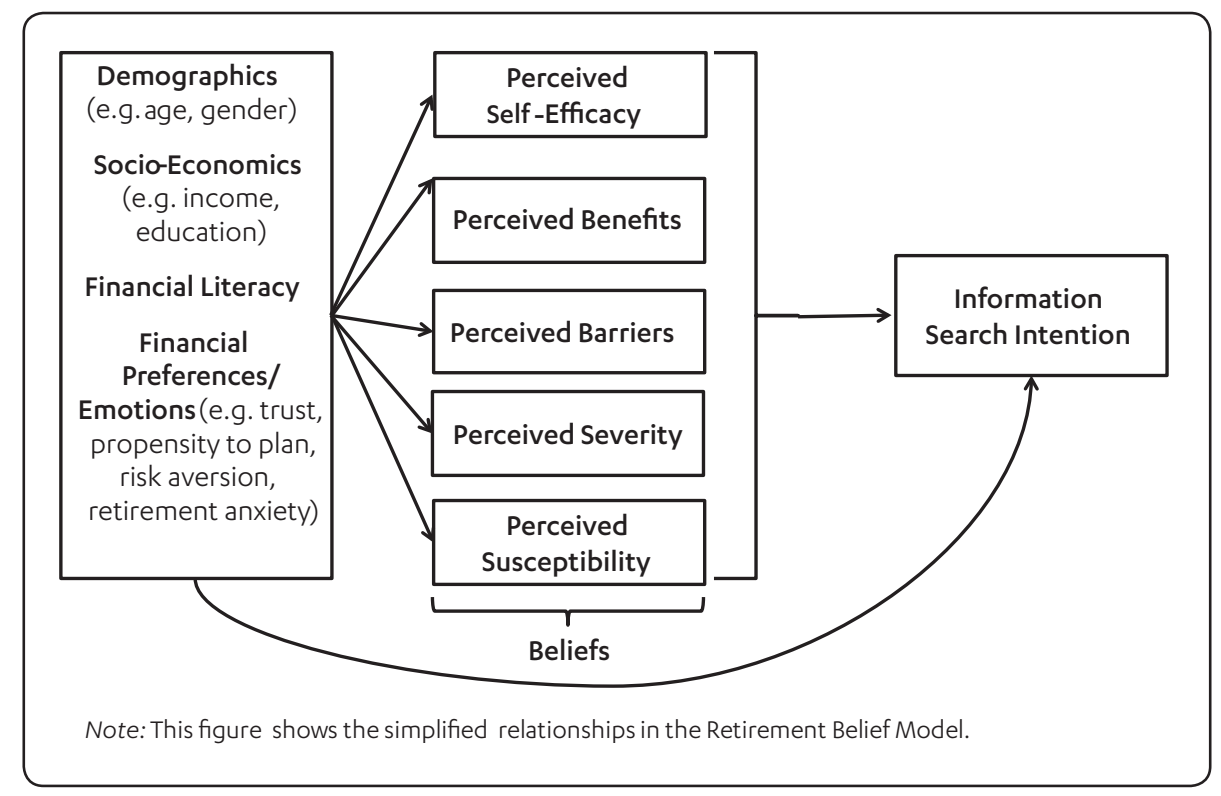

Figure 2.1: Retirement Belief Model 
probability that the object has a certain attribute" (Ajzen and Fishbein 2000). Individuals can, for example, believe that there are no benefits in searching for information about one's expected retirement income. Individuals form different beliefs about a behavior, but only the strongest, accessible beliefs then determine the attitude.

We formulate five hypotheses concerning the central part, the core constructs of our RBM: the influence of beliefs on behavioral intention to search for information about one's retirement income situation.

Perceived self-efficacy is defined as the certainty that one can accomplish a behavior to produce a desired outcome (Bandura 1994). In our context, self-efficacy is the degree to which participants feel that they are capable of searching for information, that they know where to look for information, and understand the acquired information. Especially the latter is important, since previous research found that when facing retirement related information, participants feel powerless and do not know how to act upon information (Lusardi, Keller, and Keller 2009). When participants feel confident about their own skills to look for financial information, they show more positive retirement-related behavior such as saving for an emergency fund, and figuring out how much money they need for retirement (Fernandes et al. 2014). Furthermore, efficacy and achievability of goals have been shown to positively influence saving behaviors of participants (Cheema and Bagchi 2011). We therefore expect that:

H1: Participants are more likely to search for information on retirement savings, if their perceived self-efficacy is high.

Perceived benefits are the advantages that participants expect to receive from information search. Participants want relevant and insightful information on their current situation and potential future actions. Benefits could include peace of mind because participants gain a sense of security about their pension situation and are able to determine what future actions to take for a comfortable retirement. Achieving smaller goals on the way to a larger one further away in the future can help individuals to stay motivated (Gal and McShane 2013). Taking the first step towards long-term financial well-being can make participants feel good about themselves. Anticipating this can help increasing participants' motivation to take action.

H2: Participants are more likely to search for information on retirement savings, if their perceived benefits of informing themselves are high.

Perceived barriers are the obstacles that may prevent participants from searching for information. In contrast to benefits of information search, barriers are specific and include time, effort, and money it costs to search for information. Additionally, individuals are even more focused on the present and what happens today when making choices that require effort than when making choices that cost money (Augenblick, Niederle, and Sprenger 2013). This means that present bias may even be larger with effort-intense activities such as information search. 
H3: Participants are less likely to search for information on retirement savings, if their perceived barriers of informing oneself are high.

Perceived severity describes an individual's personal perception of the seriousness of a condition, in our retirement context defined as severity of not saving enough for retirement. Many participants have false confidence in their retirement preparations, assume that they do not need much money later or never computed how much they would need to save (Ellen et al. 2012). If participants do not save enough for retirement, financial and social consequences can be severe. However, only if participants anticipate the full range of resulting difficulties, they will also act upon them.

H4: Participants are more likely to search for information on retirement savings, if their perceived severity is high.

Perceived susceptibility is the degree to which individuals see themselves at risk of having a pension gap, that is, as not accumulating enough money for retirement. Depending on internal factors (such as their own personal social environment) and external factors (such as news media items on recent pension system reforms and ageing societies), participants form a belief on how likely it is that they themselves save too little. In order for participants to search for information, they need to consider themselves as vulnerable for a pension gap. Thus, we hypothesize:

H5: Participants are more likely to search for information on retirement savings, if their perceived susceptibility is high.

\section{Psychographic factors}

Next to beliefs, we include additional psychographic factors that either directly or indirectly (through an impact on the core beliefs for example) influence information search intention. Empirical evidence suggests that these factors matter for retirement planning, but they have not yet been studied jointly. We do not formulate hypotheses for these factors, but highlight key relationships as found in previous literature.

Propensity to plan reflects differences between participants in their frequency of forming planning goals and a personal preference to planning (Lynch et al. 2010). Individuals differ in their preference for planning. Participants who have a preference to plan experience comfort after an information search process (Lynch et al. 2010). Planners understand the benefits of acquiring information, and anticipating those benefits makes them more likely to search for information.

Retirement anxiety is defined as "preretirement expectations of the consequences of retirement" (van Solinge and Henkens 2008). Some participants may not associate the retirement phase with good times, but rather with unpleasant health and disability problems (Hayslip et al. 1997). We therefore expect a high level of retirement anxiety to be positively related with a willingness to search for information. Yet, retirement anxiety can also have the opposite effect: individuals get scared and shy away from taking action at all (Ellen et al. 2012). In order to decrease anxiety about an event (such as retirement in our 
case), individuals may choose to avoid searching for information and thereby find out about a risk (Golman et al. 2017). Whether retirement anxiety has a positive or negative effect on information search intention is therefore difficult to predict. Besides that, we expect participants with a high level of retirement anxiety to also perceive a high level of severity and see themselves as more susceptible for a pension gap.

Trust towards one's service provider (Hansen 2012) - in this case the participants' pension provider - is another component of the RBM. If participants expect that the service provider can be relied on to deliver on its promises (Hansen 2012), that is their trust in their pension provider is high, they will consider their provider as first contact point for retirement information, and therefore be more willing to search for information. Trusting participants will also perceive higher benefits, since they have a better relationship with their service provider than non-trusting participants.

Risk taking is the willingness of individuals to take risks (Dohmen et al. 2011). We assess participants' level of financial risk taking, and expect risk taking to be a preference that is positively correlated with self-efficacy. Risk-averse individuals experience more fear and want to minimize the risk of the unknown (Loewenstein, Weber, Hsee, and Welch 2001), while risk taking individuals have more confidence in themselves.

Financial literacy is the degree to which individuals understand financial concepts, and possess the ability and confidence to manage their finances, both in the short and in the long run (Remund 2010). We expect that if participants are financially literate, they understand that it is wise to acquire information concerning one's retirement and are more willing to do so than less financially literate individuals. We measure financial literacy by using the three basic financial knowledge questions by Lusardi and Mitchell (2011), and expect that financially literate participants have higher self-efficacy while perceiving lower barriers.

\section{Socio-demographic dimensions}

Within the RBM, we recognize that socio-demographic characteristics influence beliefs, financial preferences, emotions and financial preferences. We include gender, age, and income because previous research has shown that these factors influence beliefs and other psychographic factors. Women for example have been shown to be more risk averse than men (Booij and van Praag 2009; Clark et al 2012; Clark et al. 2007; Bajtelsmit, Bernasek, and Jianakoplos 1999) meaning that many of them are also less risk-taking when investing for retirement, which can result in insufficient income during retirement. Moreover, women are often less financially literate and less secure about their capabilities to make financial decisions (Bucher-Koenen and Lusardi 2011). Then, older adults spend more time thinking about and planning or preparing for retirement (Adams and Rau 2011; Feldman and Beehr 2011). Younger people may think about retirement from time to time, but not take action. This may be because of financial restrictions, or because they do not see the need to act now already since retirement is still so far away (Kemp, Rosenthal, and Denton 2005). And finally, 
a high income facilitates individuals to save for retirement, and households with higher income have shown to be more willing to save and to be better prepared for their last phase of life (Van Rooij, Lusardi and Alessie 2012). We refrain from formulating separate hypotheses for relationships between additional constructs, core constructs and information search intention. Yet, we include them accordingly in our conceptual model. By incorporating dimensions of heterogeneity from health promotion and financial research into one single framework, we aim to discover underlying differences between participants that determine information search.

\subsection{EMPIRICAL APPLICATION}

We test the Retirement Belief Model in the Netherlands and the United Kingdom (UK) with the purpose of examining whether the Retirement Belief Model holds in two very different regulatory environments. The Netherlands has an A-rated pension system, and therefore one of the best pension systems in the world, while the UK scores C+ on its pension system, particularly because of the low adequacy of the system (Mercer 2017). While the systems are very different, they share the same challenge for policy makers and financial service providers, that is to motivate pension plan participants to search for information. In the Netherlands, this challenge exists because of planned reforms and changes to the pension systems, in the UK it exists because of low overall pension benefits.

\section{Background}

The Dutch systems consists of a flat-rate first pillar public pension, and a quasi-mandatory second pillar occupational pension. $95 \%$ of employees are covered by these occupational schemes with industry-wide DB plans. For years, the Dutch system has been the best pension system in the world and the poverty rates for the elderly are the lowest in the OECD (1.4\% in 2010; 2\% in 2012; Mercer 2016). However, the pension system has undergone shocks because of the financial crisis, the low interest rates, and the aging of the Dutch society, which showed that the system is more vulnerable than anticipated (Alessie, van Rooij, and Lusardi 2011). After the financial crisis, many funds had to cut pension benefits, affecting more than five million participants (Bovenberg and Gradus 2015). This surprised many retirees, who thought that their pension could not be cut. And it changed the prospects for many Dutch consumers. The Dutch government is currently discussing major pension reforms, which would further affect the prospects of financial-well-being during retirement. A broader societal trend is that the government pulls back and more responsibility is with the individual, as well as more freedom of choice - a role that many are not yet ready for. Current pension schemes become too expensive for employers, which results in the employers taking a facilitator role for their employees rather than a care-taking role as they had in the past. In light of these developments, Dutch people are still overly optimistic about what they will receive when they retire: more than $80 \%$ of Dutch participants for 
example expect that they will receive $70 \%$ of their final salary as retirement income (GfK 2014). While most participants in Dutch pension schemes consider themselves as saving enough, almost half of all households face replacement rates of below 70 percent when taking into account first and second pillar savings (Knoef et al. 2016). Participants simply expect significantly higher replacement rates than they will eventually receive (Van Duijn et al. 2013). Suggestions for improvement therefore include stimulating household savings (Alessie et al. 2011; Mercer 2017). Thus it is, and will get even more important that people properly search for information about whether they are at a risk of facing a retirement income gap.

In contrast, the UK system consists of a single tier state pension which is complemented by voluntary occupational and private pensions. By 2017, nearly all employees are covered by these occupational schemes via automatic enrollment, but can opt out and minimum contributions are still as low as 2 percent (Mercer 2017). Since the expected replacement rate in the UK is much lower than in the Netherlands, it is even more important that people are properly informed about their expected retirement income so that they can potentially increase their savings. As the main challenge in both systems is to activate participants to acquire information, we do expect the RBM to hold in both settings. However, given the differences in regulations and quality of the pension systems, we expect that beliefs and other factors differ in their impact.

\section{Survey development}

We obtain field survey data by sending out survey questionnaires. We started the questionnaire by asking about participants' behavioral intention to search for information about their expected pension benefits, and added a question on whether participants are already informed about their pension. After that, we continued with the beliefs dimensions perceived self-efficacy, benefits, barriers, severity, and susceptibility (adapted from Grispen et al. 2011). For retirement anxiety (Hayslip et al. 1997), propensity to plan (Lynch et al. 2010), risk-taking (Dohmen et al. 2011), financial literacy (Lusardi and Mitchell 2011), trust towards the financial service industry and the pension provider (Hansen 2012), we use established scales by the authors mentioned. Except for risk-taking (10 point scale) and financial literacy, all scales are seven-point Likert agreement scales. At the end of the questionnaire, we asked respondents to indicate their gender, age, whether they live together with a partner, marital status, children, monthly net household income, the percentage of the household income they contribute, education, the sector they work in, and whether they own or rent a house (the latter with or without governmental support). The questionnaire is given in Appendix $A$, and the differences in mean scores between the country samples in Table 2.1.

Before we turn to the details of the data collection, we want to highlight here that differences in regulatory setting are already visible in participants' answers. Perceived susceptibility for a pension gap is significantly higher among UK participants, as are feelings 
Table 2.1: Descriptive statistics on RBM constructs

\begin{tabular}{|c|c|c|c|}
\hline \multirow[t]{2}{*}{ Variables } & \multirow{2}{*}{$\begin{array}{l}\text { The Netherlands } \\
(\mathrm{N}=583) \\
\text { Mean (SD) }\end{array}$} & \multirow{2}{*}{$\begin{array}{l}\text { United Kingdom } \\
(\mathrm{N}=1,156) \\
\text { Mean (SD) }\end{array}$} & \multirow{2}{*}{$\begin{array}{c}t \text {-statistic } \\
\text { on difference } \\
t\end{array}$} \\
\hline & & & \\
\hline Information search intention (1-7) & $\begin{array}{c}3.83 \\
(1.58)\end{array}$ & $\begin{array}{l}4.13 \\
(1.67)\end{array}$ & $3.70^{+* * *}$ \\
\hline Already informed & $\begin{array}{l}4.51 \\
(1.66)\end{array}$ & $\begin{array}{c}4.06 \\
(2.03)\end{array}$ & $4.56^{* * *}$ \\
\hline Perceived self-efficacy & $\begin{array}{c}3.50 \\
(1.42)\end{array}$ & $\begin{array}{l}4.15 \\
(1.39)\end{array}$ & $9.09^{* * *}$ \\
\hline Perceived barriers & $\begin{array}{c}3.31 \\
(1.23)\end{array}$ & $\begin{array}{c}3.61 \\
(1.32)\end{array}$ & $4.40^{* *+}$ \\
\hline Perceived benefits & $\begin{array}{c}5.24 \\
(1.00)\end{array}$ & $\begin{array}{c}5.59 \\
(1.04)\end{array}$ & $6.68^{* * *}$ \\
\hline Perceived susceptibility & $\begin{array}{c}3.64 \\
(1.42)\end{array}$ & $\begin{array}{l}4.46 \\
(1.54)\end{array}$ & $10.89^{\star \star \star}$ \\
\hline Perceived severity & $\begin{array}{l}4.58 \\
(1.47)\end{array}$ & $\begin{array}{c}5.34 \\
(1.54)\end{array}$ & $9.88^{*+*}$ \\
\hline Retirement anxiety & $\begin{array}{c}3.42 \\
(1.32)\end{array}$ & $\begin{array}{c}4.70 \\
(1.44)\end{array}$ & $17.99^{*+*}$ \\
\hline Propensity to plan & $\begin{array}{c}4.76 \\
(1.48)\end{array}$ & $\begin{array}{l}4.96 \\
(1.44)\end{array}$ & $2.74^{* *}$ \\
\hline Trust own pension provider & $\begin{array}{l}4.51 \\
(1.42)\end{array}$ & $\begin{array}{c}4.75 \\
(0.96)\end{array}$ & $4.28^{* * *}$ \\
\hline Financial risk-taking (1-10) & $\begin{array}{c}4.03 \\
(2.26)\end{array}$ & $\begin{array}{r}4.26 \\
(2.31)\end{array}$ & $1.96^{* *}$ \\
\hline
\end{tabular}

Note: Standard deviations are given in parentheses. ${ }^{*}{ }^{* *}$, and ${ }^{* * *}$ denote statistical significance at the $10 \%, 5 \%$, and $1 \%$ level for a two-tailed independent sample t-test.

of retirement anxiety. British participants also feel that it is more severe to not save enough for retirement. We now come to estimating the RBM in the two countries.

\section{STUDY 1: TESTING THE RBM IN THE NETHERLANDS}

\section{Data collection}

The survey was translated to Dutch, and pre-tested with administrative university administrative staff and faculty $(\mathrm{N}=21)$ to ensure that wording and structure of the questionnaire are straightforward. Any inconsistencies or lack of clarity were resolved.

We test the RBM with Dutch pension plan participants of a large international insurance company and occupational pension provider. Together with a newsletter, the survey was sent out via e-mail to 7,122 participants (the complete active DC participant base of 
the provider) in September 2014. Focusing on DC plan participants makes the results of the study more generalizable to other countries where this form of pension plan is used predominantly. Moreover, DC participants are facing higher risks, and have more choices in their pension plan. In this specific pension plan, participants can choose between a life cycle fund and selecting one's own portfolio. Therefore, it is especially important to raise awareness and stimulate action in this group.

The participants in this DC base are all building up their second pillar pension in this scheme via their employer. Their employer chose this DC pension plan, so participation is mandatory for employees and the monthly contribution rate is set. Participants who have previously been in the DC scheme, but are not actively building up retirement benefits anymore (so-called "sleepers") are not included in the sample. Most of the participants (> 90\%) have stayed in the default investment portfolio with low risk exposure. For their participation in the survey respondents could win one of five $€ 50$ gift vouchers. Participants had 20 days to respond, with a reminder being sent after one week. 885 participants opened the survey link, and 638 participants filled out the complete questionnaire. We match survey and anonymized administrative data of the pension provider. Our final sample includes only the participants for which this matching was successful: 583 participants, a final response rate of $8 \%$. The descriptive statistics of the sample are given in Table 2.2.

Concerning gender, our sample of 583 participants is fairly representative for the total base of 7,122 participants: $66 \%$ of the total DC base is male, compared to $68 \%$ in our sample. However, the total base and sample differ significantly in age, income and marital status. Mean age is 42 for the total base, so with a mean age of 45 the sample is slightly older. The majority of respondents are married (60\%), while half of all DC participants are married, and yearly pensionable salary is somewhat higher for respondents as compared to the total base (see Table 2.2, panel D).

Table 2.2: Descriptives sample The Netherlands ( $N=583)$

\section{Panel A. Education}

Highest educational degree

\begin{tabular}{lccc} 
Highest educational degree & $\%$ & $\begin{array}{l}\text { Financial literacy } \\
\text { (\# questions } \\
\text { correctly answered) }\end{array}$ & $\%$ \\
High school & 23.0 & 0 & 3.9 \\
Intermediate vocational (Dutch: MBO) & 22.1 & 1 & 7.0 \\
College (bachelor degree) & 35.4 & 2 & 31.4 \\
University (master degree) & 14.9 & 3 & 57.6 \\
PhD & 2.9 & & \\
Other & 1.7 & & \\
\hline
\end{tabular}


Table 2.2: (continued)

Panel B. Income

\begin{tabular}{lccc}
\hline Net monthly household income & $\%$ & $\begin{array}{l}\text { Contribution to } \\
\text { household income }\end{array}$ & $\%$ \\
\hline Less than 1200 & 0.3 & $0-20$ & 3.9 \\
1200-1800 & 7.2 & $20-40$ & 21.4 \\
1800-2800 & 24.2 & $40-60$ & 21.6 \\
$2800-3800$ & 26.6 & $60-80$ & 30.5 \\
$3800-5000$ & 15.4 & $80-100$ & 15.3 \\
More than 5000 & 9.4 & No answer & \\
No answer & 16.8 & & \\
\hline
\end{tabular}

Panel C. Marital status and children

\begin{tabular}{lclc}
\hline Marital status & $\%$ & Children & $\%$ \\
\hline Married & 60.2 & None & 31.2 \\
Separated & 0.2 & 1 child & 14.8 \\
Divorced & 8.7 & 2 children & 38.8 \\
Widowed & 1.4 & 3 or more & 15.3 \\
Never married & 29.5 & & \\
\hline
\end{tabular}

Panel D. Non-response analysis

\begin{tabular}{llcc}
\hline & $\begin{array}{c}\text { All DC } \\
\text { participants }\end{array}$ & Respondents & $\begin{array}{l}t \text {-statistic on } \\
\text { mean difference }\end{array}$ \\
\hline $\mathrm{N}$ & 7,122 & 583 & -0.74 \\
Proportion of men (\%) & $66 \%$ & $68 \%$ & $9.18^{* * *}$ \\
Mean age (SD) & 42 & 45 & $2.40^{* * *}$ \\
Age range & $(10.55)$ & $(10.85)$ & $21-64$ \\
Mean annual pensionable salary (SD) & $20-66$ & $50,758 €$ & $(24,944.67)$ \\
Married (\%) & $48,189 €$ & $60 \%$ & $5.20^{* * * *}$ \\
\hline
\end{tabular}

Note: This table presents the distribution of education, financial literacy, net monthly household income, respondent's contribution to household income, marital status, and number of children ( $N=583)$. Panel $D$ shows a comparison between the sample of participants that received the survey link via e-mail and the respondents, and the results of a two-tailed independent samples t-test. Standard deviations are given in parentheses. ${ }^{*},{ }^{* *}$, and ${ }^{* * *}$ denote statistical significance at the $10 \%, 5 \%$, and $1 \%$ level. 


\section{Data Analysis}

We estimate the RBM by building a structural equation model, which allows us to test a network of relationships between different latent variables (measured by several indicators) simultaneously. We apply the partial least squares (PLS) approach to the structural equation model, which includes an iterative algorithm to first evaluate the measurement model and second to estimate the path coefficients in the structural model. In contrast to ordinary least squares regression procedures, the estimation procedure in PLS is named partial because it alternates a series of single and multiple regressions step by step (Vinzi, Trinchera, and Amato 2010).

For analyzing the data, we use PLS structural equation modeling instead of covariancebased structural equation modeling, because the purpose of our research is exploratory, our data is partly non-normally distributed and some constructs are composed of less than three items (Hair, Ringle, and Sarstedt 2011). All analyses are carried out using SmartPLS 3 (Ringle, Wende, and Becker 2015).

We start by estimating the influence of demographics on behavioral intention, and use the observable characteristics of participants to predict information search intention. The result is shown in Figure 2.2. The variables gender, high income, and married are all coded to binary dummies: 1 if gender is female, if monthly net household income is equal to or higher than €2,800-€3,800 (based on median split), and if the participant is married. We

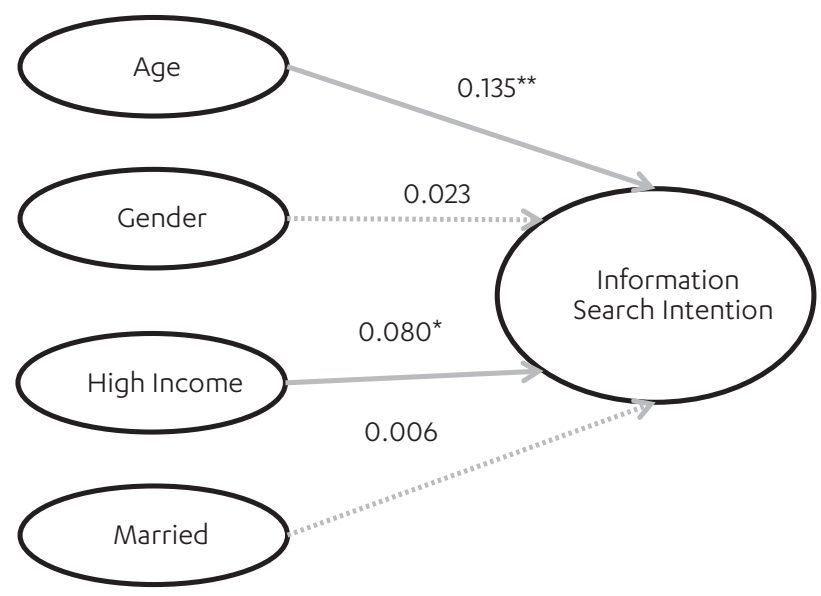

Note: This figure displays the path coefficients for demographics on information search intention. *, ${ }^{* *}$, and ${ }^{* *}$ denote statistical significance at the $10 \%, 5 \%$, and $1 \%$ level (estimated with PLS). Dotted lines show insignificant relationships, solid lines significant relationships.

Figure 2.2: Demographics on intention (NL) 
only see a significant effect for age and high income, so the older and wealthier participants are, the higher is their intention to search for information. However, this model does not explain information search intention very well (adjusted $R^{2}$ of 0.019 ), which shows that we cannot only rely on demographics, but need a richer model to explain information search intention. Therefore, the next step of our analysis is to estimate the full RBM.

\section{Measurement Model}

The measurement model is of a reflective nature, since the indicators are consequences rather than antecedents to the constructs, indicators for the different constructs are expected to be correlated, and we expect measurement error at indicator level (Churchill 1979; Jarvis, Mackenzie, and Podsakoff 2003). We first run a traditional PLS to test reliability of our multi-item measures, the prerequisite for validity. Concerning construct reliability, all Cronbach's $\alpha$ values are close to or above 0.8 (see Appendix B). Cronbach's $\alpha$ underestimates reliability because it assumes a tau-equivalent measurement model (i.e. all indicators are equally important), while we deviate deliberately from this assumption with PLS (Vinzi, Trinchera, and Amato 2010, p. 51). We therefore also look at the composite reliability values, and find satisfactory values between 0.8 and 0.9 .

Second, we investigate validity and find acceptable average variance extracted (AVE) values (>0.5) for convergent validity. To check discriminant validity, we look at the crossloadings and all indicators load higher on its assigned latent variable than on the other latent variables. The given Fornell-Larcker criterion value (calculated with consistent PLS) is also highest for the corresponding latent variables (Fornell and Larcker 1981). Since the FornellLarcker criterion requires consistent PLS, while we estimate our model using traditional PLS, we also take a look at the Heterotrait-monotrait Ratio of Correlations (HTMT, Henseler, Ringle, and Sarstedt 2015). All values are lower than threshold values $\mathrm{HTMT}_{.85^{\prime}}$ (see Appendix C) which is why we can conclude that we can assume discriminant validity. However, when investigating the outer loadings, we see that indicators 4, 5, 6 and 7 for construct perceived barriers have loadings lower than 0.4 . We analyze the impact of indicator deletion (see Appendix D) on the Fornell-Larcker criterion and composite reliability (Hair, Hult, Ringle, and Sarstedt 2013). Only after deleting all indicators 4, 5, 6 and 7, the Fornell-Larcker criterion improves, but composite reliability does not, which is why we decide to retain all indicators.

\section{Structural Model}

We estimate the RBM using the traditional PLS algorithm. The results are displayed in Table 2.3. In model 1, we only look at the influence of the core constructs, the beliefs, on behavioral intention to search for information. In model 2, we are interested in what dimensions of heterogeneity influence beliefs (and behavioral intention), and how sociodemographic factors influence the different dimensions and beliefs.

Concerning the hypotheses, we find no support for H1: for self-efficacy, the path on behavioral intention is significant, but with an unexpected negative sign, contrary to 
Table 2.3: PLS results: sample The Netherlands $(\mathrm{N}=583)$

\begin{tabular}{|c|c|c|c|c|c|c|}
\hline & \multicolumn{3}{|c|}{ Model 1} & \multicolumn{3}{|c|}{ Model 2} \\
\hline & $\begin{array}{c}\text { Path } \\
\text { Coefficient }\end{array}$ & SD & $t$-statistics & $\begin{array}{c}\text { Path } \\
\text { Coefficient }\end{array}$ & SD & $t$-statistics \\
\hline \multicolumn{7}{|l|}{$\begin{array}{l}\text { Beliefs on Information Search } \\
\text { Intention (ISI) }\end{array}$} \\
\hline Barriers $\rightarrow|S|$ & -0.18 & 0.16 & 1.19 & -0.14 & 0.06 & $2.40^{* *}$ \\
\hline Benefits $\rightarrow|S|$ & 0.28 & 0.04 & $6.62^{+* *+}$ & 0.24 & 0.05 & $4.93^{* * *}$ \\
\hline Self-Efficacy $\rightarrow|S|$ & -0.16 & 0.05 & $2.91^{+* *}$ & -0.10 & 0.05 & $1.95^{* *}$ \\
\hline Severity $\rightarrow|S|$ & 0.15 & 0.04 & $3.37^{\cdots *}$ & 0.13 & 0.04 & $3.05^{4 * *+}$ \\
\hline Susceptibility $\rightarrow$ ISI & 0.03 & 0.05 & 0.56 & 0.02 & 0.04 & 0.46 \\
\hline \multicolumn{7}{|l|}{ Psychographic on ISI } \\
\hline Propensity to Plan $\rightarrow|S|$ & & & & 0.06 & 0.04 & 1.46 \\
\hline Retirement Anxiety $\rightarrow|S|$ & & & & 0.16 & 0.04 & $3.69^{*+*+}$ \\
\hline Trust Own Provider $\rightarrow$ ISI & & & & 0.11 & 0.04 & $2.56^{*+*}$ \\
\hline \multicolumn{7}{|l|}{ Demographic on Psychographic } \\
\hline Education $\rightarrow$ Financial Literacy & & & & 0.36 & 0.03 & $10.53^{*+* *}$ \\
\hline Education $\rightarrow$ Financial Risk-Taking & & & & 0.23 & 0.04 & $6.13^{*+*}$ \\
\hline Education $\rightarrow$ Retirement Anxiety & & & & -0.14 & 0.04 & $3.47^{* *+*}$ \\
\hline Gender $\rightarrow$ Financial Literacy & & & & -0.23 & 0.04 & $6.12^{. * *}$ \\
\hline Gender $\rightarrow$ Financial Risk-Taking & & & & -0.21 & 0.04 & $5.93^{* * *}$ \\
\hline Gender $\rightarrow$ Trust Own Provider & & & & 0.09 & 0.04 & $2.23^{* *}$ \\
\hline Gender $\rightarrow$ Propensity to Plan & & & & 0.08 & 0.04 & 1.91 \\
\hline \multicolumn{7}{|l|}{ Demographic on Beliefs } \\
\hline Age $\rightarrow$ Barriers & & & & -0.09 & 0.06 & 1.50 \\
\hline Age $\rightarrow$ Self-Efficacy & & & & 0.14 & 0.05 & $3.07^{*+*}$ \\
\hline Education $\rightarrow$ Barriers & & & & -0.12 & 0.05 & $2.50^{* * *}$ \\
\hline Education $\rightarrow$ Benefits & & & & 0.12 & 0.04 & $2.89^{+*+*}$ \\
\hline Education $\rightarrow$ Self-Efficacy & & & & 0.04 & 0.05 & 0.83 \\
\hline Gender $\rightarrow$ Barriers & & & & 0.10 & 0.04 & $2.43^{* *}$ \\
\hline Gender $\rightarrow$ Self-Efficacy & & & & -0.08 & 0.04 & 1.91 \\
\hline Income $\rightarrow$ Barriers & & & & -0.05 & 0.04 & 1.10 \\
\hline Income $\rightarrow$ Severity & & & & -0.06 & 0.04 & 1.38 \\
\hline Income $\rightarrow$ Susceptibility & & & & -0.07 & 0.04 & $2.05^{* *}$ \\
\hline
\end{tabular}


Table 2.3: (continued)

\begin{tabular}{|c|c|c|c|c|c|c|}
\hline & \multicolumn{3}{|c|}{ Model 1} & \multicolumn{3}{|c|}{ Model 2} \\
\hline & $\begin{array}{c}\text { Path } \\
\text { Coefficient }\end{array}$ & SD & $t$-statistics & $\begin{array}{c}\text { Path } \\
\text { Coefficient }\end{array}$ & SD & $t$-statistics \\
\hline \multicolumn{7}{|l|}{ Psychographic on Beliefs } \\
\hline Financial Literacy $\rightarrow$ Barriers & & & & -0.17 & 0.05 & $3.53^{* *+}$ \\
\hline Financial Literacy $\rightarrow$ Self-Efficacy & & & & 0.03 & 0.05 & 0.71 \\
\hline Financial Risk-Taking $\rightarrow$ Self-Efficacy & & & & 0.19 & 0.05 & $4.01^{* * *}$ \\
\hline Trust Own Provider $\rightarrow$ Benefits & & & & 0.30 & 0.04 & $6.79^{* * *}$ \\
\hline Propensity to Plan $\rightarrow$ Benefits & & & & 0.22 & 0.04 & $5.70^{+* *+}$ \\
\hline Retirement Anxiety $\rightarrow$ Severity & & & & 0.34 & 0.04 & $9.15^{* * *}$ \\
\hline Retirement Anxiety $\rightarrow$ Susceptibility & & & & 0.35 & 0.04 & $9.68^{* * *}$ \\
\hline Adjusted R² for ISI & 0.18 & & & 0.19 & & \\
\hline Confidence Intervals (Lower, Upper) & $(0.14,0.27)$ & & & $(0.14,0.27)$ & & \\
\hline
\end{tabular}

Note: This table presents the results of a partial least squares estimation for the Dutch sample ( $\mathrm{N}=583)$. Variables are defined in section 3 , study 1 ; ISI = information search intention; SD= standard deviation. * ${ }^{* *}$, and ${ }^{* * *}$ denote statistical significance at the $10 \%, 5 \%$, and $1 \%$ level.

findings of Fernandes et al. (2014). If we follow their explanation we would expect that participants who are confident in their ability are more likely to search for information. In a separate analysis, we investigate the influence of beliefs on the construct of already being informed, and see that self-efficacy has a significant positive influence. Individuals who have a high self-efficacy are more likely to already be informed, and therefore have no intention to do so (again) in the near future. $\mathrm{H} 2$ is supported, since we find a positive and significant path between benefits and behavioral intention. For $\mathrm{H} 3$, we find partial support: in model 1, barriers have a negative, but non-significant influence on information search intention. In model 2 barriers significantly negatively influence behavioral intention. We find support for $\mathrm{H} 4$ (severity has a positive, significant influence), but no support for H5 (susceptibility).

In addition, we find the following concerning the influence of socio-demographic characteristics on the additional factors: the more highly educated participants are, the higher their financial literacy, financial risk-taking and the lower their retirement anxiety. Age increases self-efficacy, since older participants are also more experienced with the pension information process. This is in line with findings from chapter 4 of this dissertation: older adults are more experienced with finances, which clearly benefits their financial decision making. Women are significantly less financially literate and risk-taking, but have higher trust in their own pension provider. Next to positive beliefs, retirement anxiety and trust towards one's own pension provider increase participants' intention to search for information. 
The extended model 2 has an adjusted $\mathrm{R}^{2}$ of 0.19 for explaining information search behavior. Compared to the low adjusted $R^{2}$ of 0.019 when using only demographic factors, this model explains information search behavior much better.

\section{Cross validation: linking intentions with behavior}

In a final step of the analysis, we look at the relationship between participants' behavioral intention to search for retirement savings information and their actual behavior. In December 2014, the same DC participants received two differently framed versions of a newsletter informing them about changes to their pension scheme. Details of this field experiment can be found in chapter 3 of this dissertation. Within these newsletters, participants could click on two different links: one to a movie explaining them the changes, and one to a personal website where they need to log in to look up information about their situation before the changes. We match the survey dataset with the experiment dataset and achieve a match for 573 (out of 583) participants.

We see that intention is significantly linked to behavior: in an independent sample t-test for the group which clicked on the website link ( $\left.N=37, M_{\text {clicked }}=4.57, S D=1.67\right)$ vs. the group which did not click ( $\left.N=536, M_{\text {notlicked }}=3.97, S D=1.64\right)$, intention to search for information was significantly higher $(t=-2.15, p=0.03)$. We see the same direction for the movie link: also here intention was higher ( $t=-1.93, p=0.05)$ for the group which clicked ( $N=57, M_{\text {clicked }}=4.40$, $\mathrm{SD}=1.47)$ as compared to the group which did not $\operatorname{click}\left(\mathrm{N}=516, \mathrm{M}_{\text {notclicked }}=3.78, \mathrm{SD}=1.58\right)$.

\section{STUDY 2: TESTING THE RBM IN THE UNITED KINGDOM}

\section{Data collection}

To validate whether the RBM holds in different cultural, economic, and regulatory environments, we also test the RBM in the United Kingdom. We collaborated with a large DC pension scheme provider that UK employers can use to meet the automatic enrollment requirements put in place by the Pensions Act 2008. In September 2016, we sent out the survey via e-mail to a sample of 17,756 registered and 82,143 unregistered members of the scheme. We oversampled unregistered members (i.e., members who did not sign up for access to the online environment of the pension fund) because of the lower expected response rate. Within these two groups, email recipients were randomly selected. After two weeks, a reminder was sent out and members had ten additional days to answer. In total, 2,032 members started the survey, of which 1,970 partially completed the survey (among which 1,143 unregistered). This results in a response rate of $1.4 \%$ among the unregistered, and $4.7 \%$ among the registered members. 1,349 respondents indicated their age and gender information, the final $\mathrm{N}$ is 1,156 (including all information on age, gender, income and children).

Respondents are fairly representative for the overall member population of the scheme: mean age is 41.8 years, with $53 \%$ of the sample being male ( $54 \%$ in total population), and 
annual gross median income is $£ 15,000-£ 20,000$ (19\% of survey respondents, $27 \%$ of scheme members). Furthermore, $45 \%$ of respondents are married, $48 \%$ have no children, $16 \%$ one child and $36 \%$ two or more children. $74 \%$ of respondents work full-time. Regarding housing, $55 \%$ is homeowner with or without mortgage, $36 \%$ private renter and $10 \%$ social housing renter. We unfortunately do not have data on education for this sample. Correlations are in Appendix $G$.

\section{Data Analysis}

We again use PLS to estimate the RBM. We first estimate the influence of demographics on information search intention. The way that variables are coded remains the same, and high income is again coded as 1 if it is above the median, in this case above $£ 25,001$ a year. The result is shown in Figure 2.3. Participants with a high income and participants who are married show a significant higher intention to search for information, the other variables are not significant. However, this model has again a very low adjusted $\mathrm{R}^{2}$ of only 0.014 , confirming our earlier finding that using demographic characteristics alone is insufficient to explain variation in information search intention. We therefore now estimate the full RBM.

\section{Measurement Model}

We perform the same tests of the measurement model as we did with the Dutch dataset. First, all Cronbach's $\alpha$ values are close to or above 0.8 (see Appendix B). Composite reliability values are between 0.8 and 0.9. Second, we look at validity and find satisfying AVE values

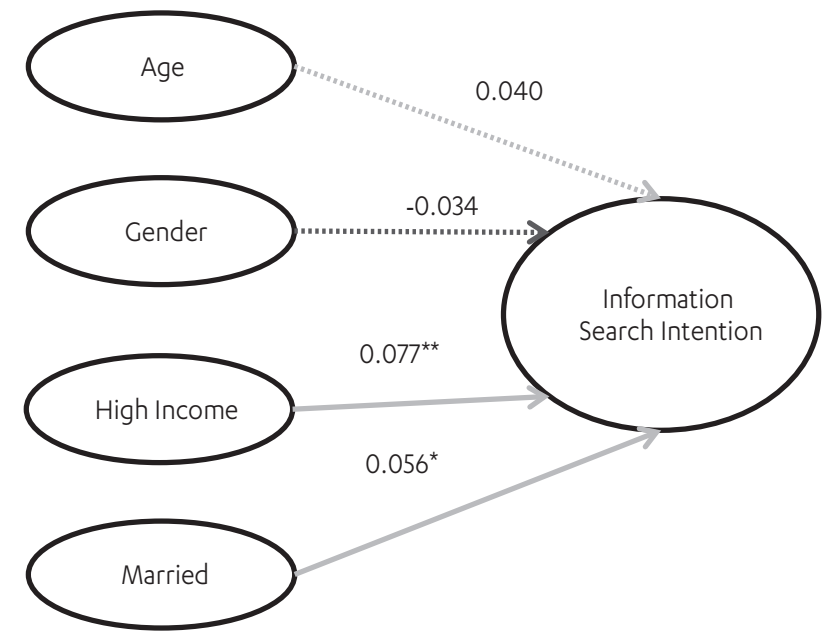

Note: This figure displays the path coefficients for demographics on information search intention. * **, and ${ }^{* * *}$ denote statistical significance at the $10 \%, 5 \%$, and $1 \%$ level (estimated with PLS). Dotted lines show insignificant relationships, solid lines significant relationships.

Figure 2.3: Demographics on intention (UK) 
(>0.5) for convergent validity. To check discriminant validity, we look the Fornell-Larcker criterion value (calculated with consistent PLS) which is also highest for the corresponding latent variables (Fornell and Larcker 1981). Our measures and models therefore satisfy the requirements and we can continue discussing our findings.

\section{Structural Model}

We again estimate model 1 (in which we only look at the influence of beliefs on information search intention) and model 2 (in which we also include demographic characteristics, emotions, financial preferences and literacy). The results are shown in Table 2.4.

In contrast to the results from the Dutch dataset, we now find support for $\mathrm{H}$ : participants with higher levels of self-efficacy also show higher information search intentions. We elaborate on the differences in our findings between the two countries in the general discussion. $\mathrm{H} 2$ is also supported since benefits have a significant and positive impact on intention, and show the highest coefficients among the beliefs. However, we cannot support $\mathrm{H} 3$ since barriers do not have a significant influence - neither in model 1, nor when we add more relationships in model 2. Severity has no significant influence, so we cannot support $\mathrm{H} 4$. Susceptibility does not have a significant influence in model 1 , but gets significant in model 2 - though with a negative sign which is why we cannot support H5. Since we added paths between income and susceptibility, we test for mediation between these variables. We find a significant positive path between susceptibility and income, so the higher participants' income, the less they perceive themselves as vulnerable for

Table 2.4: PLS results United Kingdom $(N=1,156)$

\begin{tabular}{|c|c|c|c|c|c|c|}
\hline & \multicolumn{3}{|c|}{ Model 1} & \multicolumn{3}{|c|}{ Model 2} \\
\hline & $\begin{array}{c}\text { Path } \\
\text { Coefficient }\end{array}$ & SD & $t$-statistics & $\begin{array}{c}\text { Path } \\
\text { Coefficient }\end{array}$ & SD & $t$-statistics \\
\hline \multicolumn{7}{|c|}{$\begin{array}{l}\text { Beliefs on Information Search } \\
\text { Intention (ISI) }\end{array}$} \\
\hline Barriers $\rightarrow$ ISI & 0.09 & 0.08 & 1.05 & 0.00 & 0.04 & 0.02 \\
\hline Benefits $\rightarrow$ ISI & 0.31 & 0.03 & $10.25^{* * *}$ & 0.23 & 0.04 & $6.54^{* * *}$ \\
\hline Self-Efficacy $\rightarrow$ ISI & 0.07 & 0.04 & $2.13^{* *}$ & 0.11 & 0.04 & $3.19^{* * * *}$ \\
\hline Severity $\rightarrow|S|$ & 0.05 & 0.03 & 1.37 & 0.05 & 0.03 & 1.47 \\
\hline Susceptibility $\rightarrow$ ISI & -0.06 & 0.05 & 1.27 & -0.07 & 0.03 & $2.11^{* *}$ \\
\hline \multicolumn{7}{|l|}{ Psychographic on ISI } \\
\hline Propensity to Plan $\rightarrow$ ISI & & & & 0.11 & 0.03 & $3.40^{* *+}$ \\
\hline Retirement Anxiety $\rightarrow$ ISI & & & & 0.06 & 0.04 & 1.55 \\
\hline Trust Own Provider $\rightarrow$ ISI & & & & 0.06 & 0.03 & $2.14^{* *}$ \\
\hline
\end{tabular}


Table 2.4: (continued)

\begin{tabular}{|c|c|c|c|c|c|c|}
\hline & \multicolumn{3}{|c|}{ Model 1} & \multicolumn{3}{|c|}{ Model 2} \\
\hline & $\begin{array}{c}\text { Path } \\
\text { Coefficient }\end{array}$ & SD & $t$-statistics & $\begin{array}{c}\text { Path } \\
\text { Coefficient }\end{array}$ & SD & $t$-statistics \\
\hline \multicolumn{7}{|l|}{ Demographic on Psychographic } \\
\hline Gender $\rightarrow$ Financial Literacy & & & & -0.16 & 0.03 & $6.00^{* * *}$ \\
\hline Gender $\rightarrow$ Financial Risk-Taking & & & & -0.19 & 0.03 & $6.53^{* * *}$ \\
\hline Gender $\rightarrow$ Trust Own Provider & & & & 0.02 & 0.03 & 0.56 \\
\hline Gender $\rightarrow$ Propensity to Plan & & & & 0.05 & 0.03 & $1.83^{*}$ \\
\hline \multicolumn{7}{|l|}{ Demographic on Beliefs } \\
\hline Age $\rightarrow$ Barriers & & & & -0.04 & 0.03 & 1.14 \\
\hline Age $\rightarrow$ Self-Efficacy & & & & -0.02 & 0.04 & 0.51 \\
\hline Gender $\rightarrow$ Barriers & & & & 0.02 & 0.03 & 0.46 \\
\hline Gender $\rightarrow$ Self-Efficacy & & & & -0.04 & 0.03 & 1.15 \\
\hline Income $\rightarrow$ Barriers & & & & -0.04 & 0.03 & 1.28 \\
\hline Income $\rightarrow$ Severity & & & & 0.11 & 0.03 & $3.92^{*+* *}$ \\
\hline Income $\rightarrow$ Susceptibility & & & & -0.07 & 0.03 & $2.52^{* * *}$ \\
\hline \multicolumn{7}{|l|}{ Psychographic on Beliefs } \\
\hline Financial Literacy $\rightarrow$ Barriers & & & & -0.25 & 0.03 & $8.16^{* * *}$ \\
\hline Financial Literacy $\rightarrow$ Self-Efficacy & & & & -0.17 & 0.03 & $5.56^{* * *}$ \\
\hline Financial Risk-Taking $\rightarrow$ Self-Efficacy & & & & -0.03 & 0.03 & 1.04 \\
\hline Trust Own Provider $\rightarrow$ Benefits & & & & 0.28 & 0.03 & $9.58^{* * *}$ \\
\hline Propensity to Plan $\rightarrow$ Benefits & & & & 0.35 & 0.03 & $12.02^{+* *}$ \\
\hline Retirement Anxiety $\rightarrow$ Severity & & & & 0.38 & 0.03 & $13.25^{* * *}$ \\
\hline Retirement Anxiety $\rightarrow$ Susceptibility & & & & 0.30 & 0.03 & $9.73^{* * *}$ \\
\hline Adjusted R² for ISI & 0.12 & & & 0.14 & & \\
\hline Confidence Intervals (Lower, Upper) & $(0.10,0.17)$ & & & $(0.09,0.18)$ & & \\
\hline
\end{tabular}

Note: This table presents the results of a partial least squares estimation for the British sample $(N=1,156)$. Variables are defined in section 3 , study 1 ; ISI = information search intention; SD= standard deviation. * ${ }^{* *}$, and ${ }^{* * *}$ denote statistical significance at the $10 \%, 5 \%$, and $1 \%$ level.

a pension gap. The path between susceptibility and information search intention becomes insignificant when income is added to the equation, indicating full mediation.

With regards to the additional factors, we can confirm that trust also plays a positive and significant role. However, retirement anxiety does not have a significant influence but propensity to plan does. The adjusted $R^{2}$ is 0.14 , which is a substantial improvement from the low adjusted $\mathrm{R}^{2}$ of using only demographic characteristics to predict information search intention. 


\section{Cross validation: linking intentions with behavior}

For this sample, we also check whether intentions translate into behavior. By linking the survey data with administrative data of the pension provider, we get to know whether survey respondents are registered with the pension provider. This means that they went to the pension provider's website and registered online with their e-mail address, so that they can always check their current pension savings balance and receive communication directly. Within our sample, 635 participants are not registered, while 521 participants are registered. Comparing their mean scores for information search intention, we indeed see that the registered participants have a significantly higher mean score $\left(M_{\text {registered }}=4.45\right.$, $S D=1.60)$ than the unregistered ones $\left(M_{\text {unregistered }}=3.87, S D=1.68 ; t=-5.94, p=0.00\right)$.

\subsection{GENERAL DISCUSSION}

We use the RBM to investigate which factors determine whether individuals take the first step and search for information about retirement. Focusing on this first step in the funnel provides an important contribution to the literature since all other decisions (e.g. about savings, asset allocation, or retirement age) can only be taken after acquiring the necessary information on where a person stands with respect to retirement planning. With the RBM, we developed a new and unifying framework, theoretically grounded in the theory of reasoned action and its extended version theory of planned behavior (Ajzen 1991), and enriched with factors identified in the economics, finance, and (service) marketing literature on retirement planning. We report on our key findings from two countries with different institutional contexts, the Netherlands and the United Kingdom (UK), in the following.

\section{Beliefs influence retirement information search}

For both the Netherlands and the UK, including the core beliefs increases the adjusted $\mathrm{R}^{2}$ for information search intention as compared to using only socio-demographic factors. Benefits are a strong driver of information search, both in the Netherlands and in the UK, and are therefore a key construct in our RBM. People who intend to search for information see the advantages of having information about their own retirement situation. Participants know much better where they stand, and whether or which follow-up steps they should pursue. Self-efficacy, so the belief that one knows how to find information and what to do with it, is also a significant factor influencing information search intention in both the UK and the Netherlands. However, this belief differs in sign between the countries: in the Netherlands, self-efficacy has a negative effect, while in the UK, self-efficacy has a positive effect. Dutch participants also have a lower overall mean self-efficacy (see Table 2.1) than British participants. Considering the regulatory background, Dutch participants are already used to being part of a mandatory pension system and therefore know that it is a complex system in which it can be complicated to search for and understand information. British participants may overestimate their skills to acquire the necessary information. In 
the Netherlands, benefits and severity are positive significant drivers, while barriers and selfefficacy are negative significant drivers of information search. In the UK, benefits and selfefficacy are positive significant drivers, while susceptibility is a negative significant driver.

\section{Trust as positive driver of information search}

The finding that trust plays an important role in stimulating people to acquire pension information is probably not surprising for service marketing researchers. After all, trust is one of the most widely studied variables in service research, thanks to the seminal work by Morgan and Hunt (1994). However, trust is not widely studied in the retirement planning literature in economics and finance. This underlines the value of service research and shows the value of interdisciplinary research, where a societally relevant question is studied from different perspectives, using different theoretical lenses. In both the UK and Dutch sample, trust is a positive significant driver of information search intention and is positively correlated with already being informed (see Appendix E and F).

\section{Emotions play a significant role}

Retirement anxiety, the fear of being alone, poor or unhealthy during retirement, plays a complex, yet important role. The overall mean score is higher in the UK, which makes sense considering the regulatory environment: expected retirement benefits are lower than they are in the Netherlands, and automatic enrollment is a recent development that many individuals are not yet used to. However, while retirement anxiety is a positive and significant driver of information search in the Netherlands, it does not have a significant impact in the UK. When Dutch participants already have information about retirement, they feel significantly less retirement anxiety (see Appendix E), which is not the case in the UK (see Appendix F). Both of these findings reflect that Dutch participants are more experienced with the pension system, and underline that it is important to consider the regulatory context and resulting emotions when designing communication for pension plan participants.

\subsection{IMPLICATIONS FOR PENSION PROVIDERS AND PUBLIC POLICY MAKERS}

During our research, we involved the pension sector and public policy makers in the selection of relevant variables for the RBM. Once we finished our data collections, we presented our results to the same audience and elicited feedback.

First, the important role of beliefs and emotions, as well as psychographic factors in driving information search, was a key insight for pension providers: so far, most of them have mainly focused on demographic factors such as age or income to understand why participants look for information. Thus, the insights helped them to get a much better understanding of what drives and what prevents people from acquiring information about their pension situation. 
Second, pension providers and policy makers used the insight to critically evaluate their pension communication. For example, pension communication has traditionally often included statements such as "we know that pension is a difficult topic", or "we understand that it is not easy to make time for retirement planning when you are busy with planning the here and now". These statements emphasize the barriers that many people perceive and that prevent them from acquiring information. However, we find that benefits are a more prominent predictor of the search for financial information. Based on our findings, providers of pension communication should therefore rather focus on emphasizing the benefits than the barriers to information search.

Third, our results stress the importance of collecting data on pension plan participants, linking it to administrative sources, analyzing it and applying the results afterwards. These steps require a certain amount of resources from pension providers and public policy makers, but understanding the worries and beliefs of participants is the first step to improving pension communication and services. As our additional analyses have shown, the information search intentions we measured in the survey translate into real behavior for both the Dutch and UK participants. This underlines the values of survey research and validating survey results with additional data.

\subsection{LIMITATIONS AND FUTURE RESEARCH}

This research has limitations that provide opportunities for further research. First, we do not have causal evidence but cross-sectional survey data. It would be very interesting to study individuals' beliefs over time to see how intentions translate into behavior. However, for both the Dutch and the UK sample, we linked they survey data with experimental and administrative data respectively as cross-validation. We saw that participants with higher information search intentions also click more on informational movie links (Netherlands) and are more likely to register themselves on the pension provider's website (UK).

Second, even if we designed the Retirement Belief Model (RBM) in a most thorough way, we cannot rule out that we excluded important factors that could also affect information search. We derived the factors for the RBM in a thorough, two-stage process based on an extensive literature review and the involvement of representatives from the pension sector (communication managers, customer contact agents, and key account managers from pension funds and insurance companies), public policy makers from ministries, and academic experts from the fields of economics, finance, and marketing. Future research could investigate additional components.

Third, while we focused on individual respondents, it would be interesting to study beliefs and their influence on information search not only from an individual perspective but also from collective consumer entities perspectives, such as households, social networks or friends (Anderson et al. 2013). The interaction between spouses and colleagues with regard to planning for retirement is certainly an exciting avenue for further research. 



\section{chapter $\mathbf{3}$}

\section{Framing the Future: Using Investment and Assurance Frames to Encourage Retirement Information Search}

This chapter is co-authored with: Elisabeth Brüggen (Maastricht University), Thomas Post (Maastricht University) and Chantal Hoet (Aegon) 



\subsection{INTRODUCTION}

Around half of all U.S. households are at risk of receiving insufficient retirement benefits (Munnell et al. 2015). Very often, such pension gaps remain undetected until retirement (HSBC 2015), as individuals do not gather information about their expected retirement benefits. To avoid negative surprises for individuals, an important task for pension plan providers and policy makers is to stimulate individuals to acquire this information early enough to be able to take action. Doing so is especially important in times of pension reforms (e.g., Brown 2006) and policy attempts to fight poverty among the elderly (Haveman et al. 2015).

In this chapter, we study a pension communication intervention in a situation where information search is of particular relevance: a pension reform that reduced benefits. We develop and test two new frames for pension communication. Based on a field experiment we find that an effective method to motivate pension plan participants to gather information is an assurance frame. This frame stresses that participants can prevent negative consequences through the sense of security that they obtain when learning about expected pension benefits.

Research on participants' information acquisition regarding retirement finances is scarce. A large body of literature analyzes interventions like default options and financial incentives that aim at increasing enrollment and contribution rates in pension plans, ranging from using peer effects (Beshears et al. 2015), automatic enrollment (Beshears et al. 2010), automatically escalating contributions (Thaler and Benartzi 2004), as well as interventions to delay retirement age such as financial incentives (Manoli and Weber 2016). However, information search is an important first step for participants. For example, without information about how a pension reform will affect their expected retirement finances, it is difficult for a participant to make sound choices in the first place. Especially when default options cannot be used or a participant population is too heterogeneous to find an appropriate default for most, stimulating information acquisition and active decision making are of key importance. Indeed, recent evidence shows, that providing information in a more salient way (by sending pension information letters on expected pensions vs. not) or sending reminders on saved amounts has economic impact: households respond to receiving information by increasing savings (Dolls et al. 2016; Karlan et al. 2016).

Framing, that is adapting the wording but not the content of communication, can be a powerful nudge to shape the intentions and behaviors of individuals in a desired direction. The framing of messages has been shown, for example, to influence the take-up rates of financial incentives for retirement saving (cash back vs. matching framing) (Saez 2009), saving amounts (framing savings on a high vs. low construal level) (Ülkümen and Cheema 2011), and retirement timing (willingness-to-pay vs. willingness-to-accept frames) (Merkle, Schreiber, and Weber 2017). 
Framing effects are especially interesting for policymakers since minor changes in message wording can significantly alter a consumer's perception and response, while avoiding the cost of expensive awareness campaigns and programs (Benartzi et al. 2017; Saez 2009). Wordings can be altered at low costs, in contrast to programs aimed at increasing financial knowledge which cost billions of dollars (Fernandes et al. 2014). An experiment presented by Benartzi et al. (2017) demonstrates the power of a simple email nudge. A group of military service members who received different emails nudging them to contribute to their DC pension plan had enrollment rates of $1.6 \%$ to $2.1 \%$, as compared enrollment rates of $1.1 \%$ for a group of members who did not receive an email. This effect may seem small at first glance, but the program only costed $\$ 5,000$ while generating approximately $\$ 8$ million additional savings in total. This translates into additional savings of $\$ 1,600$ per dollar spent by the government - a much more cost-effective method than using tax incentives, as the authors show.

The frames we focus on are goal frames. Goal frames are mainly used in persuasive communication, and can be divided into positive frames, which underline the goal of obtaining positive consequences (i.e., gain), and negative frames, which focus on avoiding negative consequences (i.e., loss) (Levin et al. 1998). Gain and loss frames build on the concept of prospect theory and loss aversion (Tversky and Kahneman 1981), and have been tested in different domains.

For example, encouraging a person to stay out of the sun can be achieved by emphasizing gains (e.g. "Protect yourself from the sun and you will help yourself stay healthy") or losses (e.g. "Expose yourself to the sun and you will risk becoming sick"; Detweiler et al. 1999). In the field of health promotion, gain frames have been found to be more effective than loss frames in situations where outcomes are rather certain, for example with smoking cessation (Toll et al. 2007). On the contrary, loss frames are more effective if it is uncertain that an action will lead to desired outcomes (e.g. self-examination for skin cancer), and when individuals perceive their self-efficacy (perceived ability to perform a behavior) to be low (Block and Keller 1995).

Earlier research on gain and loss framing in a financial decision-making context is mixed and suggests that different types of actions may require different frames. Brown, Kapteyn and Mitchell (2016) find that in a hypothetical setting, gain-framed (vs. loss-framed) information leads to later claiming of Social Security benefits. Hastings, Mitchell and Chyn (2010) show that participants choose lower fee pension fund managers when fees are framed as influencing the gains from contributing to a pension versus the losses. In both of these two examples, outcomes are rather certain: Social Security benefits are precisely defined in the experimental setting of Brown et al. (2016), and pension fund manager fees are set in advance and nonnegotiable (Hastings et al. 2016). In line with the explanation of Block and Keller (1995), we might therefore expect a gain frame to be more effective. However, most pension decision scenario's that participants are facing incorporate uncertainty and low levels of self-efficacy. Loss frames may therefore be the better 
choice for policy makers and pension providers when communicating in a context that is characterized by uncertain outcomes. For example, when presented with the downside of investment risks, participants make relatively fewer errors in their retirement investment choices since cognitive efforts are increased in order to avert loss (Bateman, Stevens, and Lai 2015). Agnew et al. (2008) find that frames that emphasize the potential losses when deciding on an annuity or investment can steer participants in a desired direction. When presented with loss frames, participants indicate greater willingness to save for retirement (Montgomery et al. 2011).

In this chapter we generate empirical evidence on the effectiveness of gain and loss frames for motivating participants to acquire information on expected pension benefits. We present evidence from three experiments conducted in the laboratory and one field experiment. The first laboratory experiment demonstrated that loss framing is more effective than gain framing in increasing pension information search intentions. However, the loss-framed text is viewed more negatively (individuals feel uncomfortable reading the text) than the gain frame. This frame is, therefore, neither a desirable nor viable option, since pension providers and policy makers are reluctant to use communication that makes participants feel negatively.

Second, we therefore develop and test two new frames: assurance and investment. These frames tap into similar psychological mechanisms as typical goal frames (e.g. prevention of loss, and focus on gain), but avoid the use of the word "loss". We test these frames in a field experiment with 7,315 defined contribution pension plan participants and find that assurance framing (the loss framing alternative) is twice as effective in encouraging participants to click on a movie link with specific information on pension scheme changes. Overall, our results provide a new, simple, effective, and low cost intervention that stimulates information acquisition by pension plan participants.

\subsection{INSTITUTIONAL BACKGROUND}

Our experiments are performed in the Netherlands. The Dutch pension system is a particularly interesting and relevant setting for our experiments. First, the Dutch pension system is similar to the U.S. in that a major share of retirement income is generated by funded schemes. On average, $43 \%$ of retirement income is generated by funded occupational pension plans, in the U.S. this share is 36\% (OECD Pensions Outlook 2016). Second, the Dutch pension system is in need of reform, benefits have been cut in the past and are expected to decrease further (Bovenberg and Gradus 2015). While the main source of retirement income is now still public and occupational pensions, the share of private arrangements will need to increase. Thus, acquiring information about expected benefits is economically relevant for plan participants.

The Dutch pension system belongs to the largest worldwide, with total investments of pension funds representing 178.4\% of GDP in 2015 (OECD 2016). It is built on three pillars. 
The first pillar is the basic state pension (AOW). The AOW is a pay-as-you go system that is financed by taxes on wages and general tax revenues. It provides a flat basic income that is around $50 \%$ of the minimum wage (approximately $€ 1000$, i.e. $\$ 1,130$ gross per months for retirees living alone and otherwise $€ 700$, i.e. $\$ 790$ gross per months). Every resident of the Netherlands (regardless of being employed or not) accumulates AOW pension rights for each year of living in the Netherlands. The age at which the AOW benefits can be claimed is currently increasing gradually from 65 to 67 years until 2021. After that, the claiming age will be increased depending on a formula that takes into account increases in life expectancy. The second pillar consists of collective, mandatory, funded occupational pension schemes. More than $90 \%$ of employees are covered by such schemes (Knoef et al. 2016). Schemes are administered by pension funds or insurance companies and are legally and financially separated from employers. There are three types of pension funds: industry-wide pension funds (for a whole sector, such as civil service; approximately $80 \%$ of all funds), corporate pension funds (for a single corporation), or pension funds for independent professions (e.g., medical specialists). Most schemes are run as DB plans in which years of service and the career-average wage determine the benefit entitlements. Currently, many funds are moving away from DB plans to so-called collective DC schemes, in which employers provide a fixed contribution rate and are no longer liable for shortfalls in the fund. The third pillar consist of private savings and investments that are to a limited amount tax subsidized. Economically the third pillar is of rather low importance as it generates on average $5 \%$ of retirement income (Bovenberg and Gradus 2015).

Historically, participants have been promised pension benefits amounting on average $70 \%$ of their final salary (including the basic state pension; Bovenberg and Gradus 2015). Until the beginning of the 21st century, most pension plans indeed aimed to pay a pension income of $70 \%$ of final gross wage from the end of 65 onwards if an employee had worked fulltime for at least 40 years. From 2003 onwards, pension funds had lowered their ambition to $70 \%$ of average pay. After the 2007-2009 financial crisis many pension funds could no longer provide indexation of benefits (i.e., inflation adjustment) and several funds even had to cut into nominal pension payouts. Based on current estimations, between one third and half of all households face a gross replacement rate that is lower than $70 \%$ of current income (Knoef et al. 2016). While one might expect that these changes provide substantial incentives for participants to become more active and acquire information the evidence shows that this is not the case at all. Only around one third of participants opens and reads the annual mandatory pension statements mailings they receive by their pension providers, and only $11 \%$ take time to look at their pension situation from time to time (Wijzer in Geldzaken 2016).

Our field experiment took place in December 2014. Around this time an important reform to the second pillar of the pension system took place. As a result, from January 2015 onwards, built-up of pension benefits in the second pillar was reduced (see the example below). After the increase of retirement age to 67 , this was the one of the first steps that puts 
more responsibility on the participant herself since participants will need to arrange more in the third pillar to have sufficient retirement income. Activating participants to acquire pension related information is, therefore, seriously needed.

The pension provider with whom we performed the field experiment wanted to inform its participants about this reform by sending out a newsletter linking to an education video. This hand drawn whiteboard video explained in simple language what the reform could mean for pension plan participants. It gives the example of Ted, who is currently earning $€ 35,000$ per year, living in his own house with his wife and children and works for an employer who takes care of his pension plan. The video goes on to explain that because of the reform, Ted's pension benefits will decrease by $€ 1,500$ every year from the day he retires onwards. Added up over ten years of retirement, the video continues, this would mean $€ 15,000$ less than Ted expects at the moment. In addition, the pension benefits that his wife and children would receive if he died would decrease by $€ 1,100$ on an annual basis. The goal of their pension fund's email was to get participants to click on the video link to understand the pension plan changes as of January 2015, and to provide guidance for further action (e.g., consulting an advisor or the pension provider).

\subsection{GAIN AND LOSS FRAMING Procedure}

To test the effect of gain and loss framing on the willingness of individuals to acquire information important for retirement planning, we first developed gain and loss versions of an information appeal (Figure 3.1), adapted from Apanovitch, McCarthy, and Salovey (2003) and Rothman, Bartels, Wlaschin, and Salovey (2006). Participants were asked to read a text encouraging them to look up information about their pension. After reading the text, participants completed a battery of questions regarding emotions, attitudes, and behavioral intention to search for information.

Based on these frames, we first conducted a pre-test and then a main study, both with university students in the laboratory. Following Van 't Riet et al. (2010) and Gerend and Shepherd (2007), we conducted a separate pre-test of the manipulation. We first test whether the manipulation works (i.e., whether participants think that the text emphasizes the benefits of information search more than the costs) and then in a separate experiment how the text frames influence information search intention. Otherwise, the additional manipulation check questions could increase the impact of the frames, because participants think much more about the text than they would normally do without being asked these questions. Since we use student samples in this part, all studies were conducted in English.

\footnotetext{
${ }^{1}$ The original Dutch languagevideo is available on YouTube: https://www.youtube.com/watch?v=mrBL8gmjHac
} 


\section{Gain}

\section{You gain from informing yourself today.}

(Every month, your pension fund receives and manages your contributions for your pension

income during retirement.

Because of our aging population, changing pension system and economy,

this amount of money may not be sufficient for you

to keep a decent lifestyle during retirement.)

By informing yourself about your pension now, you can learn whether you have a savings gap.

If you decide to inform yourself, you will find out whether you have saved enough for retirement.

Discovering a potential savings gap gives you the opportunity to close it by starting to save more right now.

Take advantage of this opportunity. Take the first step.

Check your expected retirement income on mijnpensioenoverzicht.nl.

\section{Loss}

\section{You lose from not informing yourself today.}

(Every month, your pension fund receives and manages your contributions for your pension

income during retirement.

Because of our aging population, changing pension system and economy,

this amount of money may not be sufficient for you

to keep a decent lifestyle during retirement.)

By not informing yourself about your pension now, you will not learn whether you have a savings gap.

If you decide not to inform yourself, you will not find out whether you have saved enough for retirement.

Not discovering a potential savings gap means that you miss the opportunity to close it

by starting to save more right now.

Do not fail to take advantage of this opportunity. Take the first step.

Check your expected retirement income on mijnpensioenoverzicht.nl.

Note: This figure shows the text frames used in study 1 . The text between parentheses is the text that all groups received.

Figure 3.1: Gain and loss frames used in study 1 


\section{Pre-Test}

Sixty-one students (27 males, mean age=19.7) participated in the study in return for course credits. They were invited to complete the study in a computer cubicle at the university laboratory, asked to remain silent, and asked to turn to the experiment supervisor for any questions. Participants randomly received either the gain or loss frame. Following Cox and Cox (2001), participants had to evaluate the English text on eight semantic differential scales (believable/not believable, realistic/not realistic, factual/not factual, good/bad, useful/not useful, appropriate/not appropriate, helpful/not helpful, and educational/not educational). The answers were recorded on seven-point Likert scales, such that 1 indicated negative evaluation (e.g., not believable) and 7 positive evaluation (e.g., believable). Then, participants had to indicate the emphasis of the text that they had just read, also on seven-point Likert scales where 1 indicated that the text emphasized the costs of not informing yourself and 7 indicated the benefits of informing yourself. As compared to the loss framing condition $(M=2.23, S D=1.69)$, participants in the gain framing condition $(M=4.67, S D=1.73)$ rated the text as emphasizing the benefits rather than the costs of informing yourself about your pension income situation ( $t=5.58, p<0.001)$. The overall evaluation of the text was better in the gainframed condition $(M=4.61, S D=0.988)$ than in the loss-framed condition $(M=4.14, S D=0.914$; $t=1.94, p<0.10)$. As such, the gain and loss manipulations worked. The loss frame, however, was perceived more negatively.

\section{Main Study: Laboratory Experiment}

The main study was conducted with 85 university students (34 males, mean age=22.2). They completed the survey on a computer at the same controlled university laboratory used for the pre-test. All participants received a text on the low interest rate environment and the resulting importance of looking up information about their retirement income situation (for an example of the loss frame see Figure 2). Participants were randomly assigned to two different text headings conditions: gain ( $N=41$, e.g., "You gain from informing yourself today"), and loss ( $N=44$, e.g., "You lose from not informing yourself today"). The text included two options to click on links, to a movie and to a website link. After reading the text, participants we asked to agree to a three-item behavioral intention measure: "How big is the chance that you will click on the link in order to watch the movie?", "How big is the chance that you will click on the link in order to visit the pension fund website?", and "I'm planning to look up information about my pension in the upcoming months." Participants also completed text evaluation measures on informativeness, ease of comprehension, credibility, and negative affect (Block and Keller 1995). The answers were recorded on seven-point Likert scales, where 1 indicated lower agreement ("totally not agree") and lower evaluations, and 7 indicated higher agreement ("totally agree") and more positive evaluations. 


\section{You lose from not informing yourself today}

You have probably heard that the interest rate is low at the moment. Maybe you also notice it on your own savings account. But, did you know that this low interest rate also affects your pension?

The contribution for your pension is being invested. This way, you build up pension capital. With this capital, you buy a life-long pension as soon as you retire. The level of your pension is (amongst other things) dependent on the level of the interest rate. We explain how this works, in a simple way, in the movie below.

By not informing yourself about your pension now, you will not learn whether you have a savings gap.

If you decide not to inform yourself, you will not find out whether you have saved enough for retirement.

Not discovering a potential savings gap means that you miss the opportunity to close it by starting to save more right now.

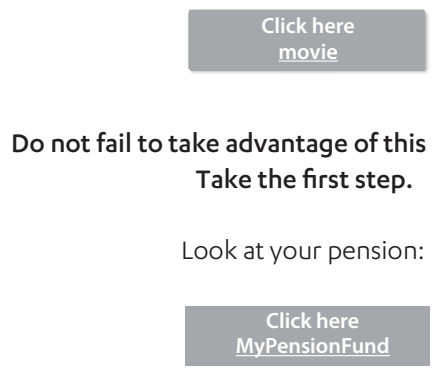

You can find the following at MyPensionFund:

- Up-to-date insight into the pension you already built up

- Insight into your pension income at your retirement date

- $\quad$ The option to add other pension schemes

Do you not have access to MyPensionFund yet? Go to www.mypensionfund .com/access and follow the steps below:

Click on "ask for access" and fill in your data

1. Choose your own user name and password

2. You will receive a temporary activation code via your e-mail or regular mail

3. Go to www.mypensionfund.com/activate and fill in yo ur log-in data and activation code

4. Your account is then activated!

If not missing the opportunity to do something about your pension is important to you... You can also look at your pension on MyPensionoverview (MPO) and on www.mpo.com

\section{Do you still hav e questions?}

Then contact us. We can also connect you to the advisor of your employer. You can reach us via telephone number 123 on working days between $8 a m$ and 9pm, and on Saturday between 9am and 1pm. Do you prefer to e-mail? Then mail your question via mypensionfund.com/email.

Figure 3.2: Loss frame used in study 1 


\section{Results}

Participants who received the loss framing text reported higher intentions to visit the website $(M=4.41, S D=1.98)$ than participants in the gain framing group ( $M=3.66, S D=1.94$; $t=1.76, p=0.08$ ). Even if the results of this first two-tailed t-test are only significant on the $10 \%$ level, evaluations of this frame were significantly the lowest: it was perceived as significantly less informative $(M=3.19, S D=1.29)$ than the gain frame $(M=3.88, S D=1.43 ; t=2.32, p=0.02)$. The gain frame was overall more positively evaluated $(M=4.54, S D=0.88)$ than the loss frame $(M=4.14, \mathrm{SD}=1.11 ; t=1.91, p=0.07)$.

The results of this experiment are thus in line with evidence that framing that emphasizes prevention of losses tends to trigger desirable behavior (e.g. Keller and Lehmann 2008; Block and Keller 1995; Rothman et al. 2006). However, both in the manipulation check and in the experiment itself, evaluations of the text are lower with loss framing. Participants perceived the loss-framed text as less credible and felt less comfortable while reading it. Thus, loss frames increase negative associations in a pension context. In the long term, this could imply that participants would refrain from taking action after all. In any case, anecdotal evidence from pension funds shows that, because of the 2007 - 2009 financial crisis, pension providers are reluctant to use fear or lossframed appeals in their communication to participants as the subject of pensions already received substantial negative publicity. The level of trust in financial institutions was severely damaged, and it is a challenge for pension funds, banks, and insurance companies to restore this trust (e.g. Bovenberg et al. 2015; Hansen 2012). Since Study 1 also showed that loss frames (which include the word "loss") lead to negative perceptions, we develop two new frames that tap into similar mechanisms, but that avoid overly negative wording: investment and assurance frames.

\subsection{INVESTMENT AND ASSURANCE FRAMES}

\section{Procedure}

Investment framing is an adapted version of gain framing since it stresses that individuals will gain when investing in their future by informing themselves about their pension. The frame includes the investment wording and is described by Brown et al. (2008) as the most predominantly used by financial service providers. Assurance framing, on the other hand, is an alternative for loss framing, as it encourages participants to insure themselves against losses (i.e. avoiding the uncertainty of not knowing whether they are saving enough for retirement) and to ensure their future. Feelings such as anxiety can play an important role in decisions made by individuals faced with uncertain decision outcome options (Loewenstein et al. 2001). Assurance framing can therefore have greater impact because a person may naturally perceive her behavioral reaction as prevention behavior (Zhou and Pham 2004). In line with prospect theory (Tversky and Kahneman 1981), loss frames result 
in stronger reactions since losses loom larger than gains. While this may be positive as it results in a short-term shock effect and action, unintended consequences include a bad aftertaste and strong negative feelings surrounding pensions in a context where trust is already low (Hansen 2012). There is neurobiological evidence for loss frames resulting in more risk-seeking behavior (De Martino et al. 2006), a result that is not necessarily desirable. Here, assurance wording which is focused on certainty can be the better alternative. Since the assurance frame is the loss alternative, we hypothesize that assurance frames result in higher information search intentions and behavior than investment frames.

We first investigate whether negative emotions are triggered by the newly developed frames in a laboratory setting. We then test real behavior in a field experiment to see which frame is most effective at encouraging information search.

\section{Pre-Test}

Sixty-nine students (20 males, 49 females) participated in the laboratory experiment. Participants were randomly assigned to one of three conditions: investment $(N=23)$, assurance $(\mathrm{N}=22)$, and a control group $(\mathrm{N}=24)$. Since not all participants were native Dutch speakers, the experiment was conducted in English. Subjects were first presented with a hypothetical letter, informing them about changes to the pension system. All three letters were identical, except their headings were framed differently: neutral terms for the control group, and investment and assurance terms for the respective headings (see Figure 3.3).

We were interested in the evaluation of the text and in the emotions that participants felt when reading the text. We again used the scales developed by Block and Keller (1995) for informativeness, ease of comprehension, credibility, and negative affect. If our frames were developed well, we would expect no significant differences between the groups, and evaluations of the investment and assurance frames should then be positive. We found that this is the case: all three texts scored low on negative affect (where participants indicated whether they felt fearful, nervous, scared, nauseated, or uncomfortable), with the control group scoring the highest among the three (Mean control $=3.61$, Mean $_{\text {investment }}=3.03$, Mean $_{\text {assurance }}=3.15 ; F=1.15, p=0.32$ ). There was also no significant difference in evaluation (Mean $n_{\text {control }}=3.69$, Mean $_{\text {investment }}=3.80$, Mean $_{\text {assurance }}=3.95 ; F=.22, p=0.80$ ). Ease of comprehension was similar between the groups (Mean $n_{\text {control }}=5.09$, Mean $_{\text {investment }}=5.22$, Mean $_{\text {assurance }}=5.01 ; F=.18, p=0.83$ ), with the same applying to credibility (Mean $n_{\text {control }}=4.88$, Mean $_{\text {investment }}=4.84$, Mean $_{\text {assurance }}=4.67 ; F=.33, p=0.72$ ).

The pre-test confirms the appropriateness of the frames since participants did not experience very negative emotions while reading the text.

\section{Main Study: Field Experiment}

We conducted a field experiment with the total participant population of a DC pension plan of a large Dutch insurance and occupational pension provider. We use a between-subjects design with two framing conditions, and the dependent variable is clicking behavior. All 


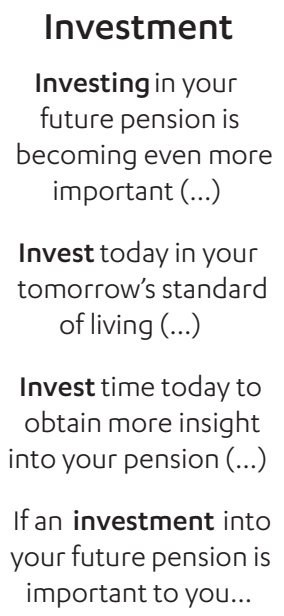

\section{Assurance}

Ensuring your future pension is becoming even more important (...)

Ensure your tomorrow's standard of living today (...)

Make sure today to obtain more insight into your pension (...)

If certainty about your future pension is important to you...

\section{Control}

Your future

pension is

becoming even

more important

What's going on?

(...)

What is my current situation? (...)

What can I expect?

(...)

Note: This figure shows the headings of the text that participants received in laboratory study 2. The paragraphs between the headings included the identical text.

Figure 3.3: Investment, assurance and control frames used in study 2

10,525 pension plan participants (active and non-active) of the pension provider received a newsletter via e-mail, which was either the assurance or the investment framed version of the letter. Just as in the laboratory setting, only the headings differed between the groups. The email included three paragraphs of text, which were exactly the same across the two frames. Assurance framing emphasized that "ensuring your future pension" is even more important after the changes, while the investment framing stressed that "investing in your future pension" is important. Since this study was conducted in Dutch, the English translation of the frames can be found in Figure 3.4. We include screenshots of both Dutch emails in Appendix $\mathrm{H}$. The frames were translated by the authors using a double-back translation method as recommended by Brislin (1980).

Within the newsletter, all participants could click on the two different links: one to a movie, and one to a website. Participants were told that the short movie explains the changes to the pension system (see Section 2) in simple language and drawings, and indicates when and how a participant needs to take action. The website would require participants to log in, after which they would be able to view general information on the amount of retirement savings that they have accumulated so far, and an estimation of their future expected retirement income under the assumption that they will continue to put the same amount of money into their retirement account. Those estimates did not, however, account for the changes to the pension system. 


\section{Investment}

Investing in your future is getting even more important

Invest today in your living standard of tomorrow

(...)

Invest time today to get insight in your pension

(...)

If an investment in your future pension is important to you

(...)

\section{Assurance}

Ensuring your pension is getting even more important

Make sure today that you understand the changes to the law (..)

Make sure you have insight in your pension

(...)

If certainty abut your future pension is important to you

(...)

Note: This figure shows the translated headings of the text that participants received in main study 2. The paragraphs between the headings included the identical text.

Figure 3.4: Main study 2 investment and assurance frames

Our final dataset includes active participants who can be matched with administrative data, including data on annual pensionable salary $(N=7,315)$. The pension provider covers participants from several employers. Within each company, the pension provider decided to send out only one of the two frames, to avoid co-workers from being confused by receiving different newsletters. Thus, the frames were randomly sent out at employer level, but not within employers. Consequently, we found significant differences in terms of age, gender, marital status, and pensionable salary between the assurance and investment groups (participants in the assurance group being somewhat older, more likely to be male and married and to earn more, see Table 3.1). We control for these differences in our analyses.

\section{Results}

We first analyzed the overall percentage of participants who clicked on one of the links. Fewer participants clicked on the website link than on the movie link. Figure 3.5 displays the percentages of participants clicking.

Assurance framing is twice as effective as investment framing in getting participants to click on the movie link (6.7\% vs. $2.7 \%, t=-7.26, p<0.001$ ). The benchmark clicking rates for links within the newsletter e-mails from the pension provider are around 1.5\%. However, the difference between assurance and investment framing is not significant for the website links ( $2.7 \%$ vs. $2.3 \%, t=-0.51, p>0.5)$. In the assurance framing condition, $1.4 \%$ of participants (and $0.4 \%$ with investment frame) clicked on both links.

Because of the within-employer non-randomization of the newsletters, we perform logit regressions controlling for age, gender, annual pensionable salary, and marital status. We 
Table 3.1: Study 2 descriptive statistics

\begin{tabular}{lccc}
\hline & $\begin{array}{l}\text { Assurance } \\
\text { framing }\end{array}$ & $\begin{array}{l}\text { Investment } \\
\text { framing }\end{array}$ & $\begin{array}{c}\text { t-statistic on } \\
\text { mean difference }\end{array}$ \\
\hline N (Total=7,315) & 3,357 & 3,958 & 2.55 \\
Percentage of males & 67.70 & 64.90 & $(0.01)$ \\
Mean age & $(0.01)$ & 39.71 & 10.96 \\
Age range & 42.38 & $(0.16)$ & 10.36 \\
Mean annual pensionable salary & $(0.18)$ & $20-65$ & \\
Percentage of married participants & $20-66$ & $45,676 €$ & $(359.95)$ \\
& $52,078 €$ & 46.6 & $(0.01)$ \\
\hline
\end{tabular}

Note: This table presents the distribution of gender, age, pensionable salary, marital status, and the results of a two-tailed independent samples t-test. Standard errors are given in parentheses.

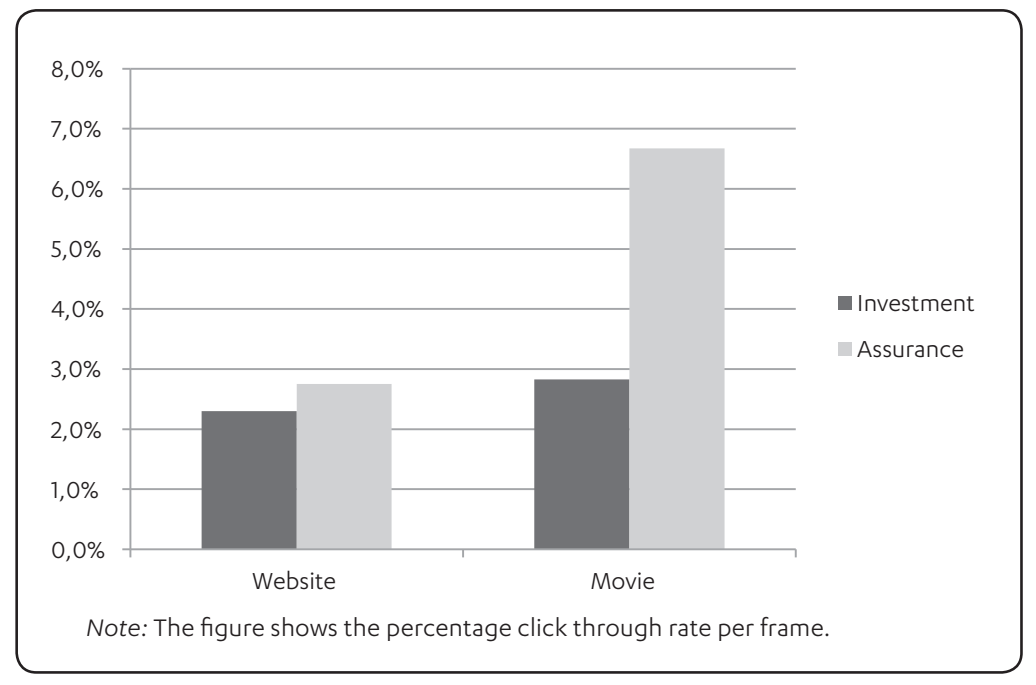

Figure 3.5: Study 2 clicking ratios within frames

cluster standard errors at the employer level. ${ }^{2}$ The dependent variables are binary variables with 0 meaning that participants did not click at all, or 1 if participants clicked.

\footnotetext{
${ }^{2}$ We do not include employer fixed effects. As there are too many separate employers $(1,153)$ in our data convergence or a proper solution for the logit model is not given. As an alternative specification, we conduct the analysis at the employer level. We collapse the variables of interest for each employer at their means and run OLS as well as Tobit regressions on the data. The results (available on request) are consistent with our main specification: framing has a significant impact (1\% level) on clicking on the movie link while not on the website link.
} 
In model 1 and 2 (see Table 3.2), we show the results for participants who clicked on at least one or both of the links. Model 3 and 4 zoom in on the movie link and model 5 and 6 show the results for clicking on the website link. When controlling for age, gender, annual pensionable salary, and marital status, assurance framing still has a positive impact on clicking overall and on the movie link in particular. Regression results reported in Table 3.2 are line with the univariate analysis. Having received the assurance frame, participants are $3.3 \%$ more likely to click on the movie link, which is close to the univariate percentage difference clicking between the two groups (i.e., 6.7\% vs. 2.7\%).

Interestingly, framing has an impact on only one of the information layers, namely the movie link and not the website link. There are two possible explanations for this difference. First, the movie link could be the natural first choice for participants to click on, since it was the first link displayed in the e-mail. Second, while the movie link was introduced as "watch the movie, including the changes that await you", the website only shows what participants currently save, that is, prior to the changes to their pension system, making it less attractive to click. Framing matters in situations where participants are required to take immediate action and engage. This was the case in the field test where it was important

Table 3.2: The effect of assurance and investment framing on information acquisition

\begin{tabular}{|c|c|c|c|c|c|c|}
\hline \multirow[t]{2}{*}{$N=7315$} & \multicolumn{2}{|c|}{ Total } & \multicolumn{2}{|c|}{ Movie } & \multicolumn{2}{|c|}{ Website } \\
\hline & (1) & (2) & (3) & (4) & (5) & (6) \\
\hline Assurance framing & $\begin{array}{l}0.038^{* * *} \\
(0.006)\end{array}$ & $\begin{array}{l}0.030^{* * *} \\
(0.006)\end{array}$ & $\begin{array}{l}0.039^{* * *} \\
(0.005)\end{array}$ & $\begin{array}{l}0.033^{* * *} \\
(0.005)\end{array}$ & $\begin{array}{c}0.005 \\
(0.004)\end{array}$ & $\begin{array}{c}0.002 \\
(0.004)\end{array}$ \\
\hline Age & & $\begin{array}{l}0.002^{* * *} \\
(0.000)\end{array}$ & & $\begin{array}{l}0.002^{* * *} \\
(0.001)\end{array}$ & & $\begin{array}{l}0.001^{*+*} \\
(0.000)\end{array}$ \\
\hline Male gender & & $\begin{array}{l}0.026^{* * *} \\
(0.007)\end{array}$ & & $\begin{array}{l}0.011^{* * *} \\
(0.006)\end{array}$ & & $\begin{array}{c}0.019^{* *+} \\
(0.005)\end{array}$ \\
\hline $\begin{array}{l}\text { Annual pensionable salary } \\
\text { (in } 10,000 € \text { ) }\end{array}$ & & $\begin{array}{c}0.001 \\
(0.001)\end{array}$ & & $\begin{array}{l}0.001^{* *} \\
(0.001)\end{array}$ & & $\begin{array}{l}-0.000 \\
(0.001)\end{array}$ \\
\hline Married & & $\begin{array}{l}-0.010 \\
(0.006)\end{array}$ & & $\begin{array}{l}-0.006 \\
(0.005)\end{array}$ & & $\begin{array}{l}-0.003 \\
(0.004)\end{array}$ \\
\hline
\end{tabular}

Note: Reported are marginal effects at means of independent continuous and discrete dummy variables. Column 1 of this table presents the marginal effects from logistic regressions of a clicking dummy $(0=$ not clicked, $1=$ clicked on both website and movie link) on framing condition ( 0 =investment, $1=$ assurance framing), while column 2 shows the regression results of this dummy on framing condition and age, male gender, annual pensionable salary and being married. Column 3 of this table presents the results of the same analysis of a clicking dummy ( $0=$ not clicked, $1=$ clicked on movie link) on framing condition, while column 4 shows the regression results of this dummy on framing condition and the additional socio-demographics. Column 5 of this table then shows the results for the regression of a clicking dummy ( $0=$ not clicked, $1=$ clicked on website link) on framing condition, while column 6 shows the regression results of this dummy on framing condition and the additional socio-demographics. Standard errors are given in parentheses. ${ }^{*},{ }^{* *}$, and ${ }^{* * *}$ denote statistical significance at the $10 \%, 5 \%$, and $1 \%$ level. 
to understand the consequences of pension system changes. The website provided participants with relatively fewer benefits since it did not include updated information on the changes to the current pension system.

\subsection{CONCLUSION}

In this chapter, we have developed and tested new frames to activate pension plan participants. The evidence is based on three laboratory studies and a field experiment. First, we find that the loss frame is more effective in increasing participants' information acquisition, which is in line with findings from the health domain, showing that loss frames are most successful with uncertain decision outcomes (e.g. Block and Keller 1995). However, loss frames also result in more negative emotions and text evaluations. Second, we find that assurance framing (the pension communication loss framing equivalent) is twice as effective as the investment frame in activating participants to search for information. With the investment and assurance frames, negative emotions are not triggered.

The evidence obtained in two laboratory experiments shows that the use of a traditional loss frames is not a desirable option if policy makers or financial service providers want to trigger individuals to search for information about retirement. Participants had more negative perceptions about the loss frame, and evaluated it lower than the gain frame as well. Thus, although the frame triggered the desired action it may induce side effects with unclear long-term consequences. Moreover, financial service providers are reluctant to use negative frames in their communication. By developing a feasible loss frame alternative, the assurance frame, we show that emphasizing security and the peace of mind feeling that information search can bring helps to activate participants. Our results show that even small changes in communication can have a large impact on behavior. Thus, it is important to carefully choose the exact wording of pension communication.

We contribute to the literature on framing effects within the pension domain (e.g. Brown et al. 2016; Brown et al. 2008), and advise to use assurance rather than investment framing, since it stimulates more participants to act. In the arena of public policy, our results provide insights about which frames have the strongest effect. The choice of frame can determine whether communication about changes to a pension system is effective. The frames that we developed, and actually used in our field study, are simple and cost efficient text frames that can be used in practice. They can be used in email subject lines, websites, regular mail communication and in campaigns to communicate policy changes. Avoiding the loss wording, and instead focusing on providing individuals with assurance and a sense of security, can provide a powerful nudge. In our field experiment, four lines of text made a strong difference in the number of participants that click further and acquire the information that is important for them and their retirement planning. 



\section{chapter 4}

\section{Aging and Financial Decision Making: The Benefit of Experience and Emotion}

This chapter is co-authored with: Wändi Bruine de Bruin (Leeds University, Carnegie Mellon University) and JoNell Strough (West Virginia University) 



\subsection{INTRODUCTION}

Populations worldwide are aging, with the segment of those older than 60 being expected to double between 2007 and 2050 (UN 2016). In the UK, the age group of 65 years and older has already grown by 47\% since 1974 (UK government 2015). While people of all ages face difficult financial decisions that affect their wealth and well-being, the literature on cognitive aging suggests that especially older adults struggle with cognitively demanding decisions (e.g. Del Missier et al. 2015; Mather and Carstensen 2005).

In recent years, choices about financial products have become increasingly difficult (Hershey, Austin, and Guitierrez 2015). In many countries, saving for retirement involves increasing personal responsibility and more risk due to shifts from defined benefits to defined contribution pension plans (Gough and Niza 2011). Other products, such as reverse mortgages, are important for the elderly, but too complex to understand for many (Davidoff, Gerhard, and Post 2017). Financial services providers use complexity to justify higher prices for their products (Célérier and Vallée 2013), with some financial offers even being deliberately manipulative (Agarwal et al. 2015). In our research setting, the UK, the Pensions Act of 2008 introduced automatic enrollment into pension schemes, with employees having the choice to opt out. Since the introduction of the 2015 freedom and choice agenda, retirees are no longer being asked to purchase an annuity. Rather, they have to choose from among six options, including taking their whole pension pot at once or in chunks, or getting an adjustable income (UK government 2016). Additionally, the UK Financial Conduct Authority sees consumer debt as one of its main priorities since outstanding credit card debts have risen steadily and have reached record levels of $£ 68$ billion in 2017 (as compared to $£ 55$ in 2012; Financial Times 2017).

The behavioral decision making literature has suggested that people may strugle to make financial decisions. For example, in a credit card repayment task, participants were given a choice between paying off one of two credit cards (Amar et al. 2011). Many did not realize that it would be most beneficial to prioritize paying off the credit card with the highest interest rate, rather than the one with the smallest debt (Amar et al. 2011). In another performance task, people were found to violate the economic "sunk-cost rule", which posits that they should discontinue investments that are no longer profitable (Arkes and Blumer, 1985). According to the cognitive aging literature, people experience a decline in cognitive ability as they get older (Salthouse, 2004), which may undermine their ability to make decisions (Bruine de Bruin, Parker, and Fischhoff, 2012). In contradiction to findings from the cognitive aging literature, however, the few studies that have examined the relationship between age and financial decision making have found that older adults generally seem to perform better than younger adults (e.g. Li et al. 2013, 2015).

Two cognitive and two non-cognitive individual-differences characteristics may potentially explain age differences in financial decision making (Bruine de Bruin 2016). While older adults face well-documented age-related decline in cognitive abilities such as 
numeracy that could potentially harm their ability to make financial decisions (Bruine de Bruin et al. 2015; Weller et al. 2013; Finucane et al. 2005), they also have more experiencebased knowledge that may benefit their financial decisions (Bruine de Bruin, Parker and Fischhoff 2007, 2012; Li et al. 2013, 2015). Additionally, older adults experience changes in emotions and motivation, which have also been identified as potentially relevant to making good decisions (e.g. Bruine de Bruin 2016; Strough, Parker, and Bruine de Bruin 2015). Our paper is part of an emerging literature that aims to analyze the role of both cognitive and non-cognitive individual-differences characteristics in one study on aging and financial decision making. We discuss these four individual-differences characteristics below.

\section{Cognitive individual-differences characteristics}

\section{Numeracy}

Numeracy has been defined as the ability to understand and manipulate probabilistic and other numerical information (Weller et al. 2013; Schwartz et al. 1997). Such numeracy is relevant for making decisions about health insurance (Peters et al. 2007), assessing inflation (Bruine de Bruin et al. 2010), and understanding risks and benefits of medical screening (Reyna et al. 2009), as well as retirement planning and other financial decisions (Lusardi 2012; van Rooij, Lusardi, and Alessie 2011).

Older adults tend to perform worse on numeracy measures than younger adults (e.g. Bruine de Bruin, McNair, Taylor, Summers, and Strough 2015; Lusardi 2012). These findings potentially reflect the cognitive demands of numerical computations (Del Missier et al. 2012), which may be more difficult for older adults due to age-related decline in fluid cognitive ability (Bruine de Bruin et al. 2012; Park and Reuter-Lorenz 2009). However, it has also been argued that some numerical computations follow mathematical rules that can be learned with experience, so as to reduce their cognitive demands and their susceptibility to age-related cognitive decline (McArdle, Smith, and Willis 2009).

\section{Experience-based knowledge}

Becoming an expert in a specific domain requires deliberate practice and building experience-based knowledge (Ericsson, Prietula, and Cokely 2007). Individuals who selfreport having more experience in relevant financial contexts have been shown to make better financial decisions, including those involving sunk costs (Fennema and Perkins 2008). A performance measure of knowledge about financial topics, also referred to as financial literacy (Fernandes, Lynch, and Netemeyer 2014), has been correlated with better financial outcomes such as less debt, even after controlling for demographic variables (Lusardi 2012; Lusardi and Mitchell 2014).

Across the life span, individuals gain experience-based knowledge in different domains, which could positively influence their decision outcomes (e.g. Baltes et al. 2006; Park et al. 2002; Salthouse 2004). Experience with financial decisions improves with age, which can counteract age-related cognitive declines and facilitate better outcomes (Li et al. 2013). For 
example, older adults are less prone to sunk cost bias, which may be partly explained by their increased level of experience (Strough, Karns, and Schlosnagle 2011). In addition, older adults may have decision 'scripts' that help them to make accurate decisions without much deliberation (e.g. Lambert-Pandrout, and Laurent 2010). Reliance on gist, or considering qualitative meaning of information rather than relying on precise and quantitative information, also increases with age (Reyna 2008).

If older adults have experience in financial numerical tasks, they can perform better than younger adults - possibly because older adults have life-long practice in implementing learned rules for financial computations while younger cohorts tend to rely more on technology for making calculations (Schaie 2012). Indeed, financial literacy has been shown to be positively correlated with age and years of education as well (e.g. McArdle, Smith, and Willis 2009).

\section{Non-cognitive individual-differences characteristics}

\section{Negative Emotions}

Emotions can facilitate decisions, as they provide meaning to the available options, and help to identify relevant information (e.g. Peters 2006). With cognitively demanding tasks, individuals may find it easier to rely more on emotions than on deliberation to make their decisions (e.g. Shiv and Fedorikhin 1999). As people get older, they aim to optimize positive emotional experiences in the limited time they have left to live (Carstensen 2006). They also cope better with negative experiences (Bruine de Bruin, Strough, and Parker 2014). Perhaps as a result, emotional well-being improves with age, seen in a reduction in negative emotions (Carstensen et al. 2000; Charles et al. 2001; Kessler and Staudinger 2009). Individuals who rely more on their emotional gut feelings or intuitions when making decisions, tend to report better decisions about sunk costs, as well as better financial and life decision outcomes as reported on the Decision Outcome Inventory (Bruine de Bruin et al. 2007).

\section{Motivation}

The motivation to think hard about complex problems is also referred to as need for cognition (Petty, Cacioppo, and Kao 1984). Individuals vary in their motivation to engage in complicated tasks, with the effort that people put in their money management being negatively correlated with their debt accumulation and impulsive buying (Garðarsdóttir and Dittmar 2012).

Older adults become less motivated to put effort into tasks they perceive as potentially irrelevant to achieving their goals (Hess 2014; Strough, Bruine de Bruin, and Peters 2015). They also become less motivated to spend effort on complex tasks that lack personal relevance (Bruine de Bruin et al. 2015). Whether this shift towards more personally relevant goals results in better financial decisions may depend on the personal relevance of the task at hand (Hess, Queen, and Ennis 2013), and has not yet been studied in the context of financial decisions. 
We pose three related research questions that look into relationships between age, financial decision making, cognitive and non-cognitive individual-differences characteristics in increasingly complex consecutive steps.

1. What are the correlations between financial decision making, the two cognitive and two non-cognitive individual-differences characteristics, and age?

2. Do the two cognitive and the two non-cognitive characteristics contribute to financial decision making after controlling for (a) demographic variables and (b) each other?

3. What is the role of the two cognitive and the two non-cognitive individualdifferences characteristics in statistically explaining the relationships between age and financial decision making?

\subsection{METHOD}

\section{Participants}

Through ResearchNow, we recruited a national UK-wide sample, oversampling adults aged 60 years and older. In total, 1,072 participants completed the full questionnaire. We removed data from 125 individuals who refused to indicate their income and an additional 21 who took five minutes or less to answer. The final sample included 926 participants, ${ }^{1}$ with $48.8 \%$ being male (49\% of the overall UK population is male, Office of National Statistics, 2014). Median age was 49 years with one third of our participants being 60 years or older $(M=48.3$, $S D=15.95$; range 18-88). By comparison, median age for the UK population is 40 years (Office for National Statistics, 2014). In our sample, $37.9 \%$ of participants reported having a college degree, and $43.4 \%$ had a net monthly household income at or below the median of $£ 2,100$. By comparison, 33\% of the UK population has a college degree (Office for National Statistics 2014) and the median UK household income is $£ 2,133$ (Office for National Statistics 2015).

\section{Procedure}

Our survey received ethical approval at the University of Leeds. We recruited participants through ResearchNow's (https://www.researchnow.com/) online panel, for a study about "decisions including money matters." Participants received $£ 4.50$ for completing the survey, which took on average 27.26 minutes $(S D=35.19)$. At the end of the survey, participants were presented with website links of Stepchange.org and Citizensadvice.org, which provide financial advice.

\footnotetext{
1 The 146 excluded participants did not differ significantly from the 926 included participants in terms of age $(t(1070)=0.05, p=0.95)$, gender $\left(\chi^{2}(1)=0.33, p=0.56\right)$ or college education $\left(\chi^{2}(1)=0.47, p=0.52\right)$. We also tested for differences among the four factors and four financial decision making measures, and the 146 excluded participants again did not differ from the 926 included ones. The only significant difference was found in two variables: the 146 excluded ones had significantly lower numeracy scores (mean ${ }_{146}=0.39, S D=0.28$ vs. mean $_{926}=0.47, S D=0.25 ; t=3.50$, $p^{<.05^{* * *}}$ ) and lower financial DOI scores (mean ${ }_{146}=4.36, S D=1.98 \mathrm{vs}$. mean ${ }_{926}=4.91, S D=1.68 ; t=3.55, p^{<.05^{* * *}}$ ). Their lower scores for numeracy can be explained by the fact that they filled out fewer items, not that they gave morewrong answers.
} 


\section{Cognitive individual-differences measures}

Numeracy. Participants received the 8-item numeracy scale composed by Weller et al. (2013). For example, it asked "Imagine that we roll a fair, six-sided die 1,000 times. Out of 1,000 rolls, how many times do you think the die could come up as an even number?" Answers were scored as correct (1) or incorrect (0). Missing responses were scored as incorrect. Cronbach's alpha was sufficient (Table 4.1) to compute an overall score by taking the mean of all eight items. A higher overall score indicates higher numeracy.

Experience-based knowledge. Our experience-based knowledge measure consisted of two parts. First, participants answered the 20 -item financial experience scale developed by $\mathrm{Li}$ et al (2015). They indicated whether they had experience with twenty different financial products, including savings accounts and credit cards. Responses were provided on a scale from 1 ("never heard of it") to 6 ("have a lot of personal experience with it"). Because the scale was created for the US, we adapted it for the UK by revising four items (401k replaced by personal pension scheme; IRA plan replaced by ISA plan; Auto loan replaced by car loan; car title loan replaced by logbook loan). In the second part, participants answered the 3 -item financial literacy measure developed by Lusardi and Mitchell (2011). An example item asked "Suppose you had $£ 100$ in a savings account and the interest rate was $2 \%$ per year. After 5 years, how much do you think you would have in the account if you left the money to grow?" Because the items had different response scales, we z-transformed each item score before computing the average across item z-scores. Cronbach's alpha was sufficient to warrant this computation of an overall score (Table 4.1). Higher scores indicated greater experiencebased knowledge.

Table 4.1: Descriptive statistics, number of items, and Cronbach's alpha

\begin{tabular}{lccccccc}
\hline Variable & Mean & SD & Min & Median & Max & \# items & $\alpha$ \\
\hline Individual difference characteristics relevant to decision making & & & & \\
Numeracy & 0.47 & 0.25 & 0.00 & 0.50 & 1.00 & 8 & 0.71 \\
Experience-based knowledge & 0.01 & 0.50 & -1.87 & -0.02 & 1.84 & 23 & 0.87 \\
Negative emotions & 3.25 & 0.65 & 1.00 & 3.20 & 6.00 & 6 & 0.88 \\
Motivation & 3.32 & 0.58 & 1.00 & 3.28 & 5.00 & 18 & 0.85 \\
\hline Financial decision-making measures & & & & & & & \\
Resistance to sunk costs & 3.42 & 1.47 & 1.00 & 3.50 & 6.00 & 2 & 0.14 \\
Credit card repayment & 1.00 & 0.79 & 1.00 & 1.00 & 2.00 & 2 & 0.42 \\
Money management & 3.96 & 0.75 & 1.00 & 4.09 & 5.00 & 11 & 0.87 \\
Financial DOI & 4.91 & 1.67 & 0.11 & 5.00 & 8.20 & 9 & 0.64 \\
& & & & & & & 0.69 \\
\hline
\end{tabular}

Note: N=926; for Financial DOI we computed the Cronbach's $\alpha$ for general items (e.g. whether they have had a credit card) first, and then the $\alpha$ for negative items (e.g. whether they had credit card debt). 


\section{Non-cognitive individual-differences characteristics}

Negative emotions. Participants used a 5 -item scale of negative emotions (Thompson 2007), to rate their agreement with whether they had felt upset, hostile, nervous, afraid or ashamed when making financial decisions in everyday life (1=never; 5=always). We added "guilty" to the scale, since previous research in the financial domain indicated that guilt is also relevant to financial decision making (e.g. Ackert 2003). Cronbach's alpha across the

five items was sufficient to warrant the computation of an overall score (Table 4.1), which reflected the mean rating across the five items. Higher scores indicated higher levels of negative emotions.

Motivation. Participants used the 18-item scale of need for cognition (Petty, Cacioppo, and Kao 1984) to rate their motivation to put effort into deliberation. Participants rated how they felt about statements like "I like to have the responsibility of handling a situation that requires a lot of thinking" ( $1=$ completely false $-5=$ completely true). Cronbach's alpha was sufficient (Table 4.1) to warrant the computation of an overall score. It reflected the mean rating across items, such that higher scores indicated higher need for cognition.

\section{Performance measures of financial decision making}

Resistance to sunk costs. Our first performance measure of financial decision making was resistance to sunk costs, based on two items from Bruine de Bruin et al. (2007). The first asked participants to imagine that they already paid $£ 100$ on a $£ 200$ ring, upon discovering the same ring being on sale for $£ 90$ at another store. Participants gave their answers on a six-point scale, with (1) being "most likely to continue paying at the old store" and (6) "most likely to buy from the new store". The second item asked participants to imagine that they had already paid to watch a pay TV movie at a hotel, upon discovering a more interesting free cable channel movie (Bruine de Bruin et al. 2007). Here, participants gave a (1) for most likely to watch pay TV up to a (6) for "most likely to watch free cable". Cronbach's alpha was quite low due to the small number of items (Table 4.1), but previous research showed that the overall measure was reliable and valid (Bruine de Bruin et al. 2007). We took the average across ratings for the two items, so higher scores reflected better ability to resist sunk costs.

Credit card repayment. Our other performance measure of financial decision making asked participants to make a credit card repayment decision (Amar et al. 2011; see Figure 4.1). Participants received two scenarios in random order in the beginning of the survey or just before the demographic questions. Item A asked participants to imagine that they had two credit card accounts, a Master Card with a $£ 100$ balance and a 10\% (item B: 15\%) annual percentage rate (APR), and a Visa Card with a $£ 1,000$ balance and a $15 \%$ (item B: 10\%) APR. They were then told that they received a government stimulus rebate of $£ 100$ (item B: $£ 1,000$ ), and were asked to indicate how much they would repay on each account. For optimal financial outcomes, participants should repay the account with the higher APR first. Responses were coded as correct (1) if the full amount for the card with the higher APR was 
indicated, and incorrect (0) if otherwise. We computed the number of correct answers given across the two items, with higher scores reflecting better credit card repayment performance. We report the low Cronbach's alpha value in Table 4.1, but in line with Li et al. (2015) we also looked at the correlations of the two items. Participants' answers to both items were highly correlated $(r=0.26, p<0.001)$ and out of the people who had at least one of the two items correct, $46.2 \%$ answered both items correctly. This analysis and its result is in line with Li et al. (2015), which makes us confident that we use a good measure.

\section{Self-report measures of financial decision making}

Money management. We used the 9-item money management self-report scale developed by Garðarsdóttir and Dittmar (2012). An example item stated "I stay within my budget(s)". Participants indicated their agreement on a scale ranging from (1) "does not describe me at all" to (5) "very descriptive of me". We added two items about savings, including "I tend to make sure I save for the short to mid-term, e.g. to go on holiday, put a deposit down for a house" and "I tend to make sure I save for the long term so I can retire comfortably". Cronbach's alpha across the eleven items was sufficient to warrant the computation of an overall score (Table 4.1). We computed the mean across the eleven items, with higher scores indicating better self-reported money management.

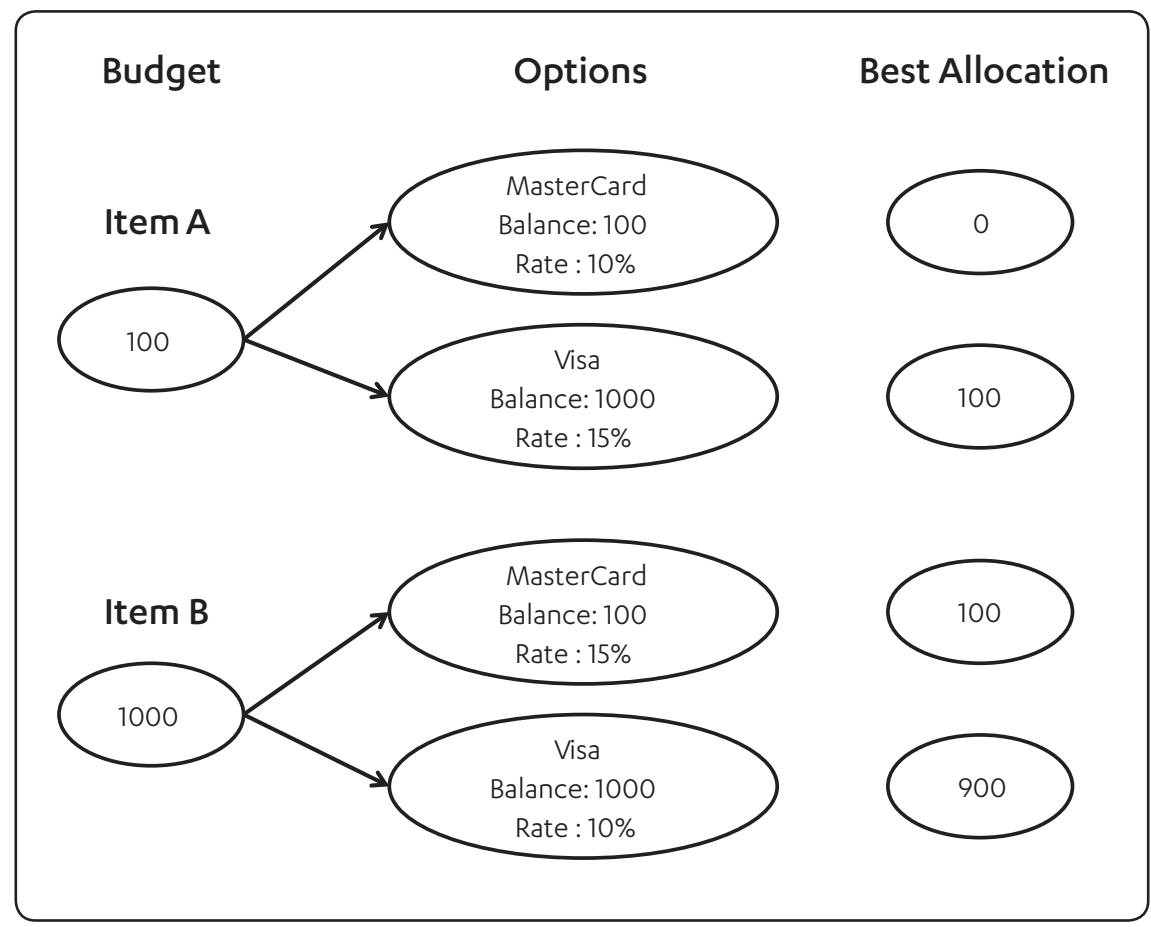

Figure 4.1: Schematic representation of credit card repayment task 
Financial decision outcome inventory. Participants self-reported whether or not they had experienced seven financial outcomes from the decision outcome inventory (DOI) developed by Bruine de Bruin, Parker and Fischhoff (2007; Parker et al. 2015): being foreclosed on a mortgage or loan, paying rent or mortgage payment at least 2 weeks too late, having a check bounce, having more than $£ 5,000$ in credit card debt, losing more than $£ 1,000$ on a stock market investment, having gone bankrupt, and having electricity, cable, gas or water shut off because one did not pay on time. Although experienced decision outcomes partly reflect chance, good decision making processes should on average lead to better decision outcomes (Keren and Bruine de Bruin 2003). Each item consisted of two parts. First, participants indicated whether they had engaged in a behavior (e.g. whether they ever had a credit card). Second, they indicated whether they experienced a related negative outcome (e.g. had more than $£ 5,000$ in credit card debt). We added two financial items regarding saving for retirement, which is one of the most complex and uncertain financial tasks (Hershey et al. 2015) ("In the last ten years, have you ever... 1.a. been enrolled in a pension scheme, 1.b. opted-out of a pension scheme?, 2.a. switched from the default to other funds in your pension scheme, 2.b. lost money after switching funds in your pension scheme?"). In line with Bruine de Bruin et al. (2007), we weighted the separate items by the proportion of participants who experienced a negative outcome to incorporate the lower chance that of experiencing a very severe outcome. We then took the average and subtracted it from zero, so higher scores reflected better decision outcomes. We report two Cronbach's alpha values in Table 4.1, first the one for general items (e.g. whether they have had a credit card), and then the value for negative items (e.g. whether they had credit card debt). Both values are slightly below 0.7 .

\section{Data analysis}

Our analyses were conducted to answer our three research questions. To answer our first research question, we present a plot of $z$-score means of the two cognitive and two noncognitive individual-differences characteristics. We also computed Pearson correlations between financial decision making, the two cognitive and two non-cognitive individualdifferences characteristics, and age.

Our second research question asked whether the two cognitive and the two noncognitive characteristics contribute to financial decision making after controlling for (a) demographic variables and (b) each other. We conducted a set of three regression models to predict performance on each of the financial decision making tasks (resistance to sunk costs, credit card repayment, money management and financial DOI). In the first model, we entered only the two cognitive variables (numeracy and experience-based knowledge). In the second model, we entered only the two non-cognitive variables (negative emotions and motivation). In the third model, we entered both the two cognitive and the two noncognitive variables. All models included demographic variables for age, gender (female is 
coded as 1), college education (being college educated is coded as 1), and income (income above the median is coded as 1). We used linear regressions to predict performance on resistance to sunk costs, money management, and financial DOI because these measures were continuous. We used logistic regressions to predict performance on the credit card repayment task, because this measure was dichotomous. We compared the first two models to Pearson correlations to examine whether cognitive and non-cognitive variables predicted financial decision making after controlling for demographics. We compared the first two models with the third model to identify the predictive ability of including cognitive and noncognitive variables as opposed to either alone.

To answer our third research question, we go through two steps. First, we estimated four multiple mediation models, using the PROCESSmacro for SPSS with 1,000 bootstrap samples (Preacher and Hayes 2008; Hayes 2013). That is, we computed one multiple mediation model for every financial decision-making measure (resistance to sunk costs, credit card repayment, money management and financial DOI). In each model, we entered the two cognitive measures (numeracy and experience-based knowledge) and the two noncognitive measures (negative emotions and motivation) as the four potential mediators. For each mediation model, we report (a) the relationship between age and each potential mediator; (b) the relationship between each potential mediator and the financial decision making measure; and (c) the relationship between age and financial decision making, before and after controlling for the potential mediators. We follow Preacher and Hayes (2008) conducting this analysis. Second, we take a closer look at the relationship between age and numeracy by conducting linear regressions with a squared age term for the whole sample and three separate age groups. All analyses were conducted in SPSS (version 23).

\subsection{RESULTS}

\section{(1) What are the correlations between financial decision making, the two cognitive and two non-cognitive individual-differences characteristics, and age?}

Descriptive statistics showed sufficient variation to warrant analyses of individual differences (Table 4.1). The plot of z-score means of all four individual-differences characteristics per age decade to understand how the factors look per decade (Figure 4.2). While experiencebased knowledge steadily increases with age and negative emotions steadily drop in value, we do not see a lot of change in values for motivation. For numeracy, we only see a sharp drop in scores in the small $80-89$ age decade group.

The correlations between measures showed three notable patterns (Table 4.2). First, better scores on all four decision-making tasks were associated with higher levels of numeracy, more experience-based knowledge, more motivation, and less negative emotions - though the latter did not reach significance for resistance to sunk costs. Second, 


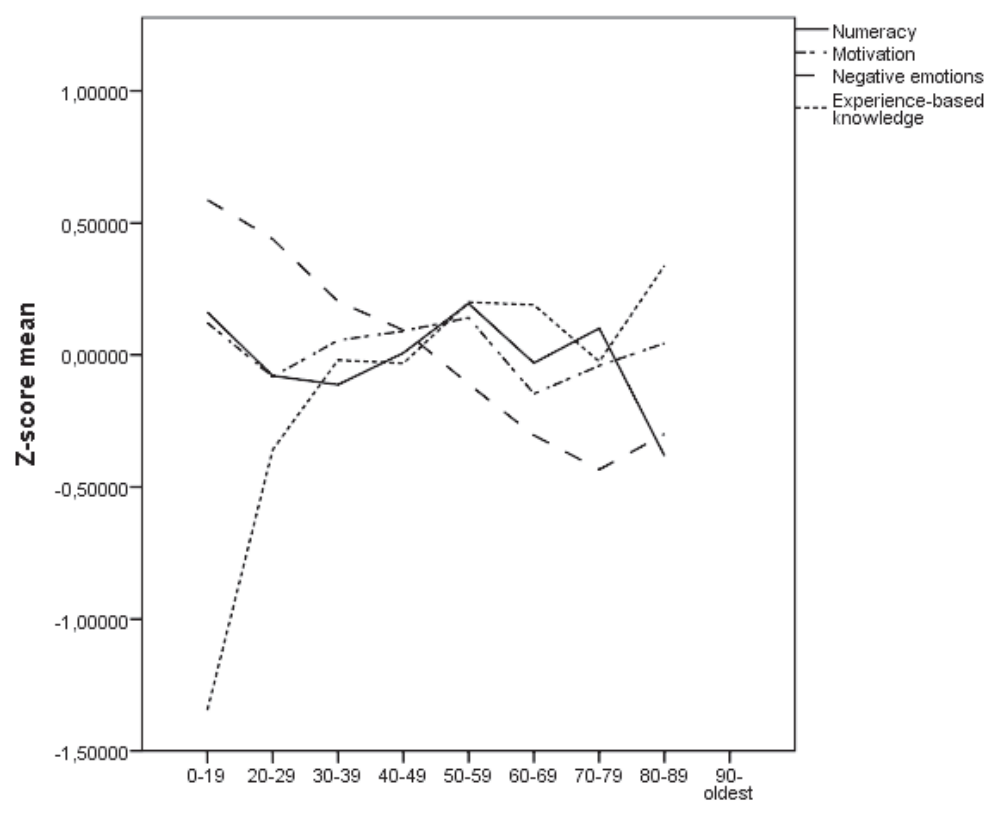

Age decades

Note:This figure shows thez-score mean values for all four individual-differences characteristics (numeracy, motivation, negative emotions, and experience-based knowledge) across age decades. Group sizes are 13 (0-19), 130 (20-29), 182 (30-39), 153 (40-49), 149 (50-59), 227 (60-69), 68 (70-79) and 4 (80-89).

Figure 4.2: Characteristics per age decade

Table 4.2: Correlations

\section{$\begin{array}{lll}\text { 1. Numeracy } & \text { 2. Experience- } & \text { 3. Negative }\end{array}$ based knowledge emotions}

\section{Individual difference characteristics relevant to decision making}

1. Numeracy

2. Experience-based knowledge

$0.18^{* * *}$

3. Negative emotions

$-0.14^{* * *} \quad-0.25^{* * *}$

4. Motivation

$0.22^{\text {t*t+ }}$

$0.28^{* * *+}$

$-0.15^{*+*}$

Financial decision-making measures

5. Resistance to sunk costs

$0.08^{*+}$

$0.16^{* * *}$

$-0.06^{+}$

6. Credit card repayment

$0.38^{*+*}$

$0.13^{*+*}$

$-0.15^{4+* x}$

7. Money management

$0.08^{* * *}$

$0.29^{*+*+}$

$-0.39^{* *}$

8. Financial DOI

$0.25^{* * *}$

$0.36^{\text {*t+ }}$

$-0.23^{* * *}$

9. Age

0.03

$0.22^{*+*+}$

$-0.28^{\star * \star}$

Note: ${ }^{* * *} p<.001 ;{ }^{* *} p<.01,{ }^{*} p<.05+p<.10 ; N=926$ 
age was significantly correlated with better scores on all four financial decision making measures, including the two performance measures (resistance to sunk costs and credit card repayment) and the two self-report measures (money management and financial DOI). Third, age was correlated to more experience-based knowledge, and a decrease in negative emotions about financial decisions. Numeracy and motivation were not significantly correlated with age. We therefore plot the $z$-score means of all four individual-differences characteristics per age decade to understand how the factors look per decade (Figure 4.2). While experience-based knowledge steadily increases with age and negative emotions steadily drop in value, we do not see a lot of change in values for motivation. For numeracy, we only see a sharp drop in scores in the small 80-89 age decade group.

\section{(2) Do the two cognitive and the two non-cognitive characteristics contribute to financial decision making after controlling for (a) demographic variables and (b) each other?}

Comparing the correlations (Table 4.2) and regressions (Table 4.3), we see that for resistance to sunk costs, numeracy does not have the significant positive relationship anymore when we include demographic variables (Table 4.3, model 1) and non-cognitive characteristics (model 3). In contrast, experience-based knowledge keeps its significant positive impact throughout the analysis. Negative emotions do not have a significant relationship with resistance to sunk costs in any of the tables. Motivation is positively significantly correlated with resistance to sunk costs, and also keeps this effect when controlling for demographics, but not when including the cognitive characteristics (model 3).

$0.19^{n+*}$

$0.11^{* * *}$

$0.20^{\text {t*t }}$ 
Table 4.3: Regressions predicting financial decision making measures

\begin{tabular}{|c|c|c|c|c|c|c|}
\hline \multirow[t]{2}{*}{ Model } & \multicolumn{3}{|c|}{ Resistance to sunk costs } & \multicolumn{3}{|c|}{ Credit card repayment } \\
\hline & 1 & 2 & 3 & 1 & 2 & 3 \\
\hline \multicolumn{7}{|c|}{ Key individual difference characteristics } \\
\hline Numeracy & $\begin{array}{c}0.23 \\
(0.20)\end{array}$ & & $\begin{array}{c}0.17 \\
(0.21)\end{array}$ & $\begin{array}{l}3.04^{* * *+} \\
(0.28)\end{array}$ & & $\begin{array}{c}2.99^{* * *} \\
(0.28)\end{array}$ \\
\hline Experience-based knowledge & $\begin{array}{c}0.25^{* *} \\
(0.07)\end{array}$ & & $\begin{array}{c}0.22^{*} \\
(0.08)\end{array}$ & $\begin{array}{l}-0.04 \\
(0.11)\end{array}$ & & $\begin{array}{l}-0.07 \\
(0.11)\end{array}$ \\
\hline Negative Emotions & & $\begin{array}{l}-0.00 \\
(0.06)\end{array}$ & $\begin{array}{c}0.02 \\
(0.06)\end{array}$ & & $\begin{array}{l}-0.19^{* *} \\
(0.07)\end{array}$ & $\begin{array}{l}-0.13^{+} \\
(0.08)\end{array}$ \\
\hline Motivation & & $\begin{array}{c}0.22^{* *} \\
(0.08)\end{array}$ & $\begin{array}{c}0.16+ \\
(0.09)\end{array}$ & & $\begin{array}{c}0.20^{+} \\
(0.11)\end{array}$ & $\begin{array}{r}0.01 \\
(0.11)\end{array}$ \\
\hline \multicolumn{7}{|l|}{ Demographic characteristics } \\
\hline Age & $\begin{array}{c}0.01^{* *} \\
(0.00)\end{array}$ & $\begin{array}{c}0.01^{*} \\
(0.00)\end{array}$ & $\begin{array}{c}0.01^{* *} \\
(0.00)\end{array}$ & $\begin{array}{l}0.02^{* * * *} \\
(0.00)\end{array}$ & $\begin{array}{c}0.02^{* * *} \\
(0.00)\end{array}$ & $\begin{array}{c}0.02^{* \star *} \\
(0.00)\end{array}$ \\
\hline Gender & $\begin{array}{l}-0.28^{* *} \\
(0.09)\end{array}$ & $\begin{array}{l}-0.37^{4+*} \\
(0.09)\end{array}$ & $\begin{array}{l}-0.30^{* *} \\
(0.10)\end{array}$ & $\begin{array}{r}0.05 \\
(0.13)\end{array}$ & $\begin{array}{l}-0.16 \\
(0.12)\end{array}$ & $\begin{array}{r}0.06 \\
(0.13)\end{array}$ \\
\hline College education & $\begin{array}{c}0.14 \\
(0.10)\end{array}$ & $\begin{array}{c}0.16 \\
(0.10)\end{array}$ & $\begin{array}{c}0.12 \\
(0.10)\end{array}$ & $\begin{array}{c}0.42^{* *} \\
(0.14)\end{array}$ & $\begin{array}{l}0.58^{* \star *} \\
(0.13)\end{array}$ & $\begin{array}{c}0.42^{* *} \\
(0.14)\end{array}$ \\
\hline Income & $\begin{array}{l}-0.09 \\
(0.10)\end{array}$ & $\begin{array}{l}-0.07 \\
(0.00)\end{array}$ & $\begin{array}{l}-0.10 \\
(0.10)\end{array}$ & $\begin{array}{c}0.13 \\
(0.14)\end{array}$ & $\begin{array}{r}0.06 \\
(0.13)\end{array}$ & $\begin{array}{c}0.13 \\
(0.14)\end{array}$ \\
\hline AIC & 689.88 & 694.68 & 689.52 & 1862.91 & 1973.42 & 1862.76 \\
\hline Adjusted $\mathrm{R}^{2}$ & 0.03 & 0.03 & 0.04 & 0.20 & 0.07 & 0.20 \\
\hline
\end{tabular}

Note: OLS regressions were conducted for resistance to sunk costs, money management and financial DOI; while logistic regressions were conducted for credit card repayment. For credit card repayment, we report the Nagelkerke statistic instead of adjusted $\mathrm{R}^{2}$. Standard errors are given in parentheses. ${ }^{* * *} p<.001 ;{ }^{* *} p<.01,{ }^{*} p<.05$ ${ }^{+} p<.10 ; N=926$

For credit card repayment, numeracy is the only variable that keeps its significance from the correlations to model 1 and model 3. Experience-based knowledge loses its significance when incorporating demographics (age and college education in particular), just as motivation. Negative emotions become insignificant when adding the cognitive characteristics in model 3.

Looking at the results for money management, all variables except for numeracy keep their significance (positive for experience-based knowledge and motivation, negative for negative emotions).

For financial DOI, all characteristics are significantly correlated with the outcome variable (Table 4.2) and keep their significance throughout the three models in Table 4.3.

Since we conducted OLS regressions for resistance to sunk costs, money management and financial DOI, but an ordinal regression for credit card repayment, we show the Akaike 


\begin{tabular}{|c|c|c|c|c|c|}
\hline \multicolumn{3}{|c|}{ Money management } & \multicolumn{3}{|c|}{ Financial DOI } \\
\hline 1 & 2 & 3 & 1 & 2 & 3 \\
\hline $\begin{array}{c}0.20^{*} \\
(0.09)\end{array}$ & & $\begin{array}{c}0.03 \\
(0.09)\end{array}$ & $\begin{array}{c}1.43^{* * *} \\
(0.21)\end{array}$ & & $\begin{array}{c}1.24 \\
(0.21)\end{array}$ \\
\hline $\begin{array}{c}0.27^{* * *} \\
(0.04)\end{array}$ & & $\begin{array}{c}0.19^{.+*} \\
(0.04)\end{array}$ & $\begin{array}{c}0.65^{*+*} \\
(0.08)\end{array}$ & & $\begin{array}{c}0.55^{* * *} \\
(0.08)\end{array}$ \\
\hline & $\begin{array}{l}-0.29 \\
(0.03)\end{array}$ & $\begin{array}{l}-0.28 \\
(0.03)\end{array}$ & & $\begin{array}{l}-0.31 \\
(0.06)\end{array}$ & $\begin{array}{l}-0.24 \\
(0.06)\end{array}$ \\
\hline & $\begin{array}{c}0.18^{* * *} \\
(0.04)\end{array}$ & $\begin{array}{c}0.14^{* * *} \\
(0.04)\end{array}$ & & $\begin{array}{c}0.44^{+* * *} \\
(0.09)\end{array}$ & $\begin{array}{c}0.22 \\
(0.09)\end{array}$ \\
\hline $\begin{array}{c}0.01 \\
(0.00)\end{array}$ & $\begin{array}{c}0.01 \\
(0.00)\end{array}$ & $\begin{array}{c}0.01^{* *} \\
(0.00)\end{array}$ & $\begin{array}{c}0.02 \\
(0.00)\end{array}$ & $\begin{array}{c}0.02 \\
(0.00)\end{array}$ & $\begin{array}{c}0.01^{+* *} \\
(0.00)\end{array}$ \\
\hline $\begin{array}{c}0.13^{* *} \\
(0.05)\end{array}$ & $\begin{array}{c}0.08^{+} \\
(0.04)\end{array}$ & $\begin{array}{c}0.13^{* *} \\
(0.05)\end{array}$ & $\begin{array}{r}0.10 \\
(0.11)\end{array}$ & $\begin{array}{l}-0.16 \\
(0.10)\end{array}$ & $\begin{array}{c}0.09 \\
(0.10)\end{array}$ \\
\hline $\begin{array}{c}0.00 \\
(0.05)\end{array}$ & $\begin{array}{c}0.01 \\
(0.05)\end{array}$ & $\begin{array}{l}-0.01 \\
(0.05)\end{array}$ & $\begin{array}{c}0.41^{* * *} \\
(0.11)\end{array}$ & $\begin{array}{c}0.56 \\
(0.11)\end{array}$ & $\begin{array}{c}0.39 \\
(0.11)\end{array}$ \\
\hline $\begin{array}{c}0.03 \\
(0.05)\end{array}$ & $\begin{array}{c}0.04 \\
(0.05)\end{array}$ & $\begin{array}{c}0.02 \\
(0.05)\end{array}$ & $\begin{array}{c}0.22^{*} \\
(0.11)\end{array}$ & $\begin{array}{c}0.24^{*} \\
(0.11)\end{array}$ & $\begin{array}{c}0.20^{+} \\
(0.11)\end{array}$ \\
\hline-612.12 & -704.69 & -726.58 & 787.64 & 838.40 & 768.95 \\
\hline 0.09 & 0.18 & 0.21 & 0.17 & 0.13 & 0.19 \\
\hline
\end{tabular}

Information Criteria (AIC). Comparing the three models based on their AIC value, model 3 has the lowest values and therefore the best fit across all regression analyses (DeCarlo 2003). We build up the models like this to understand what the non-cognitive factors add over and above the cognitive ones, and whether the cognitive factors keep their signs and significance.

\section{(3) What is the role of the two cognitive and the two non-cognitive individual difference characteristics in statistically explaining the relationships between age and financial decision making?}

Next, we conducted PROCESS analyses (Hayes 2013) to investigate the contribution of the two cognitive and the two non-cognitive individual-differences characteristics to age differences in the measures of financial decision making (see Figure 4.3).For every 
financial decision making measure, we conducted one parallel mediation model: age is the independent variable influencing four potential mediators (i.e. numeracy, experiencebased knowledge, negative emotions, and motivation) and age and these mediators then influence the respective financial decision making measure (i.e. resistance to sunk costs, credit card repayment, money management and financial DOI). Figure 4.3 shows the coefficients and significance levels of all four models, and tells us about (1) the effect of age on the potential mediators, (2) the effect of the mediators on the financial decision making outcome, and (3) the effect of age on the financial decision making outcome measure before and after controlling for the mediator.

As a guide on how to read the figure, if we go from the left side of the figure to the right, age for example has a significant negative relationship with negative emotions $(r=-0.02, p<0.001)$, negative emotions have a significant negative relationship with money management ( $r=-0.28, p<0.001$ ), and age keeps its significant positive impact on money management even after including the four potential mediators $(r=0.004, p<0.01$; before $r=0.009, p<0.001$ ).

We found that older adults' better performance is statistically explained by their higher levels of experience-based knowledge and lower levels of negative emotions. Regarding the contribution of the four individual-difference characteristics to financial decision making, findings were in line with the regression analyses reported above. That is, the two performance measures of decision making showed better performance with better scores on cognitive individual-differences characteristics. First, older adults' better sunk cost decisions were statistically explained by their increased experience-based knowledge. We test for mediation with a Sobel test (Preacher and Hayes 2008) and see that experiencebased knowledge indeed mediates the age and resistance to sunk cost relationship ( $z=2.91$, $p=0.004$ ). Second, participants with higher numeracy performed better on the credit card repayments, but we find no significant mediation relationships related to age. Additionally, the two self-report measures of decision making relied on both cognitive and noncognitive characteristics. That is, age differences in self-reported money management were statistically explained by older adults' lower levels of negative emotions ( $z=6.68, p=0.000$ ) and higher levels of experience-based knowledge $(z=3.51, p=0.000)$. The same holds for age differences in the self-reported financial DOI: negative emotions ( $z=3.48, p=0.000)$ and experience-based knowledge $(z=4.33, p=0.000)$ are significant mediators of the age and financial DOI relationship.

Then, in an additional analysis step, we look at interaction effects of age and the four characteristics ${ }^{2}$. We only find a significant interaction between age and numeracy on financial DOI. Since we did not see a significant correlation between numeracy and financial DOI in the first place (Table 4.2), we split the sample in three groups and include age squared in the analyses. Table 4.4 shows the regressions between the two cognitive and two non-

\footnotetext{
${ }^{2}$ Results can be obtained at request from the authors.
} 


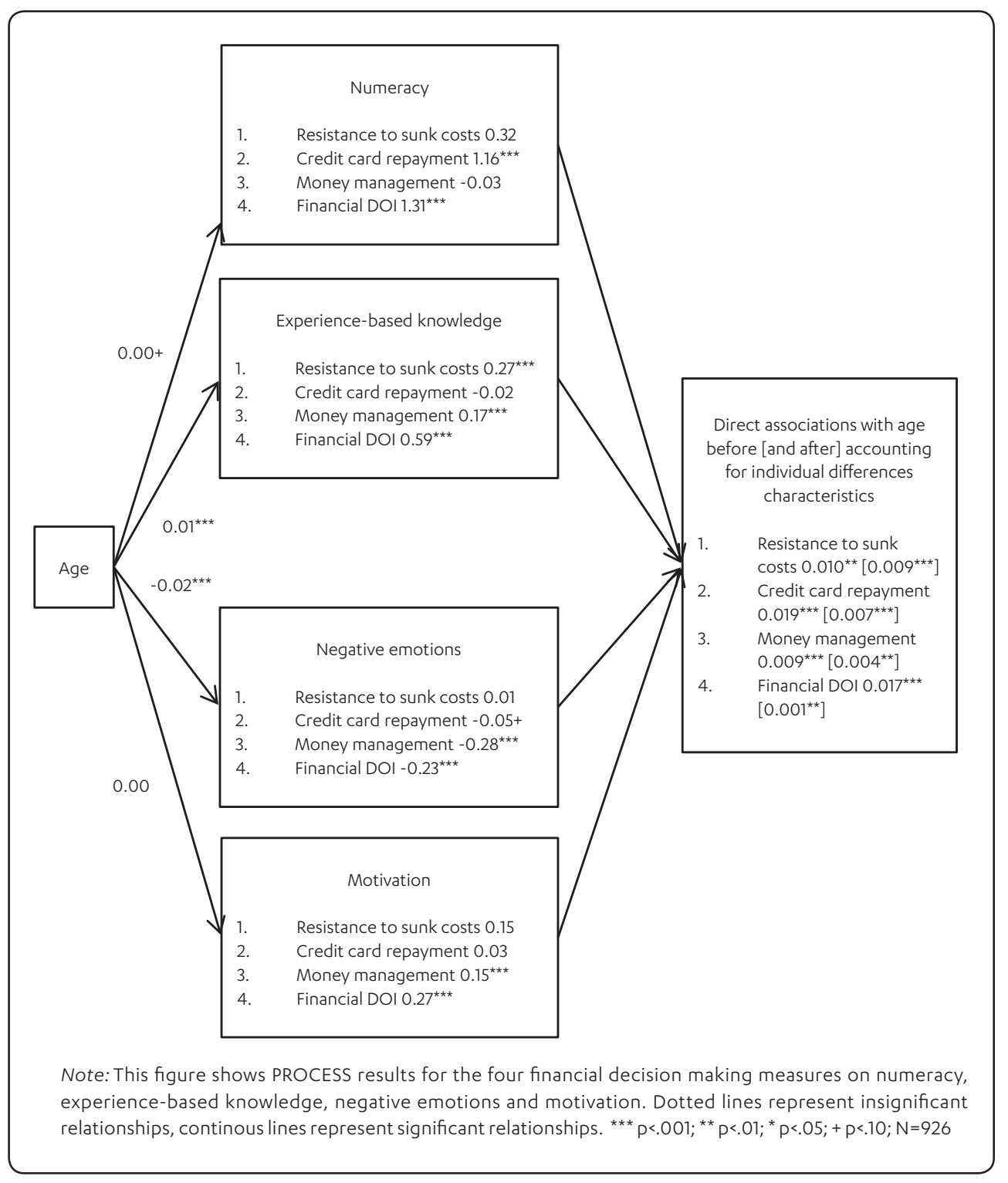

Figure 4.3: PROCESS models

cognitive characteristics, age and age squared and other demographic characteristics for the whole sample and for three different age groups ( $<=38,39-59$ and 60+). We find a positive effect of age, but negative effect of age squared which indicates that the positive effect of age lessens with old age. This is exactly what we find for numeracy: numeracy has a positive effect for age groups until 59, then the effect becomes insignificant. 
Table 4.4: Regressions predicting financial DOI

\begin{tabular}{|c|c|c|c|c|}
\hline & \multirow[t]{2}{*}{ All } & \multicolumn{3}{|c|}{ Three age groups } \\
\hline & & $<=38$ & $39-59$ & $60+$ \\
\hline$N$ & 926 & 316 & 311 & 299 \\
\hline \multicolumn{5}{|c|}{ Key individual difference characteristics } \\
\hline Numeracy & $\begin{array}{c}1.22^{+* \star *} \\
(0.21)\end{array}$ & $\begin{array}{l}2.13 \\
(0.39)^{* * *}\end{array}$ & $\begin{array}{c}1.26 \\
(0.37)^{* \star \star}\end{array}$ & $\begin{array}{c}0.14 \\
(0.32)\end{array}$ \\
\hline Experience-based knowledge & $\begin{array}{c}0.50^{* * *} \\
(0.08)\end{array}$ & $\begin{array}{c}0.39 \\
(0.14)^{*+}\end{array}$ & $\begin{array}{c}0.61 \\
(0.15)^{*+*}\end{array}$ & $\begin{array}{c}0.62 \\
(0.14)^{+* * *}\end{array}$ \\
\hline Negative emotions & $\begin{array}{l}-0.24^{* * *} \\
(0.06)\end{array}$ & $\begin{array}{l}-0.25 \\
(0.11)^{*}\end{array}$ & $\begin{array}{l}-0.18^{+} \\
(0.10)\end{array}$ & $\begin{array}{l}-0.31 \\
(0.09)^{\star * *}\end{array}$ \\
\hline Motivation & $\begin{array}{c}0.22^{*} \\
(0.09)\end{array}$ & $\begin{array}{c}0.16 \\
(0.19)\end{array}$ & $\begin{array}{c}0.12 \\
(0.16)\end{array}$ & $\begin{array}{c}0.30^{*} \\
(0.12)\end{array}$ \\
\hline \multicolumn{5}{|l|}{ Demographic characteristics } \\
\hline Age & $\begin{array}{l}0.13^{* * *} \\
(0.02)\end{array}$ & $\begin{array}{c}0.57 \\
(0.18)^{+*+*}\end{array}$ & $\begin{array}{c}0.17 \\
(0.28)\end{array}$ & $\begin{array}{c}0.15 \\
(0.26)\end{array}$ \\
\hline $\mathrm{Age}^{2}$ & $\begin{array}{l}-0.00^{* * *} \\
(0.00)\end{array}$ & $\begin{array}{l}-0.01^{* *} \\
(0.00)\end{array}$ & $\begin{array}{l}-0.00 \\
(0.00)\end{array}$ & $\begin{array}{l}-0.00 \\
(0.00)\end{array}$ \\
\hline Gender & $\begin{array}{c}0.07 \\
(0.10)\end{array}$ & $\begin{array}{c}0.30 \\
(0.20)\end{array}$ & $\begin{array}{c}0.14 \\
(0.19)\end{array}$ & $\begin{array}{l}-0.24 \\
(0.15)\end{array}$ \\
\hline College education & $\begin{array}{c}0.33^{* *} \\
(0.11)\end{array}$ & $\begin{array}{r}0.26 \\
(0.19)\end{array}$ & $\begin{array}{c}0.24 \\
(0.19)\end{array}$ & $\begin{array}{c}0.41^{*} \\
(0.17)\end{array}$ \\
\hline Income & $\begin{array}{r}0.20^{+} \\
(0.02)\end{array}$ & $\begin{array}{r}0.32^{+} \\
(0.19)\end{array}$ & $\begin{array}{r}0.04 \\
(0.19)\end{array}$ & $\begin{array}{r}0.20 \\
(0.16)\end{array}$ \\
\hline AIC & 738.94 & 316.65 & 281.71 & 121.91 \\
\hline Adjusted $\mathrm{R}^{2}$ & 0.22 & 0.24 & 0.12 & 0.24 \\
\hline
\end{tabular}

Note: This table presents the results from regressions of financial DOI on numeracy, experience-based knowledge, negative emotions, motivation and socio-economic characteristics. All models controlled for gender, education, and income. ${ }^{* * *} p<.001 ;{ }^{* *} p<.01,{ }^{*} p<.05+p<.10 ; \mathrm{N}=926$

\subsection{DISCUSSION}

We are amongst the first to examine the role of both cognitive and non-cognitive individualdifferences characteristics in one study on aging and financial decision making. Based on an online survey among a UK national sample ( $\mathrm{N}=926)$, we reported three main findings.

First, we found that better financial decision making was related to higher levels of numeracy, more experience-based knowledge, more motivation, and less negative emotions (except for resistance to sunk costs). Previous research suggested that both fluid and crystallized cognitive abilities tend to be associated with better credit scores, making 
less credit-related mistakes and better retirement planning (Agarwal et al. 2009; Li et al 2015; Lusardi and Mitchell 2014). While previous studies had hinted on the importance of emotions in financial decisions such as stock market trading (e.g. Hirshleifer and Schumway 2003; Guiso et al. 2008) as well as borrowing and spending (McNair, Summers, Bruine de Bruin, and Ranyard 2016), we found that motivation and negative emotions played a role in obtaining better financial decision-making scores for money management and financial decision outcomes, even when taking into account cognitive variables. This is in line with findings of Brounen, Koedijk and Pownall (2016), who observed that consumers who report a positive economic outlook also show a significantly higher willingness to save, and being interested in one's finances is more relevant for explaining saving than education or numeracy.

Second, we found that older age was related to better performance on all four financial decision making measures, even after controlling for demographics, cognitive and non-cognitive individual-differences characteristics. As in previous studies, older adults performed better on sunk cost decisions (Bruine de Bruin et al. 2007; Del Missier et al. 2013; Strough et al. 2008; Strough et al. 2014) and credit card repayment tasks (Li et al. 2015). We additionally found that older adults self-reported better money management and financial decision outcomes, thus showing relationships that had not previously been investigated. Important to note here is that financial abuse is still one of the most common types of abuse among the elderly, often committed by family members, caregivers or other people that these elderly are familiar with and trust, and ranging from investment fraud, to telephone and internet scams and identity theft (Consumer Financial Protection Bureau 2017).

Third, we found that older adults' better financial decision making may at least partially be explained by them having more experience-based knowledge and lower levels of negative emotions, despite taking into account individual differences in numeracy and motivation, at least with regards to resistance to sunk costs, money management and financial DOI. Past research focused on either of those individual-difference variables in isolation. Indeed, older adults had been shown to report less negative emotions than younger ones (Carstensen, Pasupathi, Mayr, and Nesselroade 2000; Charles, Reynolds, and Gatz 2001). Older adults worry less about adverse life events (Sütterlin, Paap, Babic, Kübler, and Vögele 2012), which may explain why they perform better at the resistance to sunk costs measures (Bruine de Bruin et al. 2014). Experience-based knowledge, had also been shown to improve with age (Park, Lautenschlager, Hedden, Davidson, Smith, and Smith 2002; Salthouse 2004) and benefit financial decisions (Li et al. 2013; 2015) - though older adults may have experience-based decision scripts, which prevent them from changing their habits and reacting to new information (Lambert-Pandrout and Laurent 2010; LambertPandrout, Laurent, and Lapersonne 2008). Indeed, financial literacy is a skill that is partially experience-based and benefits financial decisions (Lusardi and Mitchell 2007). However, even when older adults can benefit from their greater experience, many of the decisions that the elderly need to take are new decisions - such as whether to take an annuity or lump sum when they retire. With new rules and regulations, the financial environment keeps 
changing and the decisions that consumers need to take are getting more complex (Hershey et al. 2015). As our findings show, older adults are better in decisions such as budgeting and money management, that is skills that they have developed over time, and resisting the sunk cost temptation, a skill that is based on emotional regulation; but not in decisions that involve numerical computation such as credit card repayment. This finding is in line with earlier research on age-related decline in cognitive abilities (Bruine de Bruin et al. 2015; Weller et al. 2013; Finucane et al. 2005), which shows that older adults may very well need cognitive training to stay capable of taking more challenging financial decisions. In addition, many older adults have peers that can share their wisdom on new financial decisions which may help them to take good decisions themselves.

One limitation of our research is that we conducted correlational cross-sectional analyses, as is common in aging research (Salthouse 2004). As a result, we are unable to draw causal conclusions about age-related improvements in for example emotions contributing to better financial decisions in older age (e.g., Lindenberger, von Oertzen, Ghisletta, and Hertzog 2011; Maxwell and Cole 2007). We therefore need to be careful when evaluating regression results and PROCESS models. By discussing our findings, reflecting on earlier literature, differentiating between different types of financial decision making and including this in our implications, we aim to add to the pool of literature on aging and financial decision making while not claiming that older adults are always better making financial decisions. Indeed, correlations do not mean causation. For example, the correlations of negative emotions with self-rated money management and self-reported financial outcomes on the financial DOI would have three potential explanations. First, it is possible that negative emotions caused poor money management and bad financial outcomes. Second, being faced with poor money management and bad financial outcomes may also cause negative emotions. Finally, a third unmeasured variable may have caused both. To examine the effect of emotions on money management and financial outcomes, we would need to randomly assign participants to interventions that reduce negative emotions or a no-intervention control group, and test the effect of subsequent money management and financial outcomes. In addition, three of our eight measures have a Cronbach's alpha value below 0.7. We use established measures and also look at the inter-item correlations for credit card repayment for example, but of course have to treat our results with caution.

Another limitation is that our studies focused only on the financial context. Perhaps as a result of the financial context, we did not replicate age differences in motivation and numeracy (Bruine de Bruin et al. 2015). Previous research found that older adults are motivated to put effort into complex tasks when they perceive the context as personally relevant, but become less motivated when they perceive the context as lacking personal irrelevance (Hess 2014; Strough, Bruine de Bruin and Peters 2015). Older adults perform worse on numeracy tasks, in part because of their lower motivation (Bruine de Bruin et al. 2015). Due to its personal relevance, financial decision making may not be plagued by age differences in motivation. 
Yet, our findings have potential implications for promoting better financial decision making across the lifespan, including through ongoing efforts at the UK's Money Advice Service (Bagwell, Hestbaek, Harries, and Kail 2014), and the US Consumer Finance Protection Bureau (2015). Communications that aim to improve older adults' financial decisions may be more effective if they rely more on experience and emotions rather than on cognitively demanding facts (Williams and Drolet 2005). Additionally, young adults may benefit from building experience-based knowledge and emotional skills as part of financial education programs (see also Fernandes et al. 2014). Those individual-differences characteristics may also be developed through early exposure to financial decisions, such as youth savings accounts (Shobe and Sturm 2007). Such efforts should be carefully designed to address the needs of the specific audience, by helping them to overcome any weaknesses and building on their strengths (Bruine de Bruin and Bostrom 2013). Important to note here is that some financial decisions that older adults need to take are new decisions, highly complex and require computational skills (such as deciding on how to use retirement savings in the payout phase during retirement). Since we found that older adults are not better at credit card repayment, a task where numerical skills are most important, older adults may benefit from programs that help them to train their cognitive functions. Exchanging experiences with peers and reading leaflets that attend them to possible financial abuse scenarios (Financial Consumer Protection Bureau 2017), can also improve older adults' financial well-being. Evaluating such efforts could help us to understand how to best improve financial decisions across the lifespan. 



\section{chapter $\mathbf{5}$}

Conclusion 



\section{CONCLUSION}

Ignorance within the household financial decision making domain is costly. In order to be able to make good financial decisions about for example retirement, mortgages, and credit cards, information search is naturally the first step. However, comparable to postponing your dentist visit even when you know that it is important for your dental health, many consumers actively avoid financial information - even when they are aware that this information is freely available and useful (Golman et al. 2017). Individuals acquire information differently, which means that the way one makes sense of a piece of information may be just as (if not more) important than the specific content of the information. In line with that, subjective financial well-being or "the perception of being able to sustain current and anticipated desired living standards and financial freedom" (Brüggen et al. 2017) is often more telling than the value of financial wealth that consumers have acquired.

These differences in information search underline the importance of beliefs that we look at in chapter 2 when applying the Retirement Belief Model. Our findings from two field surveys with pension plan participants in the Netherlands and the United Kingdom show that looking at sociodemographic characteristics alone is insufficient to understand who searches for retirement related information and who does not. This is in general in line with previous research on psychological determinants for long-term decisions (e.g. Binswanger and Carman 2012). We contribute to the literature by building a unifying model for the search for retirement information. This model performs well within these two different country contexts with different pension systems. We show that beliefs and emotions, that is perceived benefits of information search, barriers such as the time and money it costs to get informed, severity, retirement anxiety and trust play a major role in driving information search.

Applying the Retirement Belief Model for segmentation purposes within the Dutch context shows how important it is to understand participants' background: for both the first (the overconfident) and the third (the alpha males) segment, self-efficacy (the belief that one can find information and understand it) has a negative relationship with information search intention. However, the overconfident have low levels of financial literacy and are not yet informed about retirement - they simply overestimate their abilities. In contrast, the alpha males are already informed and are not planning to do so again in the near future. Our findings underline that understanding heterogeneity of participants matters, and subsequently underline the need to approach these consumers differently with adapted communication.

In chapter 3, we look into what difference framing can make in triggering pension plan participants to search for retirement information. The way that information is formulated has been shown to influence retirement related behaviors such as risk taking when investing for retirement (Bateman et al., 2015), annuity take-up (Agnew et al. 2008), watching educational videos on retirement planning (Grinstein and Kronrod 2016), and take-up of 
financial subsidies for retirement saving (Saez 2009). Within health promotion, loss frames (emphasizing that you lose if you do not act) have been shown to be more effective than gain frames (emphasizing that you gain if you do act; Block and Keller 1995). Conducting a series of experiments, we find that loss frames are also more effective in increasing information search intention, but that they also result in more negative emotions. Participants get stressed by these negative emotions, which could mean that on the long term, they will refrain from taking action after all. Consumers postpone decisions that they consider as unpleasant and make them feel bad (Greenleaf and Lehmann 1995), so stressing potential losses is not desirable in this situation.

Building on work of Brown et al. (2008; 2013), we develop two new frames: the investment frame (as gain frame alternative) emphasizes that pension plan participants can gain by investing in their future and searching for information, while the assurance frame (the loss frame alternative) stresses that participants can prevent negative consequences through the sense of security that they obtain when learning about their expected pension benefits. Testing these frames in a field experiment, we show that assurance frames are twice as effective as investment frames to motivate participants to click on a movie link (explaining pension scheme changes). In subsequent laboratory experiments, we do not find any differences in evaluation or negative emotions.

These text frames can be used by pension providers at low costs. Since pension providers in the Netherlands are legally obliged to communicate with their plan participants, and annual administration costs can be up to $1.2 \%$ of pension fund assets (Bikker and De Dreu 2009), it is important to find cost effective ways to communicate. With technological developments on the horizon that offer more potential for personalized pension communication, knowledge on which frame is the most effective for which participant becomes even more important. Future research can look more into new technological developments within smart services and artificial intelligence. Here it is important to consider that, since many financial service providers face low levels of trust (Hansen 2012), tailoring communication could also backfire if participants feel that providers know too much about them or use their private information for marketing purposes. Within social norms framing this has been shown by Beshears et al. (2015), so an interesting avenue for future research would be to investigate this further and develop appropriate segment specific frames of information.

In chapter 4 , we look at how older adults differ from younger adults in their financial decision making. Past research has shown that cognitive skills such as numeracy decline with age (e.g. Bruine de Bruin et al. 2015; Lusardi and Mitchell 2014), which suggests that older adults may find it even harder to make financial decisions. However, we find that older adults perform better than younger adults on four different types of financial decision making measures (resistance to sunk costs, credit card repayment, money management and financial decision outcome inventory). 
This effect holds after adding two cognitive characteristics (numeracy and experiencebased knowledge), and two non-cognitive characteristics (negative emotions and motivation). Older adults' advantage comes mainly from their increased experience-based knowledge and lower levels of negative emotions. Older adults have been through difficult (financial) situations already and are better able to regulate their emotions (Carstensen 2006). Communicating with older adults can be more effective when being focused on emotions and experience instead of on cognitively demanding exercises (Williams and Drolet 2005). In contrast, younger adults can benefit from building up experience-based knowledge and emotional skills in financial education programs (see also Fernandes et al. 2014), or early exposure to financial decisions, such as youth savings accounts (Shobe and Sturm 2007). When carefully evaluated, such communication campaigns and educational programs can further help understanding how to best enhance consumer financial decision making. 

References 


\section{REFERENCES}

\section{A}

Acierno, Ron, et al. (2010), "Prevalence and correlates of emotional, physical, sexual, and financial abuse and potential neglect in the United States: The National Elder Mistreatment Study." American Journal of Public Health, 100.2: 292-297.

Ackert, Lucy F., Bryan K. Church, and Richard Deaves (2003), "Emotion and financial markets." Economic Review-Federal Reserve Bank of Atlanta, 88.2: 33.

Adams, Gary A., and Barbara L. Rau (2011), "Putting off tomorrow to do what you want today: planning for retirement." American Psychologist, 66.3, 180.

Agarwal, Sumit, et al. (2014), "Regulating consumer financial products: Evidence from credit cards." The Quarterly Journal of Economics 130.1: 111-164.

Agarwal, Sumit, et al. (2009), "The age of reason: Financial decisions over the life cycle and implications for regulation." Brookings Papers on Economic Activity, 2009.2: 51-117.

Agnew, Julie R., et al. (2008), "Who chooses annuities? An experimental investigation of the role of gender, framing, and defaults." The American Economic Review 98.2: 418-422.

Ajzen, Icek (1991), "The theory of planned behavior." Organizational behavior and human decision processes, 50.2, 179-211.

Ajzen, Icek, and Martin Fishbein (2000), "Attitudes and the attitude-behavior relation: Reasoned and automatic processes." European Review of Social Psychology, 11.1: 1-33.

Alessie, Rob, Maarten Van Rooij, and Annamaria Lusardi (2011), "Financial literacy and retirement preparation in the Netherlands." Journal of Pension Economics \& Finance, 10.4, 527-545.

Amar, Moty, Dan Ariel, Shahar Ayal, Cynthia E. Cryder and Scott I. Rick (2011), "Winning the battle but losing the war: The psychology of debt management." Journal of Marketing Research, 48.SPL: S38-S50.

Anderson, Laurel, Amy L. Ostrom, Canan Corus, Raymond P. Fisk, Andrew S. Gallan, Mario Giraldo, Martin Mende, Mark Mulder, Steven W. Rayburn, Mark S. Rosenbaum, Kunio Shirahada, and Jerome D. Williams (2013), "Transformative Service Research: An Agenda for the Future," Journal of Business Research, 66 (8), 1203-1210.

Apanovitch, Anne Marie, Danielle McCarthy, and Peter Salovey (2003), "Using Message Framing to Motivate HIV Testing among Low-Income, Ethnic Minority Women," Health Psychology, 22 (1), 60-67.

Augenblick, Ned, Muriel Niederle, and Charles Sprenger (2015), "Working over time: Dynamic inconsistency in real effort tasks." The Quarterly Journal of Economics, 130.3, 1067-1115.

\section{B}

Bagwell, Sally, Cecilie Hestbaek, Ellen Harries, and Angela Kail (2014), "Financial capabilitystrategy for the UK" (report commissioned by money advice service). Retrieved from: http://www.thinknpc. org/wp-content/uploads/2014/09/Financial-Capability-Outcome-Frameworks-MAS.pdf

Bajtelsmit, Vickie L., Alexandra Bernasek, and Nancy A. Jianakoplos (1999), "Gender differences in defined contribution pension decisions." Financial Services Review, 8.1, 1-10.

Baltes, Paul B., Patricia A. Reuter-Lorenz, and Frank Rösler, eds. (2006), "Lifespan development and the brain: The perspective of biocultural co-constructivism." Cambridge: Cambridge University Press.

Bandura, A. (1994). Self-efficacy. In V. S. Ramachaudran (Ed.), Encyclopedia of human behavior (Vol. 4, pp. 71-81). New York: Academic Press. 
Bateman, Hazel, Ralph Stevens, and Andy Lai (2015), "Risk information and retirement investment choice mistakes under prospect theory." Journal of Behavioral Finance 16.4: 279-296.

Benartzi, Shlomo, et al. (2017), "Should Governments Invest More in Nudging?." Psychological Science: 0956797617702501.

Beshears, John, et al. (2015), "The effect of providing peer information on retirement savings decisions." The Journal of Finance, 70.3: 1161-1201.

Beshears, John, et al. (2010), "The impact of employer matching on savings plan participation under automatic enrollment." Research findings in the economics of aging. University of Chicago Press: 311-327.

Binswanger, Johannes, and Katherine Grace Carman (2012), "How real people make long-term decisions: The case of retirement preparation." Journal of Economic Behavior \& Organization 81.1: 39-60.

Blanchard-Fields, Fredda (2007), "Everyday problem solving and emotion: An adult developmental perspective." Current Directions in Psychological Science, 16.1: 26-31.

Block, Lauren G., and Punam Anand Keller (1995), "When to accentuate the negative: The effects of perceived efficacy and message framing on intentions to perform a health-related behavior." Journal of Marketing Research, 192-203.

Bodie, Zvi, Alan J. Marcus, and Robert C. Merton (1988), "Defined Benefit versus Defined Contribution Pension Plans: What are the Real Trade-Offs?", In: Pensions in the U.S. Economy, University of Chicago Press.

Bonsang, Eric, and Thomas Dohmen (2015), "Risk attitude and cognitive aging." Journal of Economic Behavior \& Organization, 112: 112-126.

Booij, Adam S., and Bernard MS Van Praag (2009), "A simultaneous approach to the estimation of risk aversion and the subjective time discount rate." Journal of Economic Behavior \& Organization, 70.1, 374-388.

Bovenberg, Lans, and Raymond Gradus, (2015), "Reforming occupational pension schemes: the case of the Netherlands." Journal of Economic Policy Reform, 18.3, 244-257.

Brislin, Richard W. (1980). "Translation and content analysis of oral and written materials. In HC Triandis \& Jw Berry (Eds.), Handbook of crosscultural psychology: Vol. 2. Methodology, 389-444.

Brounen, Dirk, Kees G. Koedijk, and Rachel A.J. Pownall (2016), "Household financial planning and savings behavior." Journal of International Money and Finance, 69: 95-107.

Brown, Jeffrey R., et al. (2008), "Why don't people insure late life consumption: A framing explanation of the under-annuitization puzzle." American Economic Review: Papers \& Proceedings, 98:2, 304 309.

Brown, Jeffrey R., Arie Kapteyn, and Olivia S. Mitchell (2016), "Framing and Claiming: How InformationFraming Affects Expected Social Security Claiming Behavior," Journal of Risk and Insurance, 83 (1), 139-62.

Bruine de Bruin, Wändi, and Ann Bostrom (2013), "Assessing what to address in science communication." Proceedings of the National Academy of Sciences, 110. Supplement 3: 14062-14068.

Bruine de Bruin, Wändi, Wilbert van der Klaauw, Julie S. Downs, Baruch Fischhoff, Giorgio Topa, and Olivier Armantier (2010), "Expectations of inflation: The role of financial literacy and demographic variables." Journal of Consumer Affairs, 44.1:381.

Bruine de Bruin, Wändi (2016). Ageing and economic decision making. In R. Ranyard (Eds.) Economic Psychology: The Science of Economic Mental Life and Behaviour. British Psychological Society Textbook series. Wiley-Blackwell. 
Bruine de Bruin, Wändi, Andrew M. Parker, and JoNell Strough (2016), "Choosing to be happy? Age differences in "maximizing" decision strategies and experienced emotional well-being." Psychology and Aging, 31.3: 295.

Bruine de Bruin, Wändi, Andrew M. Parker, and Baruch Fischhoff (2007), "Individual differences in adult decision-making competence." Journal of Personality and Social Psychology, 92.5: 938.

Bruine de Bruin, Wändi, JoNell Strough, and Andrew M. Parker (2014), "Getting older isn't all that bad: Better decisions and coping when facing "sunk costs"." Psychology and Aging 29.3: 642.

Bruine de Bruin, Wändi, Simon J. McNair, Andrea L. Taylor, Barbara Summers, and JoNell Strough (2015), "“Thinking about Numbers Is Not My Idea of Fun" Need for Cognition Mediates Age Differences in Numeracy Performance." Medical Decision Making, 35.1: 22-26.

Brüggen, Elisabeth C., Jens Hogreve, Maria Holmlund, Sertan Kabadayi, and Martin Löfgren, (2017), "Financial well-being: A conceptualization and research agenda." Journal of Business Research, forthcoming.

Bucher-Koenen, Tabea, and Annamaria Lusardi (2011), "Financial literacy and retirement planning in Germany." Journal of Pension Economics \& Finance, 10.4, 565-584.

\section{C}

Carstensen, Laura L. (2006), "The influence of a sense of time on human development." Science, 312.5782: 1913-1915.

Carstensen, Laura L., et al. (2000), "Emotional experience in everyday life across the adult life span." Journal of Personality and Social Psychology, 79.4: 644.

CBS (2015), "Overall household debt marginally up." Retrieved from https://www.cbs.nl/en-gb/ news/2015/28/overall-household-debt-marginally-up

Célérier, Claire and Boris Vallée (2013), "What drives financial complexity? A look into the retail market for structured products." Retrieved February 28 $8^{\text {th }}, 2017$ from http://www.hbs.edu/faculty/ conferences/2013-household-behavior-risky-asset-mkts/Documents/What-Drives-FinancialComplexity_Celerier-Vallee.pdf

Chan, Sewin, and Ann Huff Stevens (2008), "What you don't know can't help you: Pension knowledge and retirement decision-making." The Review of Economics and Statistics, 90.2, 253-266.

Charles, Susan T., and Laura L. Carstensen (2010), "Social and emotional aging." Annual Review of Psychology, 61: 383-409.

Charles, Susan Turk, Chandra A. Reynolds, and Margaret Gatz (2001), "Age-related differences and change in positive and negative affect over 23 years." Journal of Personality and Social Psychology, 80.1: 136 .

Cheema, Amar, and Rajesh Bagchi (2011), "The effect of goal visualization on goal pursuit: Implications for consumers and managers." Journal of Marketing 75.2, 109-123.

Chin, Wynne W. (2000), "Frequently asked questions-partial least squares \& PLS-graph." Home Page. [On-line]. Available: http://disc-nt.cba.uh.edu/chin/plsfaq.htm

Choi, James J., et al. (2003), "Optimal defaults." The American Economic Review, 93.2: 180-185.

Choi, James J., David I. Laibson, and Brigitte C. Madrian (2005), "Are empowerment and education enough? Underdiversification in 401 (k) plans." Brookings Papers on Economic Activity, 2005.2: $151-213$.

Churchill Jr, Gilbert A. (1979), "A paradigm for developing better measures of marketing constructs." Journal of Marketing Research, 64-73.

Clark, Gordon L., and Janelle Knox-Hayes (2007), "Mapping UK pension benefits and the intended purchase of annuities in the aftermath of the 1990s stock market bubble." Transactions of the Institute of British Geographers, 32.4, 539-555. 
Clark, Gordon L., Kendra Strauss, and Janelle Knox-Hayes (2012), Saving for retirement: Intention, context, and behavior. Oxford: Oxford University Press.

Conner, Mark, and Christopher J. Armitage (1998), "Extending the theory of planned behavior: A review and avenues for further research." Journal of Applied Social Psychology, 28.15, 1429-1464.

Consumer Financial Protection Bureau (2015), Financial well-being: The goal of financial education. Retrieved from: http://files.consumerfinance.gov/f/201501_cfpb_report_financial-well-being.pdf

Consumer Financial Protection Bureau (2017), Money Smartfor Older Adults. Resource Guide. Retrieved from: http://files.consumerfinance.gov/f/documents/201703_cfpb_money-smart-for-olderadults-resource-guide.pdf

Cox, Dena, and Anthony D. Cox (2001), "Communicating the consequences of early detection: The role of evidence and framing." Journal of Marketing 65.3: 91-103.

D

Danaher, Peter J. (1998), "Customer heterogeneity in service management." Journal of Service Research, 1.2, 129-139.

Davidoff, Thomas, Patrick Gerhard, and Thomas Post (2017), "Reverse mortgages: What homeowners (don't) know and how it matters." Journal of Economic Behavior \& Organization, 133: 151-171.

Decarlo, Lawrence T. (2003), "Using the PLUM procedure ofSPSS to fit unequal variance and generalized signal detection models." Behavior Research Methods, 35.1: 49-56.

Del Missier, Fabio, Timo Mäntylä, and Wändi Bruine Bruin (2012), "Decision-making competence, executive functioning, and general cognitive abilities." Journal of Behavioral Decision Making, 25.4: $331-351$.

Del Missier, Fabio, et al. (2013), "The multifold relationship between memory and decision making: An individual-differences study." Journal of Experimental Psychology: Learning, Memory, and Cognition, 39.5: 1344.

Del Missier, Fabio, et al. (2017), "Unraveling the Aging Skein: Disentangling Sensory and Cognitive Predictors of Age-related Differences in Decision Making." Journal of Behavioral Decision Making, 30.1: 123-139.

DeMartino, Benedetto, et al. (2006), "Frames, biases, and rational decision-making in the human brain." Science 313.5787: 684-687.

Detweiler, Jerusha B., et al. (1999), "Message framing and sunscreen use: gain-framed messages motivate beach-goers." Health Psychology 18.2: 189.

Dohmen, Thomas, Armin Falk, David Huffman, Uwe Sunde, Jürgen Schupp, and Gert G. Wagner (2011), "Individual risk attitudes: Measurement, determinants, and behavioral consequences." Journal of the European Economic Association, 9.3, 522-550.

Dolls, Mathias, Philipp Doerrenberg, Andreas Peichl, and Holger Stichnoth (2018), "Do Savings Increase in Response to Salient Information about Retirement and Expected Pensions?" Journal of Public Economics, 158, 168-179.

Dushi, Irena, and Marjorie Honig (2015), "How much do respondents in the health and retirement study know about their contributions to tax-deferred contribution plans? A cross-cohort comparison." Journal of Pension Economics \& Finance, 14.3, 203-239.

\section{$\mathrm{E}$}

Ellen, Pam Scholder, Joshua L. Wiener, and M. Paula Fitzgerald (2012), "Encouraging people to save for their future: Augmenting current efforts with positive visions of the future." Journal of Public Policy \& Marketing, 31.1, 58-72.

Ericsson, K. Anders, Michael J. Prietula, and Edward T. Cokely (2007), "The making of an expert." Harvard Business Review, 85.7/8: 114. 
Feldman, Daniel C., and Terry A. Beehr (2011), "A three-phase model of retirement decision making." American Psychologist, 66.3, 193.

Fernandes, Daniel, John G. Lynch Jr, and Richard G. Netemeyer (2014), "Financial literacy, financial education, and downstream financial behaviors." Management Science, 60.8, 1861-1883.

Financial Conduct Authority (2017). Retrieved from https://www.fca.org.uk/publications/marketstudies/retirement-outcomes-review

Financial Times (2017) "Why is consumer debt hitting the headlines?" Retrieved from https://www. ft.com/content/f6992568-4149-11e7-9d56-25f963e998b2?mhq5j=e2

Finucane, Melissa L., et al. (2005), "Task complexity and older adults' decision-making competence." Psychology and Aging, 20.1: 71.

Fischhoff, Baruch (1998), "What do patients want? Help in making effective choices." Effective clinical practice: ECP2.4: 198-200.

Fornell, Claes, and David F. Larcker (1981), "Evaluating structural equation models with unobservable variables and measurement error." Journal of Marketing Research, 39-50.

\section{G}

Gal, David, and Blakeley B. McShane (2012), "Can small victories help win the war? Evidence from consumer debt management." Journal of Marketing Research, 487-501.

Gamble, Keith Jacks, et al. (2014), "Aging and financial decision making." Management Science, 61.11: 2603-2610.

Garđarsdóttir, Ragna B., and Helga Dittmar (2012), "The relationship of materialism to debt and financial well-being: The case of Iceland's perceived prosperity." Journal of Economic Psychology, 33.3: 471-481.

Gerend, Mary A. and Janet E. Shepherd (2007), "Using Message Framing to Promote Acceptance of The Human Papillomavirus Vaccine," Health Psychology, 26 (6), 745.

GfK (2014). Pensioenmonitor 2013. GfK Netherlands.

Glanz, Karen, Barbara K. Rimer, and Kasisomayajula Viswanath, eds. (2015). Health behavior: theory, research, and practice. Jossey-Bass.

Golman, Russell, David Hagmann, and George Loewenstein (2017), "Information avoidance." Journal of Economic Literature, 55(1), 96-135.

Gough, Orla, and Claudia Niza (2011), "Retirement saving choices: review of the literature and policy implications." Journal of Population Ageing, 4.1-2: 97.

Greenleaf, Eric A., and Donald R. Lehmann (1995), "Reasons for substantial delay in consumer decision making." Journal of Consumer Research 22.2: 186-199.

Grispen, Janaica EJ, Gaby Ronda, Geert-Jan Dinant, Nanne K de Vries, and Trudy van der Weijden (2011), "To test or not to test: a cross-sectional survey of the psychosocial determinants of self-testing for cholesterol, glucose, and HIV." BMC Public Health, 11.1, 112.

Grundy, Emily, and John C. Henretta (2006), "Between elderly parents and adult children: a new look at the intergenerational care provided by the 'sandwich generation'." Ageing \& Society, 26.5: 707-722.

Gubler, Timothy, and Lamar Pierce (2014), "Healthy, wealthy, and wise: Retirement planning predicts employee health improvements." Psychological Science, 25.9, 1822-1830.

Guiso, Luigi, Paola Sapienza, and Luigi Zingales (2008), "Trusting the stock market." The Journal of Finance, 63.6:2557-2600.

Gustman, Alan L., Thomas L. Steinmeier, and Nahid Tabatabai (2012), "Financial knowledge and financial literacy at the household level." The American Economic Review, 102.3, 309-313. 


\section{$\mathrm{H}$}

Hahn, Carsten, Michael D. Johnson, Andreas Herrmann, and Frank Huber (2002), "Capturing customer heterogeneity using a finite mixture PLS approach." Schmalenbach Business Review, 54, 243-269.

Hair, Joseph F., Christian M. Ringle, and Marko Sarstedt (2011), “PLS-SEM: Indeed a silver bullet.” Journal of Marketing Theory and Practice, 19.2, 139-152.

Hair, Joseph F., Tomas M. Hult, Christian M. Ringle, and Marko Sarstedt (2016), A primer on partial least squares structural equation modeling (PLS-SEM). Chicago: Sage Publications.

Hansen, Torben (2012), "Understanding trust in financial services: the influence of financial healthiness, knowledge, and satisfaction." Journal of Service Research, 15.3, 280-295.

Hastings, Justine S., Olivia S. Mitchell, and Eric T. Chyn (2010), "Fees, framing, and financial literacy in the choice of pension manager." Pension Research Council WP2010-09.

Haveman, Robert, Rebecca Blank, Robert Moffitt, Timothy Smeeding, and Geoffrey Wallace (2015), “The War on Poverty: 50 Years Later." Journal of Policy Analysis and Management 34.3: 593-638.

Hayes, Andrew F. (2013), Introduction to mediation, moderation, and conditional process analysis: A regression-based approach. Guilford Press.

Hayslip, Bert, Michael Beyerlein, and Judith A. Nichols (1997), "Assessing anxiety about retirement: The case of academicians." The International Journal of Aging and Human Development, 44.1, 15-36.

Henseler, Jörg, Christian M. Ringle, and Marko Sarstedt (2015), “Anew criterion for assessing discriminant validity in variance-based structural equation modeling." Journal of the Academy of Marketing Science, 43.1 (2015), 115-135.

Hershey, Douglas A., Joy M. Jacobs-Lawson, and Kirstan A. Neukam (2002), "Influences of age and gender on workers' goals for retirement." The International Journal of Aging and Human Development, 55.2, 163-179.

Hershey, Douglas A., and Joy M. Jacobs-Lawson (2012), "Bridging the gap: Anticipated shortfalls in future retirement income." Journal of Family and Economic Issues, 33.3, 306-314.

Hershey, Douglas A., James T. Austin, and Helen C. Gutierrez (2015), "Financial decision making across the adult life span: Dynamic cognitive capacities and real-world competence." Aging and decision making: Empirical and applied perspectives, 329-349.

Hershfield, Hal E., Daniel G. Goldstein, William F. Sharpe, Jesse Fox, Leo Yeykelis, Laura L. Carstensen, and Jeremy N. Bailenson (2011), "Increasing saving behavior through age-progressed renderings of the future self." Journal of Marketing Research, 48, S23-S37.

Hess, Thomas M., Tara L. Queen, and Gilda E. Ennis (2012), "Age and self-relevance effects on information search during decision making." Journals of Gerontology Series B: Psychological Sciences and Social Sciences, 68.5: 703-711.

Hess, Thomas M. (2014), "Selective engagement of cognitive resources: Motivational influences on older adults' cognitive functioning." Perspectives on Psychological Science, 9.4:388-407.

HSBC (2015), "The Future of Retirement - A Balancing Act", Global Report.

\section{$\mathrm{J}$}

Janz, Nancy K., and Marshall H. Becker (1984), "The health belief model: A decade later." Health Education Quarterly, 11.1, 1-47.

Jarvis, Cheryl Burke, Scott B. MacKenzie, and Philip M. Podsakoff (2003), "A critical review of construct indicators and measurement model misspecification in marketing and consumer research." Journal of Consumer Research, 30.2, 199-218.

Jin, Wenchao Michelle, et al. (2011), "Poverty and Inequality in the UK: 2011." London: The Institute for Fiscal Studies. 
Joo, So-hyun, and John E. Grable (2004), "An exploratory framework of the determinants of financial satisfaction." Journal of Family and Economic Issues, 25.1:25-50.

\section{K}

Karlan, Dean, Margaret McConnell, Sendhil Mullainathan, and Jonathan Zinman (2016), "Getting on top of mind: how reminders increase saving." Management Science 62.12: 3393-3411.

Keller, Punam Anand, and Donald R. Lehmann (2008), "Designing effective health communications: a meta-analysis." Journal of Public Policy \& Marketing 27.2: 117-130.

Kemp, Candace L., Carolyn J. Rosenthal, and Margaret Denton (2005), "Financial planning for later life: Subjective understandings of catalysts and constraints." Journal of Aging Studies, 19.3, 273-290.

Keren, Gideon, and Wändi Bruine De Bruin (2003), "Ontheassessment of decision quality: Considerations regarding utility, conflict and accountability." Thinking: Psychological perspectives on reasoning, judgment and decision making, 347.

Kiersz, A. (2014). This is when you're going to die. Business Insider Finance, Retrieved July $6^{\text {th }}, 2017$ from http://www.businessinsider.com/social-security-life-table-charts-20143? international $=$ true $\& r=U S \& I R=T$

Krijnen, Job MT, Marcel Zeelenberg, and Seger M. Breugelmans (2015), “Decision importance as a cue for deferral." Judgment and Decision Making, 10.5: 407.

Knoef, Marike, Jim Been, Rob Alessie, Koen Caminada, Kees Goudswaard, and Adriaan Kalwij (2016), "Measuring retirement savings adequacy: developing a multi-pillar approach in the Netherlands." Journal of Pension Economics \& Finance, 15.1, 55-89.

Kovalchik, Stephanie, et al. (2005), "Aging and decision making: A comparison between neurologically healthy elderly and young individuals." Journal of Economic Behavior \& Organization, 58.1: 79-94.

L

Laibson, David (1997), "Golden eggs and hyperbolic discounting." The Quarterly Journal of Economics, 112.2: 443-478.

Lambert-Pandraud, Raphaëlle, and Gilles Laurent (2010), "Why do older consumers buy older brands? The role of attachment and declining innovativeness." Journal of Marketing, 74.5: 104-121.

Lambert-Pandraud, Raphaëlle, Gilles Laurent, and Eric Lapersonne (2005), "Repeat purchasing of new automobiles by older consumers: empirical evidence and interpretations." Journal of Marketing, 69.2: 97-113.

Levin, Irwin P., Sandra L. Schneider, and Gary J. Gaeth (1998), "All frames are not created equal: A typology and critical analysis of framing effects." Organizational Behavior and Human Decision Processes $76.2: 149-188$.

$\mathrm{Li}$, Ye, et al. (2013), "Complementary cognitive capabilities, economic decision making, and aging." Psychology and Aging, 28.3: 595.

$\mathrm{Li}, \mathrm{Ye}$, et al. (2015), "Sound credit scores and financial decisions despite cognitive aging." Proceedings of the National Academy of Sciences, 112.1: 65-69.

Lindbeck, Assar, and Mats Persson (2003), "The gains from pension reform." Journal of Economic Literature, 41.1: 74-112.

Lindenberger, Ulman, et al. (2011), “Cross-sectional age variance extraction: what's change got to do with it?." Psychology and Aging, 26.1:34.

Loewenstein, George F., Elke U. Weber, Christopher K. Hsee, and Ned Welch (2001), "Risk as feelings." Psychological Bulletin, 127.2, 267.

Lusardi, Annamaria, and Olivia S. Mitchell (2007), "Financial literacy and retirement preparedness: Evidence and implications for financial education." Business Economics, 42.1: 35-44. 
Lusardi, Annamaria, Punam Anand Keller, and Adam M. Keller (2009), New ways to make people save: a social marketing approach. No. w14715. National Bureau of Economic Research.

Lusardi, Annamaria, and Olivia S. Mitchell (2011), "Financial literacy around the world: an overview." Journal of Pension Economics \& Finance, 10.4, 497-508.

Lusardi, Annamaria (2012), Numeracy, financial literacy, and financial decision-making. No. w17821. National Bureau of Economic Research.

Lusardi, Annamaria, and Olivia S. Mitchell (2014), "The economic importance of financial literacy: Theory and evidence." Journal of Economic Literature, 52.1, 5-44.

Lynch Jr, John G., Richard G. Netemeyer, Stephen A. Spiller, and Alessandra Zammit (2009), "A generalizable scale of propensity to plan: the long and the short of planning for time and for money." Journal of Consumer Research, 37.1, 108-128.

\section{M}

Manoli, Day, and Andrea Weber (2016), "Nonparametric evidence on the effects of financial incentives on retirement decisions." American Economic Journal: Economic Policy, 8.4: 160-182.

Mather, Mara, and Laura L. Carstensen (2005), "Aging and motivated cognition: The positivity effect in attention and memory." Trends in Cognitive Science, 9.10: 496-502.

Maxwell, Scott E., and David A. Cole (2007), "Bias in cross-sectional analyses of longitudinal mediation." Psychological Methods, 12.1: 23.

McArdle, John J., James P. Smith, and Robert Willis (2009), Cognition and economic outcomes in the Health and Retirement Survey. No. w15266. National Bureau of Economic Research.

McKenzie, Craig RM, and Michael J. Liersch (2011), "Misunderstanding savings growth: Implications for retirement savings behavior." Journal of Marketing Research, 48.SPL: S1-S13.

McNair, Simon, Barbara Summers, Wändi Bruine de Bruin, and Rob Ranyard (2016), "Individual-level factors predicting consumer financial behavior at a time of high pressure." Personality and Individual Differences, 99:211-216.

Mende, Martin, and Jenny Van Doorn (2015), "Coproduction of transformative services as a pathway to improved consumer well-being: Findings from a longitudinal study on financial counseling." Journal of Service Research, 18.3, 351-368.

Mercer (2016). Melbourne Mercer Global Pension Index. Mercer Australian Centre for Financial Studies. Mercer (2017). Melbourne Mercer Global Pension Index. Mercer Australian Centre for Financial Studies.

Merkle, Christoph, Philipp Schreiber, and Martin Weber (2017), "Framing and retirement age: The gap between willingness-to-accept and willingness-to-pay." Economic Policy October: 757-809.

Montgomery, Nicole Votolato, Lisa R. Szykman, and Julie R. Agnew (2011), "Temporal Distance to Retirement and Communication Framing: Enhancing Retirement Financial Decision Making." Available at SSRN.

Morgan, Robert M., and Shelby D. Hunt (1994), "The commitment-trust theory of relationship marketing." The Journal of Marketing, 20-38.

Munnell, Alicia H., Wenliang Hou, and Anthony Webb (2015), "National Retirement Risk Index (NRRI) Update Shows Half of Working-Age Americans Still Falling Short." The Journal of Retirement, 3.2, 34-42.

\section{O}

OECD Pensions Outlook. 2016. “OECD Pensions Outlook 2016”. OECD Publishing, Paris. http://dx.doi. org/10.1787/pens_outlook-2016-en

Office for National Statistics (2014). Ageing of the UK population. Retrieved March 21 ${ }^{\text {st }} 2016$, from http:// webarchive.nationalarchives.gov.uk/20160105160709/http://www.ons.gov.uk/ons/rel/pop- 
estimate/population-estimates-for-uk--england-and-wales--scotland-and-northern-ireland/ mid-2014/sty-ageing-of-the-uk-population.html

Office for National Statistics (2015), Nowcasting household income in the UK. Retrieved March $21^{\text {st }} 2016$, from http://www.ons.gov.uk/peoplepopulationandcommunity/personalandhouseholdfinances/ incomeandwealth/bulletins/nowcastinghouseholdincomeintheuk/2015-10-28

$P$

Park, Denise C., et al. (2002), "Models of visuospatial and verbal memory across the adult life span." Psychology and Aging, 17.2: 299.

Park, Denise C., and Patricia Reuter-Lorenz (2009), "The adaptive brain: aging and neurocognitive scaffolding." Annual Review of Psychology, 60: 173-196.

Parker, Sharon M., et al. (2007), "A systematic review of prognostic/end-of-life communication with adults in the advanced stages of a life-limiting illness: patient/caregiver preferences for the content, style, and timing of information." Journal of Pain and Symptom Management, 34.1: 81-93.

Parker, Andrew M., Wändi Bruine de Bruin, and Baruch Fischhoff (2015), "Negative decision outcomes are more common among people with lower decision-making competence: an item-level analysis of the Decision Outcome Inventory (DOI)." Frontiers in Psychology, 6.

Peters, Ellen, et al. (2007), "Numeracy skill and the communication, comprehension, and use of riskbenefit information." Health Affairs, 26.3: 741-748.

Petty, Richard E., John T. Cacioppo, and Chuan Feng Kao (1984), "The efficient assessment of need for cognition." Journal of Personality Assessment, 48.3: 306-307.

Preacher, Kristopher J., and Andrew F. Hayes (2008), "Asymptotic and resampling strategies for assessing and comparing indirect effects in multiple mediator models." Behavior Research Methods, 40.3: 879-891.

Post, Thomas, Helmut Gründl, Joan T. Schmitt, and Anja Zimmer (2014), "The impact of investment behaviour for individual welfare." Economica, 81.321, 15-47.

\section{R}

Remund, David L. (2010), "Financial literacy explicated: The case for a clearer definition in an increasingly complex economy." Journal of Consumer Affairs, 44.2, 276-295.

Reyna, Valerie F. (2008), A theory of medical decision making and health: fuzzy trace theory." Medical Decision Making, 28.6: 850-865.

Reyna, Valerie F., et al. (2009), "How numeracy influences risk comprehension and medical decision making." Psychological Bulletin, 135.6: 943.

Ringle, Christian M., Sven Wende, and Jan-Michael Becker (2015), "SmartPLS3," www.smartpls.com.

Ringle, Christian M., Marko Sarstedt, and Erik A. Mooi (2010), "Response-based segmentation using finite mixture partial least squares." Data Mining, Springer US, 19-49.

Ringle, Christian M., Sven Wende, and Alexander Will (2010), "Finite mixture partial least squares analysis: Methodology and numerical examples." Handbook of partial least squares, 195-218.

Rosenstock, Irwin M. (2005), "Why people use health services." The Milbank Quarterly, 83.4.

Rosenstock, Irwin M. (1974), "The health belief model and preventive health behavior." Health Education Monographs, 2.4, 354-386.

Rothman, Alexander J., Roger D. Bartels, Jhon Wlaschin, and Peter Salovey (2006), "TheStrategic Use of Gain- and Loss-Framed Messages to Promote Healthy Behavior: How Theory Can Inform Practice," Journal of Communication, 56 (1), 202-20 
Saez, Emmanuel (2009), "Details matter: The impact of presentation and information on the take- up of financial incentives for retirement saving." American Economic Journal: Economic Policy, 1.1: 204-228.

Salthouse, Timothy A. (2004), "What and when of cognitive aging." Current Directions in Psychological Science, 13.4: 140-144.

Schaie, K. Warner (2005), "Developmental influences on adult intelligence: The Seattle longitudinal study", Oxford: Oxford University Press.

Schwartz, Barry (2004), "The paradox of choice: Why more is less.” New York: HarperCollins Publishers.

Schwartz, Lisa M., et al. (1997), "The role of numeracy in understanding the benefit of screening mammography." Annals of Internal Medicine, 127.11: 966-972.

Shim, Soyeon, et al. (2009), "Pathways to life success: A conceptual model of financial well- being for young adults." Journal of Applied Developmental Psychology, 30.6: 708-723.

Shiv, Baba, and Alexander Fedorikhin (1999), "Heart and mind in conflict: The interplay of affect and cognition in consumer decision making." Journal of Consumer Research, 26.3: 278-292.

Shobe, Marcia A., and Stephanie L. Sturm (2007), "Youth individual development accounts: Retirement planning initiatives." Children \& Schools, 29.3: 172-181.

Strough, JoNell, et al. (2008), "Are older adults less subject to the sunk-cost fallacy than younger adults?." Psychological Science, 19.7: 650-652.

Strough, JoNell, Tara E. Karns, and Leo Schlosnagle (2011), "Decision-making heuristics and biases across the life span." Annals of the New York Academy of Sciences, 1235.1: 57-74.

Strough, JoNell, et al. (2014), "No time to waste: Restricting life-span temporal horizons decreases the sunk-cost fallacy.” Journal of Behavioral Decision Making, 27.1: 78-94.

Strough, JoNell, Wändi Bruine de Bruin, and Ellen Peters (2015), "New perspectives for motivating better decisions in older adults." Frontiers in Psychology, 6.

Strough, J., Andrew M. Parker, and W. Bruine de Bruin (2015), "Understanding life-span developmental changes in decision-making competence." Aging and Decision making: Empirical and Applied Perspectives, : 235-257.

Sunden, Annika E., and Brian J. Surette (1998), "Gender differences in the allocation of assets in retirement savings plans." The American Economic Review, 88.2, 207-211.

Sütterlin, Stefan, et al. (2012), “Rumination and age: some things get better.” Journal of Aging Research.

\section{T}

Thaler, Richard H., and Shlomo Benartzi (2004), "Save more tomorrow ${ }^{\mathrm{TM}}$ : Using behavioral economics to increase employee saving.” Journal of Political Economy, 112.S1: S164-S187.

Thaler, Richard H. and Cass R. Sunstein (2008), "Nudge: Improving decisions about health, wealth, and happiness", Penguin, New Haven.

Thompson, Edmund R. (2007), "Development and validation of an internationally reliable short- form of the positive and negative affect schedule (PANAS)." Journal of Cross-Cultural Psychology, 38.2: 227-242.

TIAA-CREF (2014). TIAA-CREF Survey finds Americans spend less time planning their IRA investment than choosing a restaurant. Retrieved from https://www.tiaa.org/public/about- tiaa/news-press/ press-releases/pressrelease495.html

Toll, Benjamin A., et al. (2007), "Comparing gain-and loss-framed messages for smoking cessation with sustained-release bupropion: a randomized controlled trial." Psychology of Addictive Behaviors 21.4: 534 . 
Tversky, Amos, and Daniel Kahneman (1981), "The framing of decisions and the psychology of choice." Science, 211.4481, 453-458.

\section{U}

Ülkümen, Gülden, and Amar Cheema (2011), "Framing goals to influence personal savings: The role of specificity and construal level." Journal of Marketing Research, 48.6: 958-969.

UK government (2015). Ageing of the UK population. Retrieved April28 $8^{\text {th }}, 2016$ from http://webarchive. nationalarchives.gov.uk/20160105160709/http://www.ons.gov.uk/ons/rel/pop-estimate/ population-estimates-for-uk--england-and-wales--scotland-and-northern-ireland/mid-2014/ sty-ageing-of-the-uk-population.html

UK government (2016). Pensions Freedoms. Retrieved August $9^{\text {th }}, 2017$ from https://www.gov.uk/ government/news/pension-freedoms-used-over-a-million-times-to-access-76-billion

UN (2016). Global Issues: Ageing. Retrieved January 28th, 2016 from http://www.un.org/en/ globalissues/ageing/

\section{$\mathrm{V}$}

Van Rooij, Maarten CJ, Clemens JM Kool, and Henriëtte M. Prast (2007), "Risk-return preferences in the pension domain: are people able to choose?.” Journal of Public Economics, 91.3701-722.

Van Rooij, Maarten CJ, Annamaria Lusardi, and Rob JM Alessie (2011), "Financial literacy and retirement planning in the Netherlands." Journal of Economic Psychology, 32.4:593-608.

Van Rooij, Maarten CJ, Annamaria Lusardi, and Rob JM Alessie (2012), "Financial literacy, retirement planning and household wealth." The Economic Journal, 122.560, 449-478.

Van Schie, Ron J.G., Bas Donkers, and Benedict G.C. Dellaert (2012), "Savings adequacy uncertainty: Driver or obstacle to increased pension contributions?." Journal of Economic Psychology, 33.4, 882-896.

Van Solinge, Hanna, and Kène Henkens (2008), "Adjustment to and satisfaction with retirement: two of a kind?." Psychology and Aging, 23.2, 422.

Van 't Riet, Jonathan, Robert A.C. Ruiter, Marieke Q. Werrij, and Hein De Vries (2010), "Self- Efficacy Moderates Message-Framing Effects: The Case ofSkin-Cancer Detection," Psychologyand Health, 25 (3), 339-49.

Van Duijn, Mark, Mauro Mastrogiacomo, Maarten Lindeboom, and Petter Lundborg (2013), "Expected and actual replacement rates in the pension system of the Netherlands: how and why do they differ?." Journal of Pension Economics \& Finance, 12.2, 168-189.

Vinzi, V. E., Trinchera, L., and Amato, S. (2010). PLS Path Modeling: From Foundations to Recent Developments and Open Issues for Model Assessment and Improvement. Chapter 2 in V. Esposito et al. (eds.), Handbook of Partial Least Squares, Springer Handbooks of Computational Statistics.

\section{W}

Weller, Joshua A., et al. (2013), "Development and testing of an abbreviated numeracy scale: A Rasch analysis approach." Journal of Behavioral Decision Making, 26.2: 198-212.

Wijzer in Geldzaken (2016), Pensioenmonitor 2016. Een onderzoek naar kennis, houding en gedrag rondom de oudedagsvoorziening onder de Nederlandse beroepsbevolking.

Williams, Patti, and Aimee Drolet (2005), "Age-related differences in responses to emotional advertisements." Journal of Consumer Research, 32.3: 343-354.

Willis Tower Watson (2017), "Global Pension Assets Study 2017." Received from https://www. willistowerswatson.com/en/insights/2017/01/global-pensions-asset-study-2017 
Winterich, Karen Page, and Gergana Y. Nenkov (2015), "Save like the Joneses: how service firms can utilize deliberation and informational influence to enhance consumer well-being." Journal of Service Research, 18.3: 384-404.

\section{$\mathrm{X}$}

Xin Ding, David, Paul Jen-HWa Hu, Rohit Verma, and Don G. Wardell (2010), "The impact of service system design and flow experience on customer satisfaction in online financial services." Journal of Service Research, 13.1, 96-110.

\section{Z}

Zhou, Rongrong, and Michel Tuan Pham (2004). "Promotion and Prevention across Mental Accounts: When Financial Products Dictate Consumers\& Investment Goals." Journal of Consumer Research 31.1: 125-135. 

Addendum

\section{Appendices Valorization Addendum Summary Curriculum Vitae}




\section{APPENDICES}

A. Questionnaire (chapter 2)

Overview constructs

\begin{tabular}{|c|c|c|c|c|}
\hline \multirow{2}{*}{$\begin{array}{l}\text { Construct } \\
\text { Information } \\
\text { search intention }\end{array}$} & \multirow{2}{*}{$\begin{array}{l}\text { \# Items } \\
\text { Scale } \\
7\end{array}$} & \multirow{2}{*}{$\begin{array}{l}\text { Reference } \\
\text { Self-developed }\end{array}$} & \multicolumn{2}{|c|}{ Indicators } \\
\hline & & & (1) & $\begin{array}{l}\text { How big is the chance that you will look at your pension } \\
\text { situation in the upcoming months? }\end{array}$ \\
\hline & & & (2) & $\begin{array}{l}\text { I am planning to look up information about my pension } \\
\text { in the upcoming months. }\end{array}$ \\
\hline \multirow[t]{7}{*}{$\begin{array}{l}\text { Perceived } \\
\text { barriers }\end{array}$} & 7 & $\begin{array}{l}\text { Grispen et } \\
\text { al.(2011) }\end{array}$ & (1) & $\begin{array}{l}\text { The financial costs of seeking information about my } \\
\text { pension are a barrier to me. }\end{array}$ \\
\hline & & & (2) & $\begin{array}{l}\text { The time it costs to seek information about my pension } \\
\text { are a barrier to me. }\end{array}$ \\
\hline & & & (3) & $\begin{array}{l}\text { The efforts it costs to seek information about my } \\
\text { pension are a barrier to me. }\end{array}$ \\
\hline & & & (4) & $\begin{array}{l}\text { Seeking information would make me too concerned } \\
\text { with my financial situation during retirement. }\end{array}$ \\
\hline & & & (5) & $\begin{array}{l}\text { Being overly concerned about my financial situation } \\
\text { during retirement scares me. }\end{array}$ \\
\hline & & & (6) & $\begin{array}{l}\text { Just thinking about seeking information about my } \\
\text { pension scares me. }\end{array}$ \\
\hline & & & (7) & $\begin{array}{l}\text { Just thinking about seeking information about my } \\
\text { pension scares me. }\end{array}$ \\
\hline \multirow[t]{6}{*}{$\begin{array}{l}\text { Perceived } \\
\text { benefits }\end{array}$} & 7 & & (1) & $\begin{array}{l}\text { In my opinion, seeking information about your pension } \\
\text { is important. }\end{array}$ \\
\hline & & & (2) & $\begin{array}{l}\text { Seeking information about your pension means taking } \\
\text { responsibility for your own financial situation. }\end{array}$ \\
\hline & & & (3) & $\begin{array}{l}\text { Seeking information about your pension gives a feeling } \\
\text { of certainty about your own financial situation. }\end{array}$ \\
\hline & & & (4) & $\begin{array}{l}\text { By seeking information about my pension, I can reassure } \\
\text { myself. }\end{array}$ \\
\hline & & & (5) & $\begin{array}{l}\text { By seeking information about my pension, I can take } \\
\text { care of my own financial situation. }\end{array}$ \\
\hline & & & (6) & $\begin{array}{l}\text { It feels good to take responsibility for my own financial } \\
\text { situation. }\end{array}$ \\
\hline \multirow{3}{*}{$\begin{array}{l}\text { Perceived self- } \\
\text { efficacy }\end{array}$} & 7 & & (1) & Seeking information over my pension is difficult. \\
\hline & & & (2) & $\begin{array}{l}\text { When seeking information about my pension I would } \\
\text { miss professional assistance. }\end{array}$ \\
\hline & & & (3) & $\begin{array}{l}\text { If I would like to do something with the received information } \\
\text { about my pension I would miss professional assistance. }\end{array}$ \\
\hline $\begin{array}{l}\text { Perceived } \\
\text { severity }\end{array}$ & 7 & & (1) & $\begin{array}{l}\text { In your opinion, how severe is it to not save enough for } \\
\text { your retirement? }\end{array}$ \\
\hline $\begin{array}{l}\text { Perceived } \\
\text { susceptibility }\end{array}$ & 7 & & (1) & $\begin{array}{l}\text { In your opinion, what are the chances that you discover } \\
\text { that you are not saving enough for retirement? }\end{array}$ \\
\hline
\end{tabular}


A. (continued)

\section{Overview constructs}

\begin{tabular}{llll}
\hline Construct & $\begin{array}{l}\text { Items } \\
\text { Scale }\end{array}$ & Reference Indicators \\
&
\end{tabular}

\begin{tabular}{|c|c|c|c|c|}
\hline & & & (2) & $\begin{array}{l}\text { In your opinion what are the chances that you discover } \\
\text { that you are not saving enough for retirement, compared } \\
\text { to others of your age and gender? }\end{array}$ \\
\hline $\begin{array}{l}\text { Financial risk- } \\
\text { taking }\end{array}$ & 10 & $\begin{array}{l}\text { Dohmen et al. } \\
\text { (2011) }\end{array}$ & $(1)$ & $\begin{array}{l}\text { Are you in financial matters a person who is fully } \\
\text { prepared to take risks or do you try to avoid taking risks? }\end{array}$ \\
\hline $\begin{array}{l}\text { Trust financial } \\
\text { service provider }\end{array}$ & 7 & Hansen, (2012) & $(1)$ & I believe that my [name pension provider] is trustworthy \\
\hline \multirow[t]{6}{*}{$\begin{array}{l}\text { Propensity to } \\
\text { plan }\end{array}$} & \multirow[t]{6}{*}{7} & \multirow[t]{6}{*}{$\begin{array}{l}\text { Lynch et al. } \\
\text { (2010) }\end{array}$} & $(1)$ & $\begin{array}{l}\text { I set financial goals for the next 1-2 months for what I } \\
\text { want to achieve with my money. }\end{array}$ \\
\hline & & & $(2)$ & $\begin{array}{l}\text { I decide beforehand how my money will be used in } \\
\text { the next } 1-2 \text { months. }\end{array}$ \\
\hline & & & (3) & $\begin{array}{l}\text { I actively consider the steps I need to take to stick to my } \\
\text { budget in the next 1-2 months. }\end{array}$ \\
\hline & & & (4) & $\begin{array}{l}\text { I consult my budget to see how much money I have left } \\
\text { for the next 1-2 months. }\end{array}$ \\
\hline & & & $(5)$ & $\begin{array}{l}\text { I like to look to my budget for the next } 1-2 \text { months in } \\
\text { order to get a better view of my spending in the future. }\end{array}$ \\
\hline & & & (6) & $\begin{array}{l}\text { It makes me feel better to have to have my finances } \\
\text { planned out in the next 1-2 months. }\end{array}$ \\
\hline \multirow{5}{*}{$\begin{array}{l}\text { Retirement } \\
\text { anxiety }\end{array}$} & \multirow[t]{5}{*}{7} & \multirow{5}{*}{$\begin{array}{l}\text { Hayslip et al. } \\
\text { (1997) }\end{array}$} & $(1)$ & I am concerned about my health after retirement. \\
\hline & & & (2) & I am concerned about my income after retirement. \\
\hline & & & (3) & I am concerned about where I will live after retirement. \\
\hline & & & (4) & I am concerned about feeling alone after retirement. \\
\hline & & & $(5)$ & $\begin{array}{l}\text { I am concerned about being able to care for myself after } \\
\text { retirement. }\end{array}$ \\
\hline \multirow[t]{3}{*}{ Financial literacy } & & $\begin{array}{l}\text { Lusardi \& } \\
\text { Mitchell (2011) }\end{array}$ & $(1)$ & $\begin{array}{l}\text { Suppose you had } \$ 100 \text { in a savings account and the } \\
\text { interest rate was } 2 \% \text { per year. After } 5 \text { years, how much do } \\
\text { you think you would have in the account if you left the } \\
\text { money to grow? ( } 1=\text { More than } \$ 102,2 \text { = Exactly } \$ 102,3= \\
\text { Less than } \$ 102,4=\text { Do not know, } 5=\text { Refuse to answer) }\end{array}$ \\
\hline & & & (2) & $\begin{array}{l}\text { Imagine that the interest rate on your savings account was } \\
1 \% \text { per year and inflation was } 2 \% \text { per year. After } 1 \text { year, how } \\
\text { much would you be able to buy with the money in this } \\
\text { account? ( } 1=\text { More than today, } 2 \text { = Exactly the same, } 3 \text { = } \\
\text { Less than today, } 4 \text { = Do not know, } 5 \text { = Refuse to answer) }\end{array}$ \\
\hline & & & (3) & $\begin{array}{l}\text { Please tell me whether this statement is true or false. } \\
\text { 'Buying a single company's stock usually provides a safer } \\
\text { return than a stock mutual fund'. ( } 1 \text { = True, } 2 \text { = False, } 3 \text { = } \\
\text { Do not know, } 4 \text { = Refuse to answer) }\end{array}$ \\
\hline Already informed & 7 & Self-developed & $(1)$ & I already know how much pension I have built up so far. \\
\hline
\end{tabular}


B. Measurement model The Netherlands and United Kingdom (chapter 2)

Construct \# \# Indicators \# items Likert Scale

Information search intention

$\begin{array}{ll}2 & 7 \\ 6 & 7 \\ 5 & 7 \\ 7 & 7 \\ 6 & 7 \\ 3 & 7 \\ 2 & 7 \\ 1 & 7 \\ 1 & 7 \\ 1 & 70 \\ 1 & 10 \\ 1 & 7\end{array}$

C. HTMT criterion The Netherlands (chapter 2)

\begin{tabular}{lllllll}
\hline Construct & 1. & 2. & 3. & 4. & 5. & 6.
\end{tabular}

\begin{tabular}{|c|c|c|c|c|c|c|c|}
\hline 2. Propensity to plan & 0.188 & & & & & & \\
\hline 3. Retirement anxiety & 0.199 & 0.150 & & & & & \\
\hline 4. Perceived barriers & -0.039 & 0.072 & 0.541 & & & & \\
\hline 5. Perceived benefits & 0.413 & 0.260 & -0.024 & -0.269 & & & \\
\hline 6. Perceived self-efficacy & -0.196 & -0.118 & -0.380 & -0.607 & -0.071 & & \\
\hline 7. Perceived response-efficacy & 0.315 & 0.127 & 0.023 & -0.070 & 0.739 & -0.234 & \\
\hline 8. Perceived susceptibility & 0.057 & 0.068 & 0.391 & 0.423 & -0.168 & -0.358 & -0.133 \\
\hline
\end{tabular}

Note: Square root of AVE reported on the diagonal, numbers below the diagonal represent construct correlations. 
Reliability

Cronbachs Alpha

NL UK

0.845

0.738

0.928 0.937

0.873

0.848

0.9

0.914

0.861

0.809

0.703

0.781

Composite Reliability

\begin{tabular}{l} 
Validity \\
\hline AVE \\
\hline
\end{tabular}

Validity

\begin{tabular}{cc}
\multicolumn{2}{c}{ Fornell-Larcker } \\
\hline NL & UK \\
\hline 0.931 & 0.889 \\
0.858 & 0.872 \\
0.782 & 0.812 \\
0.761 & 0.792 \\
0.772 & 0.836 \\
0.868 & 0.854 \\
0.906 & 0.877
\end{tabular}

D. Assessment of barriers indicators The Netherlands (chapter 2)

\begin{tabular}{|c|c|c|c|c|}
\hline \multirow[t]{2}{*}{ Construct } & \multicolumn{2}{|c|}{ Reliability } & \multicolumn{2}{|c|}{ Validity } \\
\hline & $\begin{array}{c}\text { Cronbachs } \\
\text { Alpha }\end{array}$ & $\begin{array}{l}\text { Composite } \\
\text { Reliability }\end{array}$ & AVE & Fornell-Larcker \\
\hline All 7 & 0.876 & 0.904 & 0.579 & 0.761 \\
\hline Without Barrier 4 & 0.849 & 0.568 & 0.283 & 0.532 \\
\hline Without Barrier 5 & 0.854 & 0.785 & 0.417 & 0.645 \\
\hline Without Barrier 6 & 0.847 & 0.637 & 0.310 & 0.557 \\
\hline Without Barrier 7 & 0.843 & 0.656 & 0.321 & 0.567 \\
\hline Without Barrier 4 and 5 & 0.821 & 0.778 & 0.454 & 0.674 \\
\hline Without Barrier 4,5, and 6 & 0.785 & 0.810 & 0.546 & 0.739 \\
\hline Without Barrier 4,5,6 and 7 & 0.775 & 0.857 & 0.680 & 0.824 \\
\hline
\end{tabular}


E. Correlations sample The Netherlands ( $N=583$; chapter 2)

\begin{tabular}{|c|c|c|c|c|c|c|c|c|}
\hline & $\begin{array}{c}1 . \\
\text { Information } \\
\text { search } \\
\text { intention }\end{array}$ & $\begin{array}{c}2 . \\
\text { Already } \\
\text { informed }\end{array}$ & $\begin{array}{c}3 . \\
\text { Age }\end{array}$ & $\begin{array}{c}4 . \\
\text { Female } \\
\text { gender }\end{array}$ & $\begin{array}{c}5 . \\
\text { Income }\end{array}$ & $\begin{array}{c}6 . \\
\text { Being } \\
\text { married }\end{array}$ & $\begin{array}{c}7 . \\
\text { Having } \\
\text { children }\end{array}$ & $\begin{array}{c}8 . \\
\text { Perceived } \\
\text { self- } \\
\text { efficacy }\end{array}$ \\
\hline 1. Information search intention & 1 & & & & & & & \\
\hline 2. Already informed & $.158^{* *}$ & 1 & & & & & & \\
\hline 3. Age & $.137^{* *}$ & $.273^{* *}$ & 1 & & & & & \\
\hline 4. Female gender & -.006 & -.036 & $-.128^{* *}$ & 1 & & & & \\
\hline 5. Income & -.001 & $.162^{*+*}$ & .078 & -.071 & 1 & & & \\
\hline 6. Being married & .068 & $.145^{* *}$ & $.379^{* *}$ & $-.144^{* *}$ & $.214^{* *}$ & 1 & & \\
\hline 7. Having children & .036 & $.148^{* *}$ & $.365^{*}$ & $-.113^{* *}$ & $.108^{* *}$ & $.511^{* *}$ & 1 & \\
\hline 8. Perceived self-efficacy & $-.162^{* *}$ & $.332^{* *}$ & $.127^{* *}$ & $-.150^{* *}$ & $.083^{*}$ & .075 & $.087^{*}$ & 1 \\
\hline 9. Perceived benefits & $.351^{*}$ & $.263^{* *}$ & .015 & .044 & .060 & .020 & .025 & -.066 \\
\hline 10. Perceived barriers & -.041 & $-.367^{* *}$ & $-.097^{*}$ & $.162^{* *}$ & $-.085^{*}$ & -.064 & $-.117^{* *}$ & $-.524^{* *}$ \\
\hline 11. Perceived severity & $.268^{* *}$ & -.081 & -.072 & .079 & $-.084^{*}$ & -.033 & -.038 & $-.323^{* *}$ \\
\hline 12. Perceived susceptibility & .044 & $-.240^{*+*}$ & -.065 & .029 & $-.100^{*}$ & -.010 & .023 & $-.289^{* *}$ \\
\hline 13. Propensity to plan & $.165^{* *}$ & $.142^{* *}$ & -.061 & $.084^{*}$ & $-.107^{* *}$ & -.014 & -.012 & $-.103^{*}$ \\
\hline 14. Retirement anxiety & $.169^{* *}$ & $-.123^{* *}$ & .078 & $.099^{*}$ & -.068 & -.051 & $-.128^{* *}$ & $-.319^{*+}$ \\
\hline 15. Trust own pension provider & $.209^{* *}$ & $.111^{* *}$ & -.005 & $.087^{*}$ & -.065 & -.003 & .027 & $-.115^{* *}$ \\
\hline 16. Financial risk taking & .014 & $.125^{* *}$ & -.068 & $-.215^{* *}$ & $.103^{*}$ & -.081 & -.052 & $.211^{* *}$ \\
\hline 17. Financial literacy & .065 & $.162^{* *}$ & .019 & $-.234^{* *}$ & .054 & $.085^{*}$ & .060 & $.111^{* *}$ \\
\hline
\end{tabular}

Note: ${ }^{* *}$. Correlation is significant at the 0.01 level (2-tailed). ${ }^{*}$. Correlation is significant at the 0.05 level (2-tailed). 
9.

benefits
10.

Perceived Perceive

barriers
11 severity
12.

14.

16.

nancial susceptibility to plan anxiety literacy pension risk

\begin{tabular}{|c|c|c|c|c|c|c|c|c|}
\hline$-.222^{* *}$ & 1 & & & & & & & \\
\hline $.219^{* *}$ & $.193^{* *}$ & 1 & & & & & & \\
\hline$-.140^{* *}$ & $.347^{* *}$ & $.242^{* *}$ & 1 & & & & & \\
\hline $.232^{* *}$ & .062 & $.116^{* *}$ & .055 & 1 & & & & \\
\hline-.012 & $.456^{* *}$ & $.304^{* *}$ & $.318^{* *}$ & $.134^{* *}$ & 1 & & & \\
\hline $.307^{* *}$ & -.005 & $.111^{\star *}$ & $-.114^{* *}$ & .080 & .002 & 1 & & \\
\hline .042 & $-.198^{* *}$ & $-.180^{* *}$ & $-.088^{*}$ & -.065 & $-.161^{\star \star}$ & -.053 & 1 & \\
\hline $.142^{* *}$ & $-.234^{* *}$ & .025 & -.034 & .007 & $-.118^{* *}$ & -.053 & $.222^{* *}$ & 1 \\
\hline
\end{tabular}




\begin{tabular}{|c|c|c|c|c|c|c|c|c|}
\hline & $\begin{array}{c}1 . \\
\text { Information } \\
\text { search } \\
\text { intention }\end{array}$ & $\begin{array}{c}2 . \\
\text { Registered }\end{array}$ & $\begin{array}{c}3 . \\
\text { Already } \\
\text { informed }\end{array}$ & $\begin{array}{l}4 . \\
\text { Age }\end{array}$ & $\begin{array}{c}5 . \\
\text { Female } \\
\text { gender }\end{array}$ & $\begin{array}{c}6 . \\
\text { Income }\end{array}$ & $\begin{array}{c}7 . \\
\text { Being } \\
\text { married }\end{array}$ & $\begin{array}{c}8 . \\
\text { Having } \\
\text { children }\end{array}$ \\
\hline 1. Information search intention & 1 & & & & & & & \\
\hline 2. Registered & $.172^{\star \star}$ & 1 & & & & & & \\
\hline 3. Already informed & $.234^{\star *}$ & $.272^{\star \star}$ & 1 & & & & & \\
\hline 4. Age & $.066^{*}$ & $.161^{\star *}$ & $.229^{* *}$ & 1 & & & & \\
\hline 5. Female gender & -.053 & $-.111^{\star \star}$ & -.034 & -.017 & 1 & & & \\
\hline 6. Income & $.119^{\star \star}$ & -.016 & $.121^{\star *}$ & $.151^{\star \star}$ & $-.215^{* *}$ & 1 & & \\
\hline 7. Being married & $.084^{\star *}$ & .052 & $.110^{\star *}$ & $.351^{\star \star}$ & -.044 & $.209^{* *}$ & 1 & \\
\hline 8. Having children & $.064^{*}$ & $.082^{\star *}$ & $.097^{* *}$ & $.511^{\star *}$ & -.044 & $.125^{* *}$ & $.435^{\star \star}$ & 1 \\
\hline 9. Perceived self-efficacy & $.127^{\star *}$ & $-.078^{* *}$ & $-.219^{* *}$ & $-.060^{*}$ & -.001 & .017 & -.016 & -.018 \\
\hline 10. Perceived benefits & $.323^{* *}$ & $.060^{*}$ & $.173^{* *}$ & .048 & $.081^{\star *}$ & .052 & $.087^{\star *}$ & $.063^{*}$ \\
\hline 11. Perceived barriers & .016 & -.030 & $-.182^{\star *}$ & $-.092^{* *}$ & $.062^{*}$ & $-.113^{* *}$ & $-.100^{\star \star}$ & -.029 \\
\hline 12. Perceived severity & $.152^{\star *}$ & -.019 & -.039 & -.054 & $.064^{*}$ & $.089^{* *}$ & .001 & .000 \\
\hline 13. Perceived susceptibility & -.006 & .027 & $-.108^{* *}$ & -.024 & $.096^{\star *}$ & $-.091^{\star *}$ & $-.077^{\star *}$ & .002 \\
\hline 14. Propensity to plan & $.224^{* *}$ & .037 & $.122^{\star *}$ & $-.081^{\star \star}$ & .050 & -.053 & -.019 & $.071^{*}$ \\
\hline 15. Retirement anxiety & $.173^{\star \star}$ & .004 & .002 & -.054 & .045 & $-.065^{*}$ & -.040 & -.030 \\
\hline 16. Trust own pension provider & $.122^{\star \star}$ & $.146^{\star \star}$ & $.143^{\star \star}$ & $.114^{\star \star}$ & .007 & $.061^{\star}$ & $.067^{\star}$ & $.082^{\star \star}$ \\
\hline 17. Financial literacy & $.069^{\star}$ & .036 & $.156^{\star \star}$ & $.208^{\star \star}$ & $-.164^{\star \star}$ & $.278^{\star \star}$ & $.152^{\star \star}$ & $.063^{*}$ \\
\hline 18. Financial risk taking & $.103^{\star \star}$ & $.078^{\star *}$ & $.116^{\star *}$ & -.016 & $-.190^{\star *}$ & $.175^{\star *}$ & .054 & .053 \\
\hline
\end{tabular}

Note: ${ }^{* *}$. Correlation is significant at the 0.01 level (2-tailed). *. Correlation is significant at the 0.05 level (2-tailed). 
9.

10.

11.

12.

13.

14.

15.

16.

17.

18.

Perceived Perceived Perceived Perceived Perceived Propensity Retirement Trust own Financial Financial self-

benefits barriers

severity susceptibility to plan

anxiety

pension literacy risk taking

efficacy

provider

1

$.057 \quad 1$

$.503^{* *}-.125^{* *} \quad 1$

$.154^{\star *} \quad .264^{* *} \quad .127^{* *} \quad 1$

$\begin{array}{lllll}.197^{\star *} & .043 & .297^{* *} & .268^{* *} & 1\end{array}$

$\begin{array}{llllll}.024 & .375^{* *} & -.008 & .137^{* *} & .008 & 1\end{array}$

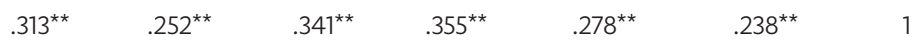

$\begin{array}{lllllll}-.110^{* *} & .288^{* *} & -.190^{* *} & .093^{* *} & .033 & .088^{* *} & .028\end{array}$

$\begin{array}{lllll}-.178^{\star *} & .112^{\star *} & -.264^{\star *} & .028 & -.069^{\star}\end{array}$

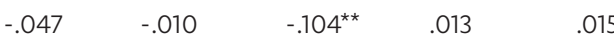

$.115^{\star *} \quad 1$

$-.044-.065^{\star} \quad .091^{\star \star} \quad .103^{\star \star}$ 


\section{G. Segmentation analysis Dutch sample (chapter 2)}

Next to estimating the RBM for the whole sample, we also estimated a finite mixture partial least squares (FIMIX-PLS) segmentation model for the Dutch sample, to understand how the impact of the different beliefs, personality, financial literacy and socio-demographic factors can be different for different segments of participants.

\section{Segmentation application}

Using the FIMIX-PLS procedure, we can estimate the parameters and at the same time investigate heterogeneity in our sample. We follow the FIMIX-PLS steps as Ringle, Sarstedt, and Mooi (2010) suggest. The scores of the PLS model we estimated before are now used as input for the finite mixture model. We estimate the mixture model with increasing number of latent classes, starting with two classes. Using the evaluation criteria suggested by Hahn et al. (2002), we aim for a number of classes with as low as possible values for log-likelihood (InL), Akaike information criterion (AIC), Bayesian information criterion (BIC), consistent Akaike information criterion (CAIC). Furthermore, a high entropy statistic (EN) indicates an unambiguous separation of classes (Ringle, Wende, and Will 2010). Evaluating the criteria (see Table G.1), three classes is the optimal choice for the dataset at hand (since with six or more classes, the segments get too small for estimation).

Table G.1: Evaluation number of segments

\begin{tabular}{lrrrrr}
\hline Number of segments & InL & AIC & BIC & CAIC & EN \\
\hline $\mathrm{S}=2$ & -8636.872 & 17447.744 & 17827.777 & 17914.777 & 0.672 \\
$\mathrm{~S}=3$ & -441.274 & 1144.548 & 1716.780 & 1847.780 & 0.883 \\
$\mathrm{~S}=4$ & -406.304 & 1162.607 & 1927.040 & 2102.040 & 0.882 \\
$\mathrm{~S}=5$ & -282.362 & 1002.723 & 1959.356 & 2178.356 & 0.921 \\
$\mathrm{~S}=6$ & 22.488 & 481.024 & 1629.857 & 1892.857 & 0.931 \\
\hline
\end{tabular}

After this step, we conduct a multi-group analysis to see whether paths are significantly different between the segments. We compute the t-statistics for differences between the segments manually, using the formula provided by Chin (2000). Results are shown in Table G.2.

We label the segments based on their characteristics: the overconfident, the emotional and alpha males. The first segment ( $\mathrm{N}=60,55 \%$ male), the overconfident, is the oldest group with the least education, income and financial literacy, and highest divorce rate. Self-efficacy and propensity to plan are the most influential variables on information search intention. We call this segment the overconfident, since they have a relatively high self-efficacy, but low financial literacy - so they think they can search for information, but they may actually 
Table G.2: FIMIX-PLS disaggregate results for three segments

\begin{tabular}{|c|c|c|c|c|c|c|c|}
\hline & $\begin{array}{l}\text { Global } \\
\text { Model }\end{array}$ & $S=1$ & $S=2$ & $S=3$ & $\begin{array}{c}t \\
\text { [mgp S1 } \\
\text { and S2] }\end{array}$ & $\begin{array}{c}t \\
\text { [mgp S1 } \\
\text { and S3] }\end{array}$ & $\begin{array}{c}t \\
\text { [mgp s2 } \\
\text { and S3] }\end{array}$ \\
\hline Relative segment size (\%) & 100 & 10.3 & 45.3 & 44.4 & & & \\
\hline $\mathrm{N}$ & 583 & 60 & 264 & 259 & & & \\
\hline $\begin{array}{l}\text { Adj. } \mathrm{R}^{2} \text { for information } \\
\text { search intention (ISI) }\end{array}$ & 0.191 & 0.242 & 0.200 & 0.327 & & & \\
\hline \multicolumn{8}{|l|}{ Panel A. Paths } \\
\hline \multirow[t]{2}{*}{ Susceptibility $\rightarrow$ ISI } & 0.018 & 0.221 & -0.054 & 0.020 & $1.861^{*}$ & 1.213 & 0.770 \\
\hline & $(0.40)$ & $(1.56)$ & $(0.85)$ & $(0.27)$ & & & \\
\hline \multirow[t]{2}{*}{ Severity $\rightarrow$ ISI } & 0.129 & -0.065 & 0.087 & 0.198 & 1.038 & $1.659^{*}$ & 1.219 \\
\hline & $(2.92)^{* *}$ & $(0.43)$ & $(1.44)$ & $(2.89)^{* * *}$ & & & \\
\hline \multirow[t]{2}{*}{ Self-efficacy $\rightarrow$ ISI } & -0.094 & -0.542 & 0.071 & -0.147 & $3.898^{* * *}$ & $2.261^{* *}$ & $2.204^{* *}$ \\
\hline & $(1.84)^{*}$ & $(3.24)^{* * *}$ & $(1.11)$ & $(1.96)^{* *}$ & & & \\
\hline \multirow[t]{2}{*}{ Benefits $\rightarrow$ ISI } & 0.24 & 0.254 & 0.301 & 0.183 & 0.322 & 0.483 & 1.256 \\
\hline & $(5.10)^{\star * *}$ & $(1.79)^{*}$ & $(4.83)^{* * *}$ & $(2.58)^{* *}$ & & & \\
\hline \multirow[t]{2}{*}{ Barriers $\rightarrow$ ISI } & -0.133 & -0.306 & -0.153 & -0.128 & 0.460 & 0.769 & 0.135 \\
\hline & $(2.35)^{\star *}$ & $(1.64)$ & $(0.99)$ & $(1.24)$ & & & \\
\hline \multirow[t]{2}{*}{ Retirement anxiety $\rightarrow$ ISI } & 0.162 & -0.194 & 0.253 & 0.154 & $2.653^{* *}$ & $2.212^{* *}$ & 1.016 \\
\hline & $(3.45)^{* * *}$ & $(1.11)$ & $(3.60)^{* * *}$ & $(2.27)^{\star *}$ & & & \\
\hline \multirow[t]{2}{*}{ Propensity to plan $\rightarrow$ ISI } & 0.064 & 0.263 & 0.036 & 0.012 & 1.566 & $1.864^{*}$ & 0.281 \\
\hline & $(1.55)$ & $(2.07)^{* *}$ & $(0.57)$ & $(0.21)$ & & & \\
\hline \multirow[t]{2}{*}{ Trust $\rightarrow$ ISI } & 0.108 & 0.084 & -0.020 & 0.232 & 0.674 & 1.069 & $2.824^{* *}$ \\
\hline & $(2.54)^{* *}$ & $(0.61)$ & $(0.30)$ & $(3.93)^{+*+*}$ & & & \\
\hline
\end{tabular}

Panel B. Descriptives

\begin{tabular}{lccc}
\hline Age & 47.55 & 43.60 & 46.19 \\
Male & $55.0 \%$ & $61.0 \%$ & $100.0 \%$ \\
Living together & $75.0 \%$ & $72.7 \%$ & $83.4 \%$ \\
Married & $60.0 \%$ & $53.8 \%$ & $66.8 \%$ \\
Own House & $71.7 \%$ & $79.5 \%$ & $89.6 \%$ \\
Financial literacy (all 3 & $21.7 \%$ & $24.2 \%$ & $100.0 \%$ \\
correct) & & \\
\hline
\end{tabular}

Note: $\mathrm{t}[\mathrm{mgp}]=\mathrm{t}$-value for multi-group comparison test. ${ }^{*},{ }^{* *}$, and ${ }^{* * *}$ denote statistical significance at the $10 \%, 5 \%$, and $1 \%$ level (two-tailed test). 
not be able to do so. Self-efficacy has a negative influence on information intention for this segment, while most of them are not informed yet about their pensions.

The second segment ( $N=264,61 \%$ male), the emotional, is the youngest, has the highest rate of not having any children (37\%), is similar to segment 1 concerning financial literacy, but generally more highly educated and has a higher household income. For this group, emotions play a large role: their level of retirement anxiety is high, they are scared of retirement. Security is important to them, and these emotions stimulate them to take action: retirement anxiety and perceived benefits (which are mainly emotional, such as getting a feeling of certainty) significantly influence intention to search for information in a positive way.

Segment 3, the alpha males, then is exclusively male, perfectly financially literate and has the highest income, education, and rate of owning a house (90\%). Especially trust in their own pension provider is important in triggering this group to search for information, they understand a lot about finances and want a partner for their retirement planning that takes them seriously. Furthermore for this group, self-efficacy has a negative influence, but this effect is significantly less strong than the negative effect for the overconfident. Yet, this segment is also the most informed segment, meaning that they not only think they can do

Table G.3: Descriptive statistics segments

\begin{tabular}{|c|c|c|c|c|}
\hline & \multirow[b]{2}{*}{ All } & \multicolumn{3}{|c|}{ Segment } \\
\hline & & $\begin{array}{c}1 \\
(\mathrm{~N}=60)\end{array}$ & $\begin{array}{c}2 \\
(N=264)\end{array}$ & $\begin{array}{c}3 \\
(\mathrm{~N}=259)\end{array}$ \\
\hline \multicolumn{5}{|l|}{ Panel A. Education } \\
\hline Highest educational degree & \multicolumn{4}{|c|}{ Percentages } \\
\hline High school & 23.0 & 45.0 & 28.0 & 13.1 \\
\hline Intermediate vocational (Dutch: $M B O$ ) & 22.1 & 15.0 & 23.1 & 22.8 \\
\hline College (bachelor degree) & 35.4 & 31.7 & 30.4 & 41.3 \\
\hline University (master degree) & 14.9 & 5.0 & 12.9 & 15.4 \\
\hline $\mathrm{PhD}$ & 2.9 & 1.7 & 2.7 & 3.5 \\
\hline Other & 1.7 & 1.7 & 3.1 & 0.4 \\
\hline
\end{tabular}


it, but they already did. Interestingly, while segment 3, for example, perceives lower barriers than the other two groups, there are no significant differences between the segments in how susceptible to a pension gap they perceive themselves to be.

In addition, the adjusted R2 values for each segment are now higher $(0.24,0.20$, and 0.33 respectively) than the adjusted $\mathrm{R} 2$ value for the whole sample (0.19). This shows that we have large differences between the segments that need to be taken into account. The path coefficients differ significantly in their size (and sign in some cases) between the different segments.

Descriptive statistics for the three segments are given in Table G.3, and comparisons between mean scores on RBM constructs of the three segments are given in Table G.4. Given the differences between the segments, one could adapt the communication. For example, for the overconfident it would be important to create a sense of urgency, since they are the most vulnerable for a pension gap, but do not act while they feel they could do so. For the emotional segment, communication can focus on feelings, emphasize the peace of mind state that participants can gain by informing themselves. In communicating with the alpha males, trust and severity should be stressed.

Segment

$\begin{array}{cccc}\text { All } & 1 & 2 & 3 \\ & (\mathrm{~N}=60) & (\mathrm{N}=264) & (\mathrm{N}=259)\end{array}$

Financial literacy

(\# questions correctly answered)

\section{Percentages}

$\begin{array}{rrr}11.7 & 6.1 & 0.0 \\ 3.3 & 12.5 & 0.0 \\ 3.3 & 57.2 & 0.0 \\ 21.7 & 24.2 & 100.0\end{array}$


Table G.3: (continued)

\begin{tabular}{|c|c|c|c|c|}
\hline & \multirow[b]{2}{*}{ All } & \multicolumn{3}{|c|}{ Segment } \\
\hline & & $\begin{array}{c}1 \\
(\mathrm{~N}=60)\end{array}$ & $\begin{array}{c}2 \\
(N=264)\end{array}$ & $\begin{array}{c}3 \\
(\mathrm{~N}=259)\end{array}$ \\
\hline \multicolumn{5}{|l|}{ Panel B. Income } \\
\hline Net monthly household income & \multicolumn{4}{|c|}{ Percentages } \\
\hline Less than $1200 €$ & 0.3 & 3.3 & 0.0 & 0.0 \\
\hline $1200-1800 €$ & 7.2 & 13.3 & 10.2 & 2.7 \\
\hline $1800-2800 €$ & 24.2 & 28.3 & 27.3 & 20.1 \\
\hline $2800-3800 €$ & 26.6 & 21.7 & 23.5 & 30.9 \\
\hline $3800-5000 €$ & 15.4 & 13.3 & 10.6 & 20.8 \\
\hline More than $5000 €$ & 9.4 & 1.7 & 8.0 & 12.7 \\
\hline Not answer & 16.8 & 18.3 & 20.5 & 12.7 \\
\hline \multicolumn{5}{|l|}{ Panel C. Marital Status and Children } \\
\hline Marital Status & \multicolumn{4}{|c|}{ Percentages } \\
\hline Married & 60.2 & 60.0 & 53.8 & 66.8 \\
\hline Separated & 0.2 & 0.0 & 0.4 & 0.0 \\
\hline Divorced & 8.7 & 15.0 & 9.1 & 6.9 \\
\hline Widowed & 1.4 & 3.3 & 1.1 & 1.2 \\
\hline Never married & 29.5 & 21.7 & 35.6 & 25.1 \\
\hline
\end{tabular}




\begin{tabular}{|c|c|c|c|}
\hline \multirow[b]{2}{*}{ All } & \multicolumn{3}{|c|}{ Segment } \\
\hline & $\begin{array}{c}1 \\
(\mathrm{~N}=60)\end{array}$ & $\begin{array}{c}2 \\
(\mathrm{~N}=264)\end{array}$ & $\begin{array}{c}3 \\
(N=259)\end{array}$ \\
\hline
\end{tabular}

\section{Contribution to household income}

\section{$0-20$}

20-40

40-60

60-80

80-100

Not answer
1
$(N=60)$

$(\mathrm{N}=264)$

\section{Percentages}

$\begin{array}{rrrr}3.9 & 5.0 & 5.3 & 2.3 \\ 7.2 & 13.3 & 10.6 & 2.3 \\ 21.4 & 26.7 & 24.2 & 17.4 \\ 21.6 & 10.0 & 11.7 & 34.4 \\ 30.5 & 26.7 & 27.3 & 34.7 \\ 15.3 & 18.3 & 20.8 & 8.9\end{array}$

\section{\&}

Children

None
1 child
2 children
3 or more

31.2
14.8
38.8
15.3

14.8

38.8

15.3

26.7

16.7

36.7

20.0

\section{Percentages}

\begin{tabular}{lcc}
\multicolumn{2}{l}{ Percentages } \\
26.7 & 37.1 & 26.3 \\
16.7 & 16.3 & 12.7 \\
36.7 & 34.5 & 43.6 \\
0.0 & 12.1 & 13.1
\end{tabular}


Table G.4: Differences in RBM constructs divided by segment

\begin{tabular}{|c|c|c|c|c|c|}
\hline \multirow[b]{3}{*}{ Variable } & \multirow{3}{*}{$\begin{array}{c}\text { Overall } \\
(\mathrm{N}=583)\end{array}$} & \multicolumn{4}{|c|}{ Segments } \\
\hline & & $\begin{array}{c}1 \\
(\mathrm{~N}=60)\end{array}$ & $\begin{array}{c}2 \\
(N=264)\end{array}$ & $\begin{array}{c}3 \\
(\mathrm{~N}=259)\end{array}$ & ANOVA \\
\hline & & & $\begin{array}{c}\text { Mean } \\
(\mathrm{SD})\end{array}$ & & $\begin{array}{c}F d f \\
(2,580)\end{array}$ \\
\hline Information search intention (1-7) & $\begin{array}{c}3.83 \\
(1.58)\end{array}$ & $\begin{array}{c}3.45 \\
(1.97)\end{array}$ & $\begin{array}{c}3.85 \\
(1.36)\end{array}$ & $\begin{array}{c}3.88 \\
(1.67)\end{array}$ & 1.94 \\
\hline Already informed & $\begin{array}{l}4.51 \\
(1.66)\end{array}$ & $\begin{array}{r}4.23 \\
(2.15)\end{array}$ & $\begin{array}{l}4.27 \\
(1.52)\end{array}$ & $\begin{array}{l}4.82 \\
(1.62)\end{array}$ & $8.40^{\star * *}$ \\
\hline Perceived self-efficacy & $\begin{array}{c}3.50 \\
(1.42)\end{array}$ & $\begin{array}{r}3.78 \\
(2.12)\end{array}$ & $\begin{array}{l}3.13 \\
(1.06)\end{array}$ & $\begin{array}{c}3.81 \\
(1.42)\end{array}$ & $17.67^{* * *}$ \\
\hline Perceived barriers & $\begin{array}{c}3.31 \\
(1.23)\end{array}$ & $\begin{array}{l}3.36 \\
(1.80)\end{array}$ & $\begin{array}{c}3.65 \\
(0.95)\end{array}$ & $\begin{array}{l}2.96 \\
(1.17)\end{array}$ & $23.50^{* * *}$ \\
\hline Perceived benefits & $\begin{array}{l}5.24 \\
(1.00)\end{array}$ & $\begin{array}{l}4.80 \\
(1.69)\end{array}$ & $\begin{array}{c}5.26 \\
(0.76)\end{array}$ & $\begin{array}{l}5.33 \\
(1.00)\end{array}$ & $7.24^{* \star *}$ \\
\hline Perceived susceptibility & $\begin{array}{c}3.64 \\
(1.42)\end{array}$ & $\begin{array}{c}3.44 \\
(2.00)\end{array}$ & $\begin{array}{l}3.74 \\
(1.11)\end{array}$ & $\begin{array}{c}3.58 \\
(1.44)\end{array}$ & 1.65 \\
\hline Perceived severity & $\begin{array}{l}4.58 \\
(1.47)\end{array}$ & $\begin{array}{c}4.40 \\
(2.25)\end{array}$ & $\begin{array}{l}4.69 \\
(1.21)\end{array}$ & $\begin{array}{l}4.52 \\
(1.44)\end{array}$ & 1.45 \\
\hline Retirement anxiety & $\begin{array}{c}3.42 \\
(1.32)\end{array}$ & $\begin{array}{c}3.49 \\
(1.88)\end{array}$ & $\begin{array}{c}3.58 \\
(1.21)\end{array}$ & $\begin{array}{c}3.22 \\
(1.25)\end{array}$ & $5.13^{* *}$ \\
\hline Propensity to plan & $\begin{array}{l}4.76 \\
(1.48)\end{array}$ & $\begin{array}{l}4.53 \\
(1.94)\end{array}$ & $\begin{array}{l}4.91 \\
(1.31)\end{array}$ & $\begin{array}{l}4.65 \\
(1.51)\end{array}$ & $2.83^{*}$ \\
\hline Trust own pension provider & $\begin{array}{l}4.51 \\
(1.42)\end{array}$ & $\begin{array}{l}4.13 \\
(1.89)\end{array}$ & $\begin{array}{c}4.77 \\
(1.10)\end{array}$ & $\begin{array}{l}4.33 \\
(1.53)\end{array}$ & $8.92^{+*+*}$ \\
\hline Financial risk-taking (1-10) & $\begin{array}{c}4.03 \\
(2.26)\end{array}$ & $\begin{array}{c}3.27 \\
(2.63)\end{array}$ & $\begin{array}{c}3.59 \\
(1.98)\end{array}$ & $\begin{array}{c}4.65 \\
(2.28)\end{array}$ & $19.35^{* * *}$ \\
\hline
\end{tabular}

Note: Standard errors are given in parentheses. The column ANOVA shows the results of a mean comparison between the segments. ${ }^{*},{ }^{* *}$, and ${ }^{* * *}$ denote statistical significance at the $10 \%, 5 \%$, and $1 \%$ level. 


\section{H. Screenshot Investment and Assurance frames (chapter 3)}

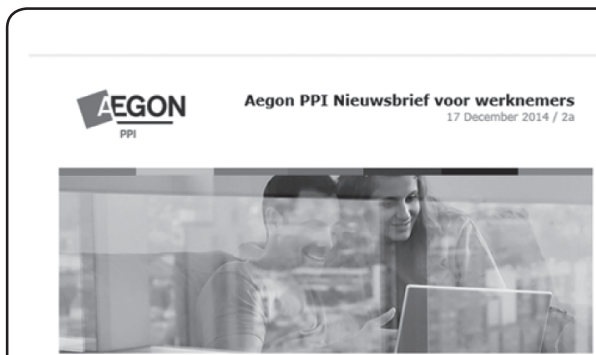

Uw pensioen veilig stellen wordt nog belangrijker in 2015

Beste werknemer,

Wat is er aan de hand?

De regelgeving voor uw oude dag verandert. De fiscale ruimte om pensioen op te bouwen wordt beperkt. Dat betekent vanaf januari 2015

- Dat u mogelijk een lager pensioen opbouw

Dat het pensioen voor uw eventuele partner en kinderen minder kan

- Worden,

stel vandaag nog zeker dat $u$ de wetswijzigingen begrijpt. Bekijk het filmpje met de veranderingen die op $\mathrm{u}$ afkomen.

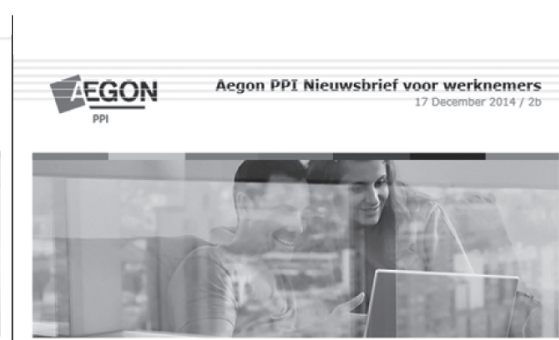

Investeren in uw toekomst wordt nog belangrijker in 2015

Beste werknemer,

Wat is er aan de hand?

De regelgeving voor uw oude dag verandert. De fiscale ruimte om pensicen op te bouwen wordt beperkt. Dat betekent vanaf januari 2015:

- Dat u mogelijk een lager pensioen opbouwt

worden,
Dat deze gevolgen groter zijn als u meer dan $€ 100.000$ verdient. Investeer daarom vandaag in uw levensstandaard van morgen. Bekijk het filmpje met de veranderingen die op u afkomen.

\section{Bekjjk filmpje}

Verzeker uzelf van inzicht in uw pensioen wat er voor u verandert hangt af van twee factoren:

- Hoeveel u verdient, en

OP Mijn Aegon heeft $u$ inzicht in uw huidige pensioensituatie bij Aegon, zo kunt u zich een beeld vormen wat u nu aan pensioen heeft voor later, vóór de wijzigingen

\section{Naar Mjn Aegon}

Als zekerheid over uw toekomstig pensioen belangrijk voor $u$ is $\checkmark$ ontvangt medio januari een brief waarin wij u informeren over deze wijzigingen en

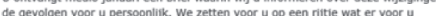
verandert. Het is belangrijk dat u vaststelt of dit pensioen nog past bij uw persoonlijke situatie.

Heeft u vragen over deze wijzigingen of wenst $u$ aanvullende verzekeringen? Neem contact op met uw werkgever en/of uw adviseur. Zl helpen u graag verder. Met vriendelijke groet,

- Hoe uw pensioenregelling er precies uitziet.
Investeer vandaag nog tijd om inzicht te krijgen in uw pensioen Wat er voor $\mathrm{u}$ verandert hangt af van twee factoren:

- Hoeveel u verdient, en

Op Mijn Aegon heeft u inzicht in uw huidige pensioensituatie bij Aegon. Zo kunt $y$ zich een beeld vormen wat u nu aan pensioen heeft voor later, vóór de wijzigingen per 1 januari.

\section{Naar Minn Aego}

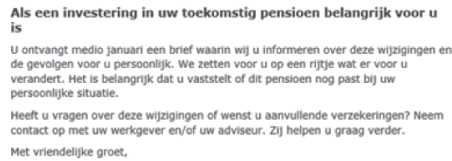

\section{\&}





\section{VALORIZATION ADDENDUM}

If you would know today that your car has a 9/10 chance of breaking down in the future, would you buy an all risk car insurance? Probably yes. Of today's 30 year olds, 8 to 9 out of 10 will reach age 70 (Kiersz 2014), which is a 9/10 chance that they will reach retirement age. And yet, the majority of consumers in this group stays passive, and does not search for information on retirement in order to deal with the risk of insufficient retirement finances.

In this dissertation, I therefore look at one of the most challenging issues for policy makers and financial service providers in aging societies: how to activate more people to prepare for retirement, how to enhance consumer financial decision making. Avoiding taking action for retirement where it would be needed, ignoring essential financial information, or having too little knowledge to be able to handle a credit card in a responsible way are all examples of "costly ignorance", as put in the title of my dissertation. In chapter 2 my co-authors and I employ a model to understand the underlying motives of pension plan participants to search for information about retirement, in chapter 3 we look at how communication framing can activate participants to take action for their retirement, and in chapter 4 we research how aging impacts the (non) cognitive skills we need to make wise financial decisions.

Next to the academic conferences in which I presented this research, I also frequently participated in Netspar (Network for Studies on Pensions, Aging and Retirement) discussion groups and conferences to disseminate our findings to a practitioner audience. As output commitment for the PhD funding we received from Netspar, my co-authors and I wrote two industry papers on chapter 2 and 3 of this dissertation. We received valuable feedback from industry members that we incorporated in the research design and interpretation of our findings. I elaborate further on what our findings mean in social and economic terms for society in the following.

\section{Chapter 2 - Understanding Retirement Information Search: The Retirement Belief Model}

In chapter 2, my co-authors and I look at why some pension plan participants search for information about their retirement while others do not. Before thinking about actions such as saving more, retiring sooner or spending less, participants need to know what they are currently saving, how they want to live later, and whether what they are saving will be enough to afford their desired lifestyle. In the past, financial service providers have mainly used socio-demographic factors to segment consumers and communicate with them accordingly. We take a broader approach and also look at the relative influence of beliefs, emotions and trust on the motivation to search for information.

Having conducted studies in two countries, the Netherlands and the UK, we can conclude that especially if participants perceive high benefits of information search (for 
example experiencing a state of security when they are informed) and trust their pension provider, they are more likely to search for information. Our findings are highly relevant in these countries where the regulatory landscape surrounding pensions is changing. Both countries have experienced reforms recently such as the incremental increase of the state pension age (from 65 to 67 to a life expectancy adjusted age) in the Netherlands, and automatic enrollment in the UK. While automatic enrollment is surely an essential first step to ensure coverage, adequacy is the next challenge. More reforms are expected in the future and will put more responsibility and risk on the individual pension plan participant. Being informed about one's expected retirement situation is therefore getting more important. So understanding what drives consumers to search for information is essential to develop good communication in the following.

Conducting the research, we worked closely together with an insurance company in the Netherlands, and a pension fund in the UK. These two pension providers use our findings to improve their communication. During frequent visits in which I presented my research to different audiences at the pension providers, we discussed several ways to apply the Retirement Belief Model we developed. Both pension providers want to adapt their communication by focusing on the participant, and we showed them which factors matter in their context. Analyzing results from two countries show for example that there are differences between participants and context specific factors such as perceived susceptibility, which do not play a role in the Dutch sample, but have a significant negative impact on information search in the UK sample. Perceived susceptibility, so the belief that one is vulnerable for having a pension gap, is also significantly higher in the UK. Other factors such as trust and perceived benefits play a positive, significant role in both countries. For pension providers in both countries, this implies that it is crucial to make people understand what they gain by looking up information. This may be more difficult in the Netherlands where participants have less choice than in the UK, but not less important. Recently, more and more pension plan participants in the UK have taken up their lump sums which is because of lack of trust in the system in light of current Brexit negotiations (Financial Conduct Authority 2017). Our findings underline the importance of creating trust around pension reforms as well, a responsibility that is shared by pension providers, governments as well as financial watchdogs such as the UK Financial Conduct Authority and Dutch Autoriteit Financiële Markten.

In addition, we used the Retirement Belief Model to segment pension plan participants (see Appendix of this dissertation). In the past, pension providers have mainly used sociodemographic characteristics to segment their participants. Taking a broader approach to segmentation by also including factors such as beliefs, emotions, and trust shows more differentiated segments, which really changed the mindset of the pension providers we worked with. 


\section{Chapter 3 - Framing the Future: Using Investment and Assurance Frames to Encourage Retirement Information Search}

While I outline the factors that influence whether people search for financial information or not in chapter 2, I focus on how to improve pension communication in chapter 3. My coauthors and I chose to test a cost efficient communication: the way that emails are worded, or "framed". We test two versions of an email: an investment frame, which emphasized that participants invest in tomorrow by looking up information, and an assurance frame, which emphasized that participants can assure themselves of insight into their pension. With the investment frame, $2.7 \%$ of participants clicked on an informational movie link while with the assurance frame, $6.7 \%$ clicked. Our findings exemplify that the frame that pension providers use has the power to double the response of participants. Assurance frames therefore prove to be an efficient low-cost alternative to expensive awareness campaigns.

Since the costs for pension communication are indirectly paid by participants contributions, it is in the pension providers' interest to keep these as low as possible. The frames we develop are simple text frames that are ready-to-use in pension providers' communication. These frames can easily and at low costs be applied to subject lines of emails, online and offline newsletters, campaigns, magazines and other elements of pension communication.

In the Netherlands, pension providers are required to communicate with their pension plan participants by law. In January 2017, the new European Pensions Directive came into force which gives member states until January 2019 to incorporate the directive into their legislation. One of the central points is clearer information and communication to participants of pension plans, underlining the importance of research on what communication works best to activate pension plan participants.

\section{Chapter 4 - Aging and Financial Decision Making: The Benefit of Experience and Emotion}

My final chapter is concentrated on one of the developments that make pension reforms necessary in the first place: aging of our societies. Due to medical innovations and overall improvement of living circumstances, people are getting older than ever before which means that the percentage of people in retirement age will also increase in the future. At the same time, the number of the financial decisions that consumers need to take increases as well and these decisions are getting more complex. News about older adults being the victim of financial fraud raises concerns about whether aging will play a positive or negative role with regard to financial decisions making. Previous research has shown that cognitive skills such as numeracy may decrease when we get older.

My co-authors and I look at how cognitive (numeracy and financial expertise) and non-cognitive (emotion and motivation to put effort in difficult tasks) factors influence financial decision making, and how age matters in these relationships. We find that across 
all measures of financial decision making, older adults do better. What helps them especially with making financial decisions are their lower levels of negative emotions and higher levels of financial expertise: older adults have often experienced both positive and negative financial decision outcomes in their life, so they are better able to deal with it and focus more on the positive.

Our findings are in line with the aging and life span psychology literature, and show that aging can provide societies with advantages as well - if financial service providers and policy makers make use of this knowledge and create products, communications and programs such that both older and younger adults benefit. First, communications to older consumers should focus more on positive emotions and acknowledge that the audience has experience. Second, our research underlines the importance of numeracy and financial expertise, and therefore the importance of financial education in school and later on in working life. While financial literacy programs may not be the holy grail as recent research has indicated (e.g. Fernandes et al. 2014), just in time workshops on specific topics by employers or banks' children programs that introduce them to the world of finance can be a first step in improving consumers' numeracy and financial expertise, and therefore help enhancing their financial decision making. Third, more exchange and sharing experiences between older and younger people for example can help self-reflection of the elderly, and building up knowledge for younger adults. Dutch pension providers for example are currently experimenting with pensioners who tell their story to non-retirees in order to motivate them to think more about retirement. As we still have a relatively well-off group of pensioners at the moment, this sharing will be especially important and insightful in the future, when a large group of baby boomers (which is less well-prepared for retirement) retires. 


\section{SUMMARY}

Due to aging societies and economic developments such as the current low interest rate environment, pensions systems around the world are under pressure for reforms. Pension providers are shifting more risk and responsibility to individual pension plan participants, which means that it is crucial that people are well-informed about what they can expect when they retire. However, most participants do not read their pension providers' communication and do not search for information. One of the most challenging tasks for policy makers and financial services providers is thus how to activate people to search for information and enhance their financial decision making. In this dissertation, I therefore look at three main research objectives that I examine in three chapters.

In chapter 2, my co-authors and I investigate what drives differences in pension plan participants' search for retirement information. We test the Retirement Belief Model (RBM) with 583 Dutch and 1,156 UK pension plan participants, and find that the RBM core beliefs (perceived barriers, benefits, self-efficacy, severity, and susceptibility) as well as trust and emotions (retirement anxiety) have significant relationships with the search for information. The findings help both pension providers and policy makers in improving pension communication by stressing, for example, the benefits of information acquisition, establishing trust, and attenuating retirement anxiety.

In chapter 3 , we look at how framing can help to activate participants. First, we show that while classical loss (vs. gain) frames can be a powerful nudge, they also evoke negative emotions and evaluations. Second, we conduct a large scale field experiment with 7,315 Dutch participants and test a gain (investment frame) and loss (assurance frame) alternative. We show that assurance framing is twice as effective in engaging participants to click on an educational movie link explaining pension scheme changes, and does not result in negative emotions or evaluations.

Finally, in chapter 4, we research the role of age-related cognitive and non-cognitive changes with regard to financial decision making in a sample of 926 UK respondents. We measured financial decision making by two self-report measures and two tasks that respondents needed to complete in the survey to test their actual skills. We find that cognitive skills are mainly important for the tasks respondents needed to do, while both cognitive and non-cognitive factors matter for the self-reported measures of financial decision making. Older adults do better across all measures, and especially benefit of their higher levels of experience and lower levels of negative emotions. 


\section{CURRICULUM VITAE}

Wiebke Eberhardt was born in Ahaus, Germany, on 14 January 1989. She obtained her BSc in Business Administration from the University of Twente in 2012 and her MSc (cum laude) in International Business from Maastricht University in 2013. Wiebke started as doctoral student in the Department of Marketing and Supply Chain Management and Department of Finance at the School of Business and Economics at Maastricht University under the supervision of Prof. Dr. Martin Wetzels, Prof. Dr. Rob Bauer, Prof. Dr. Elisabeth Brüggen, and Dr. Thomas Post. During her PhD, she collected data and collaborated in research projects at Aegon (Den Haag) and NEST Pensions (London).

All empirical chapters of this dissertation have been presented at leading international conferences, including the Boulder Summer Conference on Consumer Financial Decision Making 2016 in Boulder, the Frontiers in Service Conference 2015 in San José and 2017 in New York, the EMAC doctoral colloquium beginners track in consumer behavior 2014 in Valencia and EMAC 2017 in Groningen, the Financial Literacy and Pension related Communication Mopact International Workshop 2016 in Turin as well as practitioner oriented conferences such as the ICPM discussion forums in Toronto 2014 and in Montreal 2016, and NEST Insights conferences in London 2016 and 2017.

Wiebke is a visiting researcher at the Leeds University Business School, Centre for Decision Research, and junior research fellow at Netspar (the Network for Studies on Pensions, Aging and Retirement), a function in which she presented at the Netspar Pension Days 2015 and 2016 in Utrecht as well as at several Netspar taskforce meetings on pension communication. Chapters 2 and 3 of this dissertation are published as Netspar industry papers. Together with her co-authors Chantal Hoet, Elisabeth Brüggen and Thomas Post, she received the MOAwards Science Price 2016 by the MOA Center for Information Based Decision Making and Marketing Research for her industry publication in the MOA yearbook 2016. Her work was further honored by her receiving the 2015 IPE Pensions scholarship fund.

During her PhD, Wiebke was involved in teaching and coordinating courses on the BSc, MSc, and executive level, resulting in her successful completion of the Dutch university teacher qualification (BKO). In 2017, Wiebke received a Netspar Individual Research Grant for her project on "Facing the pension communication challenges of tomorrow: On aging, emotions, and artificial intelligence" (together with Prof. Dr. Peter Schotman), and is currently a postdoctoral researcher at the Business Intelligence and Smart Services Institute (BISS) Heerlen and Department of Finance at Maastricht University. 